\title{
Are visual threats prioritized without awareness? A critical review and meta analysis involving 3 behavioral paradigms and 2696 observers
}

Article

Accepted Version

Hedger, N., Gray, K. L. H., Garner, M. and Adams, W. J. (2016) Are visual threats prioritized without awareness? A critical review and meta analysis involving 3 behavioral paradigms and 2696 observers. Psychological Bulletin, 142 (9). pp. 934-968. ISSN 1939-1455 doi:

https://doi.org/10.1037/bul0000054 Available at https://centaur.reading.ac.uk/60087/

It is advisable to refer to the publisher's version if you intend to cite from the work. See Guidance on citing.

To link to this article DOI: http://dx.doi.org/10.1037/bul0000054

Publisher: American Psychological Association

All outputs in CentAUR are protected by Intellectual Property Rights law, including copyright law. Copyright and IPR is retained by the creators or other copyright holders. Terms and conditions for use of this material are defined in the End User Agreement. 


\section{www.reading.ac.uk/centaur}

\section{CentAUR}

Central Archive at the University of Reading

Reading's research outputs online 
ARE VISUAL THREATS PRIORITISED WITHOUT AWARENESS?

Are visual threats prioritised without awareness? A critical review and meta-analysis involving 3 behavioural paradigms and 2696 observers.

Nicholas Hedger, Katie L. H. Gray, Matthew Garner and Wendy J. Adams 
ARE VISUAL THREATS PRIORITISED WITHOUT AWARENESS?

Given capacity limits, only a subset of stimuli give rise to a conscious percept.

Neurocognitive models suggest that humans have evolved mechanisms that operate without awareness and prioritize threatening stimuli over neutral stimuli in subsequent processing and perception. In this meta analysis, we review evidence for this 'standard hypothesis' emanating from three widely used, but rather different experimental paradigms that have been used to manipulate awareness. We found a small pooled threat-bias effect in the masked visual probe paradigm, a medium effect in the binocular rivalry paradigm and highly inconsistent effects in the breaking continuous flash suppression paradigm. Substantial heterogeneity was explained by the stimulus type: the only threat stimuli that were robustly prioritized across all three paradigms were fearful faces. Meta regression revealed that anxiety may modulate threat-biases, but only under specific presentation conditions. We also found that insufficiently rigorous awareness measures, inadequate control of response biases and low level confounds may undermine claims of genuine unconscious threat processing. Considering the data together, we suggest that uncritical acceptance of the standard hypothesis is premature: current behavioral evidence for threat-sensitive visual processing that operates outside of awareness is very weak. 


\section{Background}

Our eyes receive a vast array of visual information. However, due to capacity limits, only a sub-set of stimuli are consciously perceived at any one time (Dehaene \& Changuex, 2011). The visual system must cope with these capacity constraints by guiding sensory processing towards the stimuli that are most important to our survival. Since it may take hundreds of milliseconds for visual stimulation to generate a conscious percept (Koch, 2004) it would be advantageous for threats to influence perception or behavior (e.g. by directing attention, or initiating physiological responses) before, or independently of their conscious registration. Such an advantage could, quite literally, be the difference between survival and death. The 'standard hypothesis' (Tamietto \& deGelder, 2010) holds that humans have evolved a dedicated subcortical visual pathway that evaluates threat independently of conscious awareness and guides the selection of stimulus information for prioritized processing (Ohman, 2005; Ohman, Carlsson, Lundqvist, \& Ingvar, 2007). However, despite the intuitive appeal of this notion, the extent to which threatening stimuli are genuinely processed in the absence of awareness remains strongly debated (Pessoa, 2005; Pessoa \& Adolphs, 2010).

It is clear and uncontroversial that we are not aware of all aspects of visual processing; for instance, we cannot report the 'low-level' activity of individual retinal ganglion cells. Rather, the majority of research interest (and controversy) in unconscious perception is rooted in claims that the 'meaning' of a stimulus (such as whether it is threatening) can be registered without awareness and influence subsequent perceptual and cognitive operations (Goodale \& Milner, 2004; Hannula, Simons \& Cohen, 2005; Hesselmann \& Moors, 2015; Pessoa, 2005). 
ARE VISUAL THREATS PRIORITISED WITHOUT AWARENESS?

To investigate this issue, techniques that allow visual input to be dissociated from awareness such as backward masking, binocular rivalry and continuous flash suppression have become widely used (see Figure 1). These methods have the potential to reveal the answer to the question: 'Are visual threats prioritized without awareness?'. We present a critical review and meta-analysis of this literature.

Paradigm - Backward masking - Binocular rivalry - Continuous flash suppression

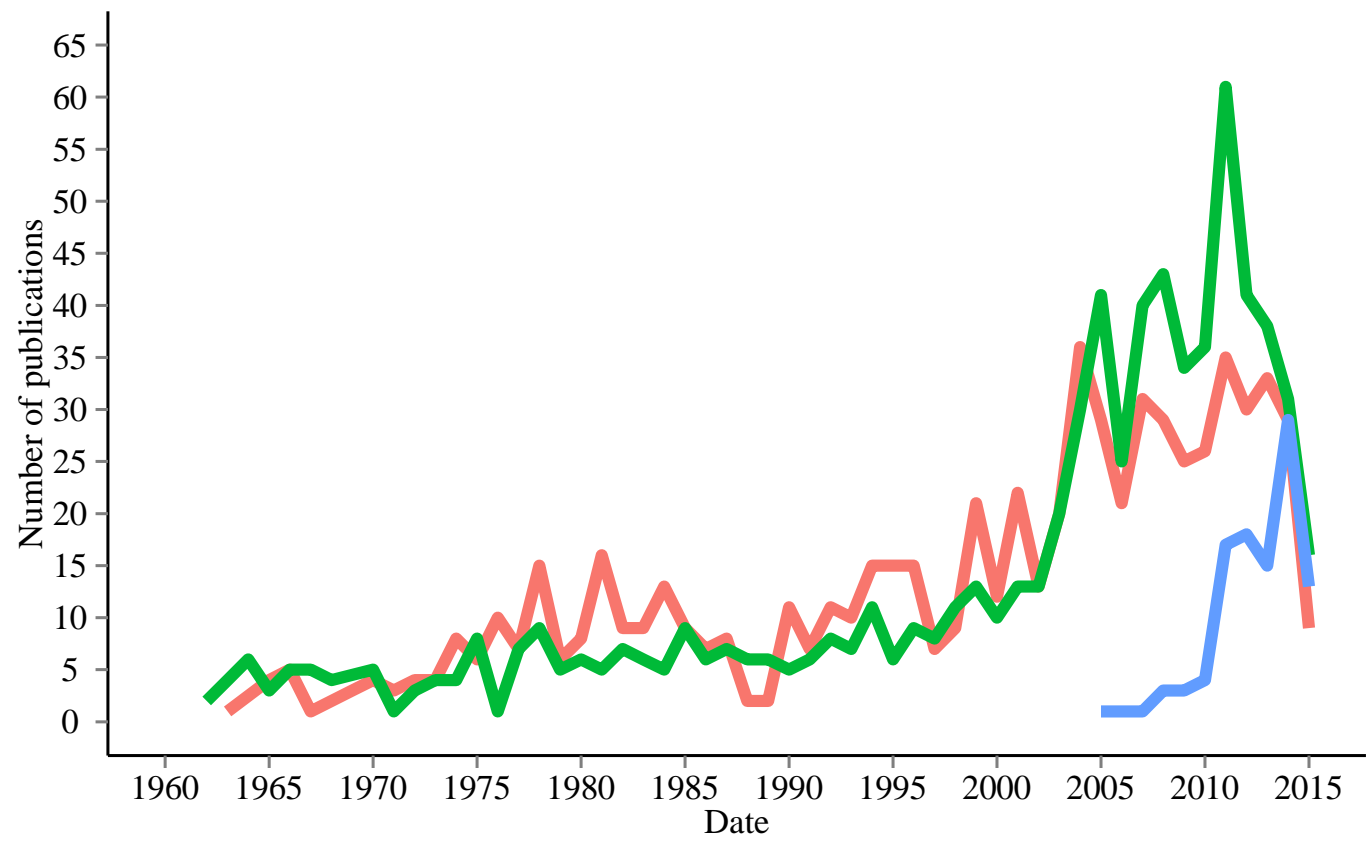

Figure 1. Number of PubMed citations that include the terms 'backward masking', 'binocular rivalry' and 'continuous flash suppression' in the title and / or abstract as a function of publication date. 


\section{The present review: Justification and Scope.}

Understanding the division of labour between conscious and unconscious processes has attracted considerable research effort (Bargh \& Morsella, 2008; Dubois \& Faivre, 2014; Gayet, Van der Stigchel, \& Paffen; Hassin, 2013). Moreover, the extent to which unconsciously presented threats modulate perception remains one of the most contested issues in psychology. Previous reviews of this topic (e.g. Hannula et al., 2005; Pessoa, 2005) have been narrative rather than quantitative, and have drawn on a limited sample of publications. A comprehensive meta-analysis is particularly valuable in the area of unconscious perception, where findings are controversial and inconsistent. Null effects induced by unconsciously presented stimuli might be due to the genuine absence of an effect, or due to the necessary weakening of visual signals induced by the paradigms used to manipulate awareness. Effect sizes in the literature may therefore be small, which makes parameter estimation and power analysis particularly informative for future studies.

Our review also provides insight into the relationship between awareness and other visual selection processes, such as attention. There is some dispute as to whether awareness of and attending to a stimulus are equivalent constructs, or whether the conscious vs. unconscious processing distinction is entirely separate from attentional selection (Koch \& Tsuchiya, 2007; Lamme, 2003). There is also a related, ongoing discussion about whether attention is necessary or sufficient for awareness and vice versa (Cohen, Cavanagh, Chun \& Nakayama, 2012; van Boxtel, Tsuchiya \& Koch, 2010). Quantifying the extent to which attentional selection occurs independently of awareness provides empirical data to inform this debate. 
ARE VISUAL THREATS PRIORITISED WITHOUT AWARENESS?

Our analyses are also important in the context of emotional disorders such as anxiety. Although threat sensitive mechanisms enable humans to respond effectively to danger, anxiety can be a maladaptive condition that is prototypically associated with hypersensitivity to threat, excessive fear and disruption to normal functioning (Eysenck, 1997). Prominent cognitive theories suggest that this hypersensitivity contributes to the etiology, maintenance or exacerbation of anxiety (Bishop, 2007; Matthews \& Macleod, 2005). Specifically, this hypersensitivity is thought to arise from dysfunction in 'automatic' threat-sensitive mechanisms that operate without conscious awareness (Mogg \& Bradley, 1998). A better understanding of mechanisms involved in unconscious emotion processing will inform cognitive-behavioural models of psychopathology, and help refine therapeutic interventions that systematically target discrete cognitive biases e.g. cognitive-behavioural therapies (Rapee \& Heimberg, 1997) or cognitive bias modification (Beard, 2011).

The standard hypothesis, which states that threats are prioritized in the absence of their conscious registration, continues to shape a large body of theoretical work, experimental research and clinical practice - our review provides a timely and comprehensive analysis of evidence in this area. It a) clarifies to what extent and under what conditions threatening stimuli are prioritized without awareness. b) It identifies important gaps and shortcomings in the literature and c) suggests new directions for future research, including improved methods of data acquisition, analysis and reporting.

\section{Definitions}

Although most people have an intuitive grasp of what 'threat' and 'conscious awareness' mean, these abstract concepts are hard to define in a manner precise enough for 
scientific exploration. In fact, in the empirical literature they are often vaguely described and have long been a source of confusion (Pessoa, 2008; Le Doux, 2013; Wiens, 2007).

\section{What is a threatening stimulus?}

Ecological theories propose that there are three braos classes of threatening stimuli, which reflect the different mechanisms by which an organism associates a signal with the likely occurrence of a negative outcome (Adolphs, 2013; Boyer \& Bergstrom, 2011). Firstly, there may be an initial repertoire of 'phylogenetic' threat stimuli (see Ohman \& Mineka, 2001, for a discussion) whose associations may have been set by evolution, such as an approaching predator (Ohman \& Mineka, 2001), or heights (Poulton, Davies, Menzies, Langley, \& Silva, 1998). Secondly, there are 'ontogenetic' threats that are learnt to be dangerous, such as weapons (Blanchette, 2006). Lastly, there are those stimuli that pose no immediate intrinsic threat themselves, but are symbolic, more abstract representations of the above two classes of stimuli (e.g. negative word stimuli, warning signs). The mechanisms through which these stimuli acquire threat value may vary: e.g. classical conditioning, vicarious conditioning/ modeling of others (Ollsson \& Phelps, 2007) or through verbal pathways (Field, Lawson \& Banerjee, 2008). Across a range of species, these three categories of stimuli have been found to elicit a continuum of adaptive physiological, behavioral and cognitive Reponses that form part of a 'defensive cascade' (Blanchard \& Blanchard, 1988). Moreover, despite the apparent diversity in these stimulus categories, they all elicit the subjective experience of negative affect in the large samples of human observers (e.g. Bradley, Codispoti, Cuthbert \& Lang, 2001). At the evolutionary level, this may reflect the fact that diverse situations of predation, contamination, status ;oss, social exclusion and conspecific violence have all been legitimate and recurrent fitness threats for humans, the 
effects of which are all well documented in the archaeological record (Boyer \& Bergstrom, 2011). At the psychological level, theories have reconciled the apparent diversity of threat stimuli with their subjective similarity by proposing that emotional evaluations are mostly based on an initial, primitive 'core' affective evaluation of whether stimuli are negative or positive (Barrett, 2006). These evaluations are termed 'core' because bivalent categorical distinctions between good and bad (appetitive and aversive) are made by all humans and are present from birth (Barret, Mesquita, Ochsner \& Gross, 2007). Indeed, emotional evaluations of stimuli are mostly explained by the basic dimensions of valence and arousal (Greenwald, Cook, \& Lang, 1989).

Based on the above literature, in this review, we define a threatening as any negatively valenced visual signal that is predictive of adverse affects to the physical or emotional well-being of the receiver. Examples of threat stimuli include fearful faces, images of animal attack, negative words and otherwise neutral stimuli that have been conditioned to predict a negative event (e.g. via pairing with an electric shock). Considerable evidence suggests that these stimuli trigger a broad pattern of defensive physiological responses (e.g. Bradley et al., 2001) and adaptive changes in perception, including their prioritized access to conscious awareness and attentional resources (e.g. Vuilleumier, 2005; Yang, Zald, \& Blake, 2007).

\section{What is 'awareness' and how is it manipulated and measured?}

Various meanings of the term 'awareness' are conflated in cognitive psychology (Bargh \& Morsella, 2008; Dehaene \& Changeux, 2011), which are rooted in two, largely independent research domains. These are i) subliminal perception: which is concerned with the processing of stimuli of which one is unaware and ii) unconscious cognition: which is 
concerned with mental processes of which one is unaware (Hassin, 2013). In our review, the term "awareness" is used to refer to the former definition, i.e. the awareness of a stimulus.

How has awareness of stimuli been measured? The simplest, but least conservative method is to use observers' reports to index whether a stimulus is perceived. Historically, this subjective approach derives its motivation from the idea that only observers themselves have access to their inner states and that this is the only reliable source of information about conscious experience (James, 1890). However the development of signal detection theory (SDT: Green \& Swets, 1996), raised concerns that subjective measures are prone to response bias or criterion effects, such as a reluctance to report a signal if it is degraded or brief. According to SDT, due to internal neural noise, the absence of a signal may elicit a strong sensory state and the presence of a signal may elicit a weak sensory state. Reports of awareness are thus probabilistic statements based on an internal threshold thay demarcates sufficient "strength of evidence" that a signal was present (Pastore, Crawley, Berens \& Skelly, 2003). If an observer sets this threshold too high, they may incorrectly reject their conscious perception (a Type 2 error) and report they are 'unaware' of the stimulis. As a result of these issues associated with subjective report, objective criteria have also been employed to determine awareness. The objective approach measures awareness according to an observer's ability to perform statistically above chance in discriminating alternative stimulus states (e.g. left or right location) in a forced-choice classification task (Macmillan \& Creelmen, 2005). For instance, observers might be given 100 trials in which they are asked to report whether a stimulus appeared left or right of fixation (where both are equally probable). Under the null hypothesis (observers are unaware of the stimulus), we would expect observers to respond correctly on approximately 50 of the trials (the most likely outcome 
given random responses). However, if an observer achieves 59 or more correct responses, the null hypothesis is rejected (performance is 'significantly' above chance performance, according to a binomial test) and that observer would be classified as 'objectively aware'. Objective awareness checks that probe stimulus detection via discrimination of a stimulus dimension (e.g. "was it on the left or right?") that is orthogonal to the critical dimension ("was it visible?") are thougth to be less prone to the response biases that can affect an observer's subjective report of the phenomena under investigation. A current view is that both objective and subjective measures have conceptual and practical limitations and so a range of measures should be used in combination to comprehensively characterize visual awareness (for extended discussion see Sandberg, Timmermans, Overgaard \& Cleeremans, 2010; Szcepanowski \& Pessoa, 2007; Wiens, 2007).

\section{Experimental Paradigms}

We applied three criteria when searching the evidence base for experimental paradigms to investigate our research question. Firstly, we reasoned that the paradigm must include an experimental manipulation that suppress threatening and neutral stimuli from awareness. Secondly the paradigm must include a behavioral measure sensitive to enhanced perceptual selection of the threatening (relative to the neutral) stimulus to index its prioritization. Paradigms that manipulate awareness, but measure 'late' semantic congruency effects unrelated to perceptual selection (Algom, Chajut, \& Lev, 2004), such as masked Stroop and masked semantic priming, were not included (other meta-analyses on these subjects exist elsewhere, see Bar Haim et al., 2007; Van den Bussche, Van den Noortgrate, \& Reynvoet, 2009). Third, we made an a priori decision that each paradigm must be represented by at least 10 independent studies to allow useful and informative analyses. A 
ARE VISUAL THREATS PRIORITISED WITHOUT AWARENESS?

summary of other excluded paradigms is included in supplementary material S1.

Implementing these criteria resulted in the inclusion of three experimental paradigms in the analyses: masked visual probe, binocular rivalry and breaking continuous flash suppression.

\section{The Masked Visual Probe Paradigm}

\section{Description.}

In backward masking, a briefly presented target stimulus is quickly replaced by a salient, co-located 'mask' stimulus (typically before $40 \mathrm{~ms}$ ). If the presentation parameters are manipulated appropriately, observers indicate being aware of the mask, but not the target stimulus, i.e. the target is masked from conscious perception. Backward masking appears to disrupt and replace visual processing of the target stimulus (Breitmeyer \& Ogmen, 2000; Rolls, Tovee, \& Panzeri, 1999). Theories suggest that masking weakens and abbreviates the target-related visual signal, eliminating re-entrant feedback from later stages of processing, which is critical for maintaining a representation in awareness (Dehaene, Changeux, Naccache, Sackur, \& Sergent, 2006; Green et al., 2005). Masking is relatively simple to administer and continues to be widely used in studies that aim to manipulate visual awareness. 
ARE VISUAL THREATS PRIORITISED WITHOUT AWARENESS?

The masked visual probe (MVP) paradigm combines backward masking with an attentional cuing paradigm. The generic trial sequence is shown in Figure 2: (i) Observers view a central fixation point. (ii) A threat stimulus and a neutral stimulus are presented either side of fixation for a brief duration (typically <40ms), immediately followed by (iii) colocated mask stimuli. (iv) A probe stimulus is then presented at either the location preceded by the threat (valid) or the neutral stimulus (invalid). (v) Observers are asked to report an aspect of the probe (a two alternative forced choice discrimination) as quickly as possible.

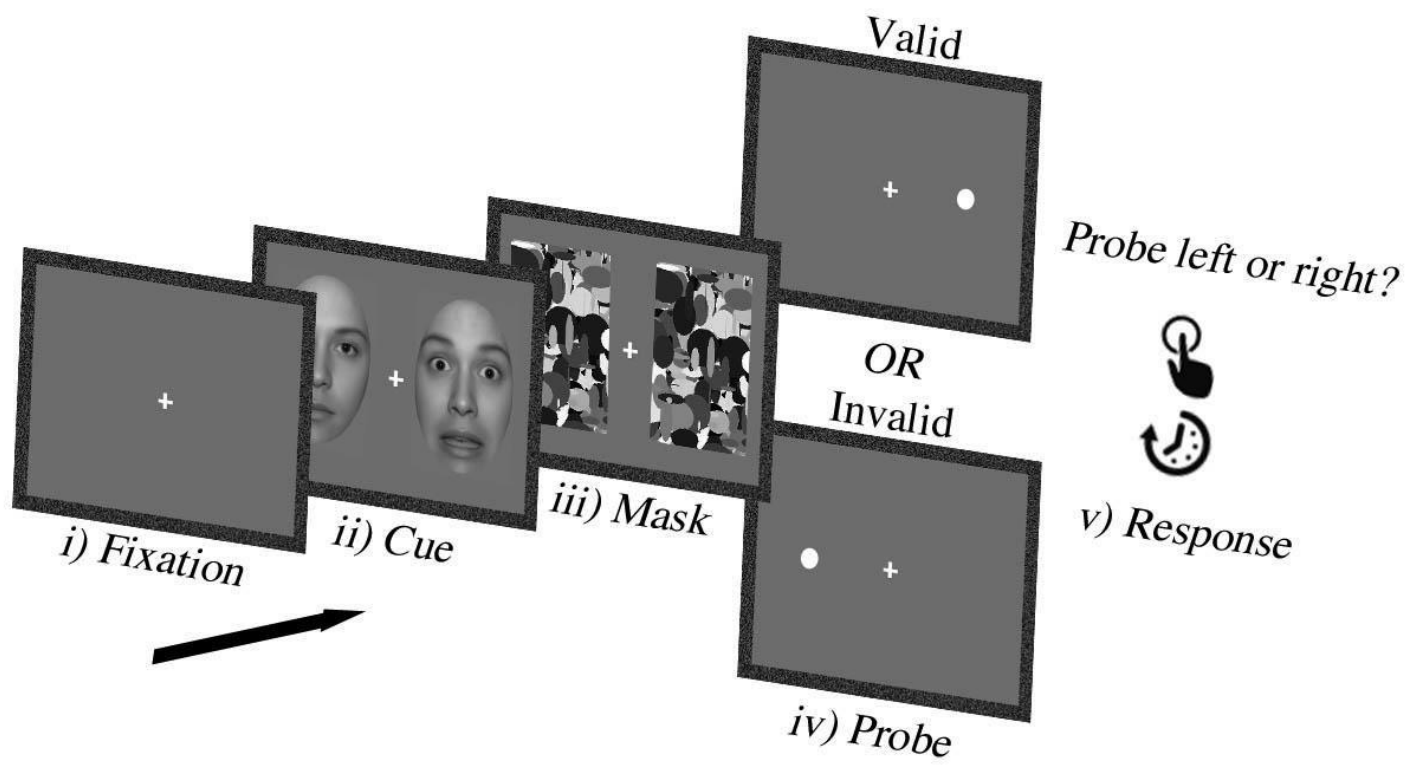

Figure 2. Schematic of generic trial sequence from a masked visual probe (MVP) task.

\section{What can the MVP paradigm tell us and how is this evidenced?}

The MVP paradigm provides an effective tool to probe the theoretical construct to the “orienting network” (Posner, 2012). Since our cognitive systems have limited capacity, they need mechanisms to selectively enhance perceptual processing of relevant, particularly threatening, stimuli. The orienting network is involved in this process by changing the distribution of processing resources across the visual field: attention is disengaged from an 
ARE VISUAL THREATS PRIORITISED WITHOUT AWARENESS?

initial location (or locations) and engaged elsewhere. This re-distribution of attention is indexed by enhanced behavioral performance and increase neural activity at attended, versus unattended locations (Chica, Martin-Arvalo, Botta \& Lupianez, 2014). The MVP task was developed after initial reports that detection latencies to probe stimuli can be modulated by preceding visual cues (Posner, Snyder, \& Davidson, 1980). It follows that spatial attention can be assessed by comparing response latencies to probes that appear in the location of the threat stimulus (often termed 'valid cue trial') to those from the neutral location ('invalid cue trial'). Faster responses in valid (vs. invalid) cue trials suggest that attention is preferentially drawn to the threat stimulus. Thus, by incorporating masking to manipulate stimulus awareness, researchers can determine the extent to which unconsciously presented threat stimuli are prioritized in spatial attention.

\section{Example study: Mogg, Bradley, and Williams (1995).}

The most frequently cited MVP study included in our analyses was conducted by Mogg, Bradley and Williams (1995). The authors examined the attentional biases towards subliminally presented negative and neutral stimuli in clinically anxious and healthy control participants. The observers completed an MVP task where they were presented masked pairs of negative and neutral words for $14 \mathrm{~ms}$. For anxious observers, but not normal controls, response to the subsequent probes were significantly faster in valid trials - consistent with attention being preferentially drawn to masked threat stimuli.

To objectively assess awareness of stimuli, the observers completed a separate block of masked trials, where they discriminated between trials in which word stimuli were presented prior to the mask ( $50 \%$ of trials), or no stimulus was presented prior to the mask (50\% of trials). Observers who performed significantly above chance (i.e. significantly above 
ARE VISUAL THREATS PRIORITISED WITHOUT AWARENESS?

$50 \%$ accuracy) were removed from the MVP analyses (5 out of 32 participants). Thus, the data suggest that anxious observers exhibit attentional biases toward threatening stimuli that they are objectively unaware of. The authors interpreted their findings as evidence for an “automatic, preconscious processing bias in anxiety" (p. 31).

\section{Binocular Rivalry}

\section{Description.}

Under normal viewing conditions, our two eyes receive slightly different views of the world. The visual system is able to combine these similar images into a coherent percept via binocular fusion (Howard \& Rogers, 1995). However, binocular rivalry (BR) may occur when our two eyes receive very different input at corresponding retinal locations, with images typically presented separately to each eye via a mirror stereoscope or as a coloured anaglyph (see Figure 3). In such cases, the visual system cannot combine the two eyes' images into a coherent percept and instead, perception alternates between them (Wheatstone, 1838). The extended and invariant visual stimulation in BR is thus rather different from backward masking, in which awareness is manipulated by rapidly changing the visual input.

At a neural level, BR has been attributed to reciprocal inhibition between neural populations representing the two eyes' stimuli at distributed stages of the visual processing hierarchy (Blake \& Logothetis, 2002). The neural population exerting strongest inhibition achieves access to awareness. Subsequent neural adaptation of the dominant population progressively reduces inhibition of the suppressed stimulus, resulting in a perceptual switch the previously suppressed stimulus reaches dominance and so on (Alais, Cass, O'Shea \& Blake, 2012). 
ARE VISUAL THREATS PRIORITISED WITHOUT AWARENESS?

\section{What can binocular rivalry tell us? How is this evidenced?}

Although BR has been investigated by vision scientists for more than 170 years, a landmark paper by Crick and Koch (1998) stimulated a renewed interest in BR research by popularizing the idea that it allows investigation of the dynamics and neural concomitants of consciousness, owing to its capacity to dissociate visual input from awareness (Baker, 2010). At a theoretical level, the perceptual alternation sin BR reflect a natural constraint: two different stimuli cannot occupy the same space at the same time, thus the visual system must 'choose' perception of one over the other. Researchers are interested in BR because the ensuing 'choices' may be indicative of a variety of processes that the visual system uses to selectively process the retinal images evoked by the environment.
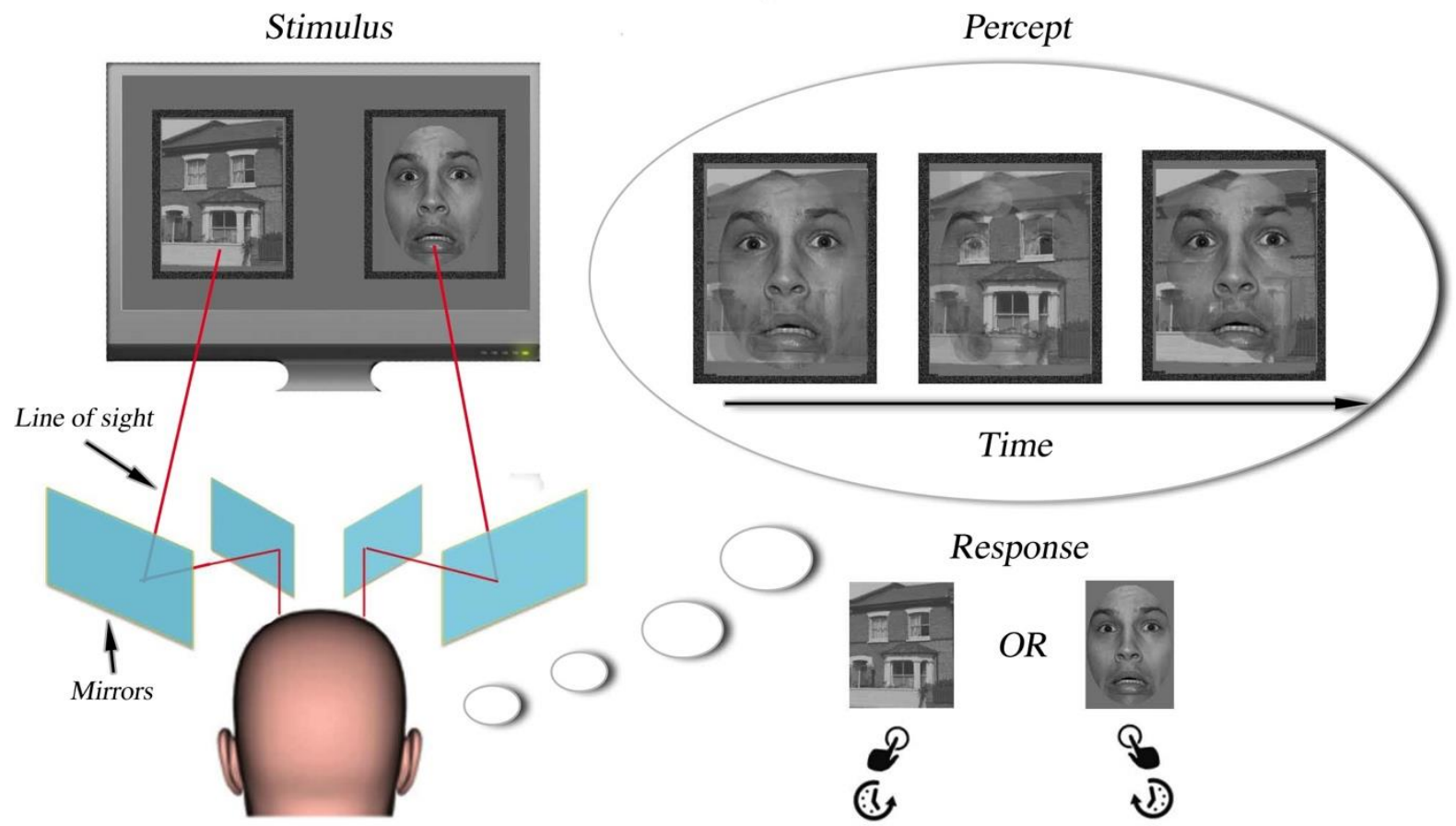
ARE VISUAL THREATS PRIORITISED WITHOUT AWARENESS?

Figure 3. Schematic of typical stimuli, percepts and response options in a binocular rivalry paradigm.

BR has some similarity to natural vision, in that competition occurs between multiple sensory inputs, with only a subset reaching conscious perception. BR has thus been conceptualized as a means to mimic this selection process under more controlled conditions, by assessing which of two co-located stimuli are prioritized in the competition for awareness. This prioritization is often indexed by the proportion of time that one stimulus dominates (i.e. is perceived) over the other (Levelt, 1965). Whereas the MVP paradigm has been used to index attentional modulation by stimulu suppressed from awareness, the BR paradigm allows researchers to index unconscious processing via the speed or probability with which stimuli gain access to conscious perception. The logic is that if a threatening image is prioritized in the competition for awareness, it will be perceived for a larger proportion of a BR trial than a competing neutral stimulus. There is some evidence that dominance in BR is modulated by higher-level factors, such as object recognition (Yu \& Blake, 1992) and surface organisation (Graf \& Adams, 2008). However, low-level stimulus properties, such as higher contrast and luminance, also robustly increase stimulus dominance in BR (Levelt, 1965). The stimulus properties that increase perceptual dominance in BR are often referred to as determining 'stimulus strength'.

During prolonged viewing periods, both rivalling images are likely to be perceived multiple times, as perception alternates between the two. This limits the extent to which dominance in BR reflects a purely unconscious processing advantage, since prolonged perception of a stimulus could be driven by conscious processes acting on the dominant 
ARE VISUAL THREATS PRIORITISED WITHOUT AWARENESS?

(visible) image. To address this issue, one can instead record which stimulus is the first to achieve perceptual dominance. This 'first percept' measure is considered more suited to investigating the early stages of perceptual selection, since only the initially dominant stimulus is reported (Carter \& Cavanagh, 2007).

Example study: Anderson, Siegal, Bliss-Moreau and Feldman Barrett (2011).

The most cited BR study in our analyses was conducted by Anderson, Siegal, BlissMoreau and Feldman Barrett (2011). Via an affective learning procedure, Anderson et al. (2011) associated neutral faces with descriptions of social behaviors that were negative (e.g. "he threw a chair at his classmate"), positive (e.g. "he gave up his seat on the bus to a pregnant lady"), or neutral (e.g. "he rode the elevator with a coworker"). In the subsequent BR task, one of the conditioned face images was presented to one eye, and an image of a house was presented to the other eye. Participants continuously reported their percept (face or house) over the 10-second rivalrous trial. Faces paired with negative social behaviors were perceived for significantly longer than the faces paired with positive or neutral social behaviors, or novel faces. The authors concluded that "what we know about someone influences not only how we feel and think about them, but also whether or not we see them in the first place" (p.1448).

\section{Breaking Continuous Flash Suppression (bCFS) Paradigm}

\section{Description.}

Continuous flash suppression (CFS, Tsuchiya \& Koch, 2005) is a variant of BR in which a stimulus presented to one eye is suppressed from awareness by a competing dynamic noise pattern presented to the other eye. Suppression during CFS is more potent than during 
traditional BR (as defined by contrast detection thresholds; Tsuchiya, Koch, Gilroy, \& Blake, 2006). Temporally, the periods of suppression induced by CFS can last about 10 times longer than suppression induced by traditional BR (Tsuchiya \& Koch, 2005). Another attractive property of CFS is that perceptual suppression of a target stimulus can reliably be induced from the onset of a trial. Thus, in comparison to traditional BR, CFS allows for more controlled, predictable and prolonged manipulations of awareness.

The relative strength of suppression induced by CFS may be due to a number of factors; the dynamic nature of the mask may reduce the neural adaptation that causes frequent perceptual switches in traditional BR (Shimaoka \& Kaneko, 2011). Moreover, the spatiotemporal structure of the mask may exploit human sensory sensitivity; the mask can be selected to maximise human contrast and flicker sensitivity (Yang \& Blake, 2012). It is currently disputed as to whether CFS constitutes a particularly robust form of binocular rivalry or whether it results from distinct mechanisms (Shimaoka \& Kaneko, 2011).

\section{What can the bCFS paradigm tell us? How is this evidenced?}

A popular application of CFS has been to use the length of the initial suppression period in CFS as a correlate of the unconscious salience of the suppressed image. This is referred to as the breaking continuous flash suppression, or bCFS paradigm (the ' $b$ ' refers to 'breaking CFS - see Figure 4). Suppression duration is usually measured by the time it takes for an observer to report the presence or location of the initially suppressed stimulus whose contrast is increased over time. This is rooted in the similar assumption that is made about traditional BR: more salient stimuli gain access to awareness more quickly. Thus, as with BR, researchers have capitalized on the bCFS paradigm since it may offer insight into the competitive dynamics that underlie prioritized access to conscious perception. For instance, 
to enable adaptive behavior, it might be predicted that threatening images would gain faster access to awareness than neutral images. The bCFS paradigm offers a means of testing this prediction.

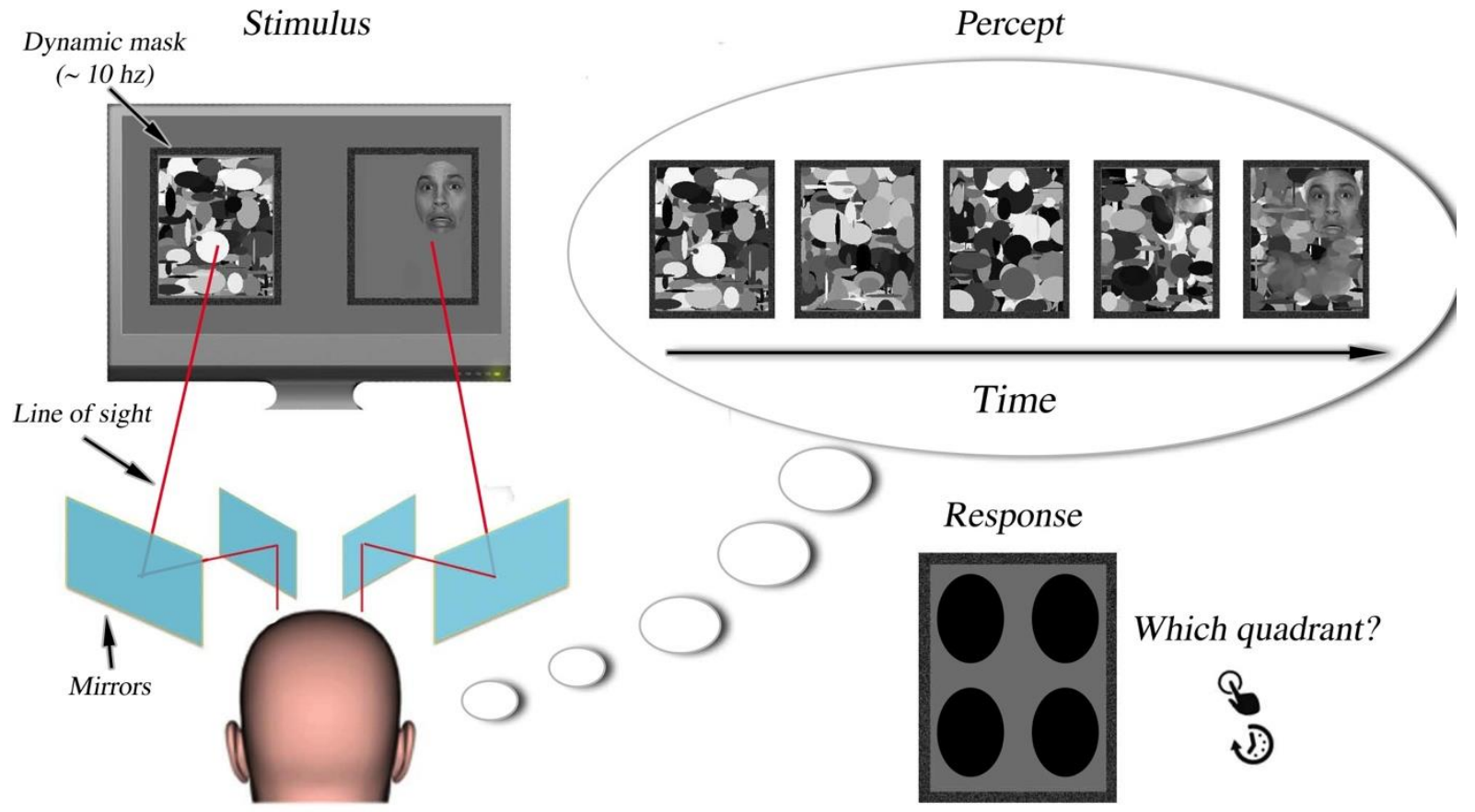

Figure 4. Schematic of typical stimuli, percepts and response options in a breaking continuous flash suppression (bCFS) paradigm.

This paradigm offers several advantages over a conventional rivalry task in which dominance durations are compared for stimuli that compete for resources at the same time and in the same space. Firstly, the likelihood of mixed percepts and associated response biases are reduced (albeit not eliminated) as the trial ends as soon as an observer detects the target stimulus. Secondly, when the duration of percepts are compared between stimuli engaged in $\mathrm{BR}$, it is hard to determine whether increased dominance is due to the salience of the dominant stimulus or the ineffectiveness of the suppressed stimulus. Instead, in bCFS, 
ARE VISUAL THREATS PRIORITISED WITHOUT AWARENESS?

response times are compared across different stimuli that compete against a common 'baseline' dynamic masking pattern, making differential suppression times easier to interpret.

\section{Example study: Yang, Zald and Blake (2007).}

The most cited bCFS paper included in our analyses was conducted by Yang, Zald and Blake (2007). Yang et al. presented happy, fearful and neutral faces under CFS and recorded the time it took for participants to detect a face. Each trial consisted of a face presented at a random quadrant in one eye, whilst the CFS mask was presented to the other eye updating at a rate of $10 \mathrm{~Hz}$. Results showed that observers were faster at detecting the location of fearful than both happy and neutral expressions. The findings were interpreted as evidence that "negatively charged facial expressions gain preferential access to awareness" (p.885).

\section{Meta Analyses: Inclusion and Coding Decisions}

\section{Inclusion Criteria}

All studies included in our analyses met all of the following criteria:

1. The study used one of the following paradigms: masked visual probe, binocular rivalry, or breaking continuous flash suppression.

2. The study was published as a journal article in the English language on or before March 31, 2015.

3. A processing difference between threat-related and neutral stimuli could be assessed. Comparisons between neutral and "emotive" (a combination of positive and threatening) stimuli were excluded.

4. The study was conducted on human subjects. 
5. The study was not a re-analysis of existing data.

6. Sufficient information was available for an effect size to be estimated (see "Meta Analysis: Methods", section below).

\section{Other Coding and Inclusion Decisions}

1. Because anxiety has consistently been linked to increased processing biases for threatening stimuli (Bishop, 2007), we treated samples that were categorized as having high or low levels of self-reported anxiety as separate samples of observers. This allowed us to quantify the effects of anxiety as a moderator. When separate analyses were reported for two or more groups according to some other dimension or personality trait (e.g. carriers of a particular gene; Carlson, Mujica-Parodi, HarmonJones, \& Hajcak, 2012), the data were pooled into one sample.

2. We excluded samples of patients that were reported to have a clinical diagnosis, unless this was an anxiety disorder. This was done to reduce unnecessary variance, as depression might be expected to modulate threat bias (Mogg et al.,1995; Mogg \& Bradley, 2005), but there were insufficient data to reliably characterize effects of disorders other than anxiety. In practice, only 12 studies included in the analyses reported a depression measure, and these varied across studies (Beck Depression Inventory: Beck, Ward, Mendelson, Mock, \& Erbaugh, 1961; Montgomery-Ashberg Depression Rating Scale: Montgomery \& Asberg ,1979; Depression Anxiety Stress Scale; Lovibond \& Lovibond, 1996).

3. When studies involved a mood induction, therapeutic intervention or drug treatment expected to reduce or enhance threat-related biases (e.g. Maoz, Abend, Fox, Pine, \& 
Bar Haim, 2013), we only included experimental data collected prior to the intervention (at baseline), or from a control group. If there were no baseline data or control group, the study was excluded.

4. If the study manipulated levels of threat intensity (e.g. by conditioning a threat image with an aversive event, or neutral event: Beaver et al., 2005), our effect size reflects the processing difference between the highest level of threat (i.e. the threat image paired with the aversive event) and a neutral stimulus.

5. If studies used spatially inverted threat stimuli to control for low-level confounds (e.g. Yang et al., 2013), the corresponding data were excluded from our main analyses, since this manipulation reduces the recognizable emotional content of the stimulus (Gray et al., 2013). Instead, independent analyses were conducted to examine the effect of this manipulation on the magnitude of threat bias.

6. If the study included a manipulation or degradation of stimuli that was not pertinent to our research question (e.g. spatial filtering: Stein, Seymour, Hebart, \& Sterzer, 2013), we included only data corresponding to the un-manipulated (e.g. unfiltered) stimuli, to reduce unnecessary variance.

7. If a study included a conditioning procedure, which assigned negative (CS+) and neutral valences (CS-) to stimuli, we excluded the data if the CS- was not intrinsically 'neutral' (e.g. if the CS+ and CS- were both angry faces; Raes, Koster, Van Damme, Fias, \& De Raedt, 2010).

\section{General Search and Coding Strategies}

The search for relevant studies and their coding was conducted by two authors $(\mathrm{NH}$, KHLG). First, we conducted PubMed database searches. Second, we examined the reference 
ARE VISUAL THREATS PRIORITISED WITHOUT AWARENESS?

sections of all relevant literature reviews for additional studies. Third, we searched the reference sections of all qualifying articles and articles listed as citing the qualifying articles on Google Scholar. Database search terms, and a summary of the excluded articles are presented according to the 'Preferred Reporting Items for Systematic reviews and Meta Analysis' guidelines (PRISMA; Moher, Liberati, Tetzlaff, Altman \& Altman, 2009). The search terms and associated PRISMA flowcharts can be found in the supplementary material (supplementary material S2).

Details of the coding / moderator variables used within each experimental paradigm are detailed in later sections. The inter-coder agreement between the two authors was high. We calculated the intra-class coefficients (ICCs) and kappa coefficients for the continuous and categorical moderators respectively. The ICCs were all 1.0 due to the straightforward nature of the continuous moderator data and the kappa coefficients ranged from 0.91 (for stimulus type) to 1.0 (for all other moderators). Rare disagreements were resolved via a discussion between the four authors.

\section{Meta Analysis: Methods}

\section{Effect Size Metric}

The effect size index used for all outcome measures was Cohen's $d$; the standardized difference between means (Cohen, 1977). In all cases, a positive value indicates a perceptual bias towards a threatening stimulus relative to a neutral stimulus.

\section{Standardizers for $d$}

Our primary estimator of Cohen's $d$ was $d_{z}$-the difference between means standardized by the standard deviation of difference scores. The advantage of this metric is 
that it can be computed directly from just $t, p$ or $F$ values and the corresponding degrees of freedom (Lakens, 2013):

$$
d_{z}=\frac{t}{\sqrt{N}}
$$

As our effects emanated from repeated measures designs, we also estimate an effect size estimate that corrects for the pre-post correlation $\left(d_{R M}\right)$ wherever possible (see supplementary material S3)

In both cases $\left(d_{z}, d_{R M}\right)$, the standard error was calculated via the generic formula:

$$
S E=\sqrt{\frac{1 / N+d^{2}}{2 N}} \quad \sqrt{2(1 r)}
$$

If no exact $t$ or $p$ values were reported (e.g. " $p<.05$ "), we either estimated the effect size from the available information, or, when necessary, excluded it from the analyses (see supplementary material S4). Additionally, we used two multiple imputation methods to estimate unreported values of moderator variables (see supplementary material S5). Regression imputation (RI) is 'optimistic' and uses the existing relationship between the reported moderator values and effect size to predict the unreported values. Conversely, random-sample imputation (RSI) is more conservative and assumes that missing values are random samples of the reported moderator values (i.e. the existing relationship is not predictive of the missing values).

\section{Model and Analysis Decisions}

We made an a priori decision to analyze our effect size data in a random effects model, due to its tolerance of heterogeneous effect sizes and conservative nature of estimation (Cumming, 2012). The random effects model assumes that each study estimates 
ARE VISUAL THREATS PRIORITISED WITHOUT AWARENESS?

different values from a distribution of population parameters, rather than assuming that studies are direct replications of each other (Schmidt, Oh, \& Hayes, 2009).

We assessed heterogeneity across effect sizes by using Cochran's $Q$ and $I^{2}$ statistics. Unless reported otherwise, parameter estimates were obtained via restricted maximum likelihood estimation, owing to its superior accuracy given a smaller number of studies (Lopez-Lopez, Marin-Martinez, Sanchez-Meca, Van den Noortgate, \& Viechtbauer, 2014). Statistical tests of model coefficients were computed via Wald-type chi squared tests. We additionally used a pseudo- $R^{2}$ statistic (Raudenbush, 1994) to assess the extent of effect size heterogeneity that was explained by moderators included in the model (see Supplementary material S6). Model comparisons were conducted via likelihood ratio tests. All analyses were conducted with the 'metafor' package (Viechtbauer, 2010) using the $R$ programming language.

\section{Handling Dependency Amongst Effect Sizes}

For each paradigm, we explicitly coded the number of included conditions (nested within samples) and samples (nested within studies). Many of the samples were exposed to multiple conditions, which generates multiple effect sizes for these samples. For instance, in some cases, participants were exposed to more than one stimulus type (e.g. to fear and angry faces; Gray et al., 2013), meaning that this important moderator occurs at the within sample level and information would be lost by aggregating these effects. Thus, to minimize this information loss and increase statistical power, we used conditions, rather than samples as the unit of analysis in our models ( $k=$ conditions).

When samples contribute multiple effect sizes in this way, the assumption of independence may be violated and bias the outcome of the meta-analysis, particularly if there 
ARE VISUAL THREATS PRIORITISED WITHOUT AWARENESS?

is anything unrepresentative about these samples (Matt \& Cook, 2009; Rosenthal, 1991). To examine the influence of dependency on our results, we used two strategies. Firstly, we created multi-level models (see Cheung, 2014) wherein conditions (level 2) were nested within their samples (level 3). Because a structural equation modelling approach is used to estimate these models, this allowed us to specify interesting constraints that are otherwise very difficult to test. Using this approach, we were able to partition the heterogeneity between effect sizes into that occurring at level 2 (between conditions) or level 3 (between samples) and also statistically examine whether there was a significant amount of effect size dependency (i.e. does a 3 level model provide a significantly better fit than a 2 level model?). Secondly, we examined the influence of dependency via sensitivity analyses: using random selection procedures, we created data sets where dependency was eliminated by selecting one effect size per independent sample (Greenhouse \& Iyengar, 1994).

\section{Meta Analysis: Results}

\section{The MVP paradigm}

\section{Summary of included data.}

Our inclusion criteria resulted in 28 MVP studies being analyzed, comprising 1407 participants across 39 independent samples. We derived 44 estimates of the threat effect size. The coding system and summary of effects used in the analyses are shown in Tables 1 and 2 . Detailed information about each included effect and demographic information can be found in the supplementary material (S7). 


\section{Dependent measures.}

For the MVP paradigm, Cohen's $d$ reflects the difference in response time between valid and invalid cue trials. Positive values indicate that attention is biased towards the spatial location of threat-related stimuli (faster responses in valid trials).

\section{Overall effect size of threat-related bias.}

Figure 5 depicts the outcome of the MVP meta-analysis. A small, pooled effect of threat bias was detected $\left(k=44, N=1407, d_{z}=0.28,95 \%\right.$ CI $\left.[0.160 .40], p<.001\right)$. The probability of superiority metric (Grissom \& Kim, 2005) indicates that, after controlling for individual differences, the likelihood that a randomly sampled observer will respond faster to probes following threat relative to neutral stimuli is $58 \%$ [55\% 61\%]. The pooled effect remained significant when any single contributing effect was removed from the model (leaveone-out analysis, all $p s<.001)$. Moreover, Rosenthal's 'fail safe N' (Rosenthal, 1991) revealed that the number of effects averaging null results required to render the pooled effect non-significant was $1125^{1}$. Non-parametric 'trim and fill' analyses (Duval, 2005), did not suggest that any effects had been suppressed by publication bias (see also funnel plot in Figure 5b). 


\section{ARE VISUAL THREATS PRIORITISED WITHOUT AWARENESS?}

Table 1

Coding of Individual Effects in the MVP Paradigm.

\begin{tabular}{|c|c|c|c|c|c|}
\hline Moderator & Type & Values & Description of variable / theoretical justification & $\begin{array}{l}\text { Descriptive } \\
\text { statistics }\end{array}$ & $\begin{array}{l}\text { Missing } \\
\text { cases }\end{array}$ \\
\hline $\begin{array}{l}\text { Stimulus } \\
\text { type }\end{array}$ & Categorical & $\begin{array}{l}1=\text { fearful face } \\
2=\text { angry face } \\
3=\text { disgust face } \\
4=\text { threatening } \\
\text { word. } \\
5=\text { IAPS image } \\
6=\text { fear } \\
\text { relevant CS }+\end{array}$ & $\begin{array}{l}\text { The type of threatening stimulus used in the experiment. Justification: The magnitude of threat bias may differ } \\
\text { as a function of the semantic/physical properties of the stimulus. In addition, masking may not be equally } \\
\text { effective for all stimulus types (Wiens \& Ohman, 2007). }\end{array}$ & $\begin{array}{l}k=44 \\
1=15 \\
2=17 \\
3=1 \\
4=8 \\
5=2 \\
6=1\end{array}$ & 0 \\
\hline SOA & Continuous & $12-34$ & $\begin{array}{l}\text { Stimulus onset asynchrony (SOA) between presentation of the threat and mask stimulus. Justification: } \mathrm{SOA} \text { is } \\
\text { directly related to visibility/awareness of the target stimulus, which may modulate biases towards threat-stimuli. }\end{array}$ & $\begin{array}{l}k=44 \\
M=20.89 \\
S D=8.07 \\
\text { Range }=12-34\end{array}$ & 0 \\
\hline $\begin{array}{l}\text { Awareness } \\
\text { measure }\end{array}$ & Dichotomous & $\begin{array}{l}0=\text { none } \\
1=\text { objective }\end{array}$ & $\begin{array}{l}\text { How awareness of stimuli was assessed (with an objective awareness check, or with no awareness check). } \\
\text { Justification: Previous research suggests that threat-related biases to briefly presented stimuli may be a function } \\
\text { of the criteria used to assess awareness (Pessoa, Japee, Sturman, \& Ungerleider, 2006). }\end{array}$ & $\begin{array}{l}k=44 \\
0=26 \\
1=18\end{array}$ & 0 \\
\hline $\begin{array}{l}\text { Probe } \\
\text { response }\end{array}$ & Dichotomous & $\begin{array}{l}1=\text { 'where' } \\
2=\text { 'what' }\end{array}$ & $\begin{array}{l}\text { The response that an observer is required to make to the visual probe in the response phase: 'where' tasks } \\
\text { involve reporting the location of the probe (left or right), whereas 'what' tasks involve discriminating the } \\
\text { probes' orientation. Justification: Previous research has shown that these tasks are associated with different } \\
\text { response times and error rates (Mogg \& Bradley, 1999a). }\end{array}$ & $\begin{array}{l}k=44 \\
1=33 \\
2=11\end{array}$ & 0 \\
\hline $\mathrm{h}^{\mathrm{pwr}}$ & Continuous & $0.27-0.43$ & $\begin{array}{l}\text { Metric that summarises the statistical power of objective awareness checks (see text). Justification: Awareness } \\
\text { checks with low power increase the probability that target stimuli were not fully / always suppressed from } \\
\text { awareness, i.e. deviations from chance performance in the awareness check may not be detected. This increases } \\
\text { the likelihood that threat-related biases could be driven by a small proportion of undetected trials where the } \\
\text { observer was aware of stimuli (Hannula et al., 2007; Reingold, 2004). }\end{array}$ & $\begin{array}{l}k=26 \\
M=0.38 \\
\mathrm{SD}=0.06 \\
\text { Range }=0.27 \\
0.43\end{array}$ & 0 \\
\hline $\begin{array}{l}\text { Stimulus } \\
\text { size }\end{array}$ & Continuous & $2.8-7.0$ & $\begin{array}{l}\text { Diameter of the threat stimulus in degrees of visual angle. Justification: Affective processing of threat images } \\
\text { may increase with stimulus size (Codispoti \& Cesarei, 2007). Moreover, masking may not be as effective for } \\
\text { larger stimuli (Wiens \& Ohman, 2007). }\end{array}$ & $\begin{array}{l}k=22 \\
M=5.3 \\
S D=1.4 \\
\text { Range=2.8- } \\
7.0\end{array}$ & 22 \\
\hline STAI-T & Continuous & $29.4-58.1$ & $\begin{array}{l}\text { The samples' mean trait anxiety level, as assessed by the Spielberger state-trait anxiety scale (Spielberger, } \\
\text { Gorsuch, Lushene, Vagg, \& Jacobs, 1983). Justification: Anxiety is associated with enhanced processing biases } \\
\text { towards threatening stimuli in visual probe tasks (Bar Haim et al., 2007). }\end{array}$ & $\begin{array}{l}k=15 \\
M=41.34 \\
S D=8.85 \\
\text { Range=29.4- }\end{array}$ & 29 \\
\hline
\end{tabular}




\section{ARE VISUAL THREATS PRIORITISED WITHOUT AWARENESS?}

Table 2

\section{Summary of Effects Included in the MVP Analyses}

\begin{tabular}{|c|c|c|c|c|c|c|c|c|c|c|c|c|c|c|}
\hline Study/Effect & $\begin{array}{l}\text { Sample } \\
\text { code }\end{array}$ & $\begin{array}{l}\text { Condition } \\
\text { code }\end{array}$ & Exp & $N$ & Stim & SOA & Aw meas & $\begin{array}{l}\text { Probe } \\
\text { resp }\end{array}$ & $\mathrm{H}_{\mathrm{pwr}}$ & VF & Group & $\begin{array}{l}\text { Ret } \\
\text { size }\end{array}$ & STAI-T & Pool ID \\
\hline 1) Mogg et al., 1994 (i) & 1 & 1 & 1 & 36 & 4 & 14 & 1 & 1 & 0.38 & 0 & High Trait Anxious & & 42.4 & 0 \\
\hline Mogg et al., 1994 (ii) & 2 & 2 & 1 & 30 & 4 & 14 & 1 & 1 & 0.38 & 0 & Low Trait Anxious & & 29.1 & 0 \\
\hline 2) Mogg et al., 1995 (i) & 3 & 3 & 1 & 17 & 4 & 14 & 1 & 1 & 0.36 & 0 & Clinical Anxiety & & 58.1 & 0 \\
\hline Mogg et al., 1995 (ii) & 4 & 4 & 1 & 15 & 4 & 14 & 1 & 1 & 0.36 & 0 & Normal Controls & & 39.1 & 0 \\
\hline 3) Mogg \& Bradley, 1999b (i) & 5 & 5 & 1 & 33 & 2 & 17 & 1 & 1 & 0.41 & 1 & & 2.9 & 42.0 & 0 \\
\hline Mogg \& Bradley, 1999b (ii) & 5 & 6 & 1 & I & 2 & 17 & 1 & 1 & 0.41 & 2 & & 2.9 & 39.0 & 0 \\
\hline Mogg \& Bradley, 1999b (iii) & 6 & 7 & 3 & 22 & 2 & 17 & 1 & 1 & 0.43 & 1 & & 2.9 & 39.0 & 0 \\
\hline Mogg \& Bradley, 1999b (iv) & 6 & 8 & 3 & l & 2 & 17 & 1 & 1 & 0.43 & 2 & & 2.9 & 42.0 & 0 \\
\hline 4) Mogg \& Bradley, 2002 (i) & 7 & 9 & 1 & 11 & 2 & 17 & 1 & 2 & 0.43 & 0 & High Social Anxiety & 4.5 & 43.7 & 0 \\
\hline Mogg \& Bradley, 2002 (ii) & 8 & 10 & 1 & 16 & 2 & 17 & 1 & 2 & 0.43 & 0 & Low Social Anxiety & 4.5 & 33.9 & 0 \\
\hline 5) Fox, 2002 (i) & 9 & 11 & 2 & 18 & 1 & 17 & 1 & 2 & 0.43 & 1 & High Trait Anxious & 5.7 & 50.4 & 0 \\
\hline Fox, 2002 (ii) & 9 & 12 & 2 & l & 1 & 17 & 1 & 2 & 0.43 & 2 & High Trait Anxious & 5.7 & 50.4 & 0 \\
\hline Fox, 2002 (iii) & 10 & 13 & 2 & 18 & 1 & 17 & 1 & 2 & 0.43 & 1 & Low Trait Anxious & 5.7 & 29.4 & 0 \\
\hline Fox, 2002 (iv) & 10 & 14 & 2 & I & 1 & 17 & 1 & 2 & 0.43 & 2 & Low Trait Anxious & 5.7 & 29.4 & 0 \\
\hline 6) Keogh et al., 2003 (i) & 11 & 15 & 1 & 81 & 4 & 17 & 1 & 1 & 0.43 & 0 & & & & 0 \\
\hline 7) Beaver et al., 2005 (i) & 12 & 16 & 2 & 10 & 6 & 17 & 1 & 2 & 0.43 & 0 & High-aversive group & & & 0 \\
\hline 8) Hunt et al., 2006 (i) & 13 & 17 & 1 & 55 & 4 & 17 & 1 & 1 & 0.43 & 0 & & & & 0 \\
\hline 9) Koster et al., 2007 (i) & 14 & 18 & $1 \mathrm{a}$ & 49 & 2 & 34 & 1 & 1 & & 0 & & 6.7 & & 0 \\
\hline Koster et al., 2007 (ii) & 15 & 19 & 2 & 24 & 2 & 34 & 1 & 1 & 0.27 & 0 & & 6.7 & & 0 \\
\hline
\end{tabular}




\section{ARE VISUAL THREATS PRIORITISED WITHOUT AWARENESS?}

\begin{tabular}{|c|c|c|c|c|c|c|c|c|c|c|c|c|c|c|}
\hline Koster et al., 2007 (iii) & 16 & 20 & 3 & 19 & 2 & 14 & 1 & 1 & 0.27 & 0 & & 6.7 & & 0 \\
\hline 10) Murphy et al., 2007 (i) & 17 & 21 & 1 & 12 & 1 & 17 & 0 & 2 & & 0 & Placebo control & & & 0 \\
\hline 11) Stone \& Valentine, 2007 (i) & 18 & 22 & 1 & 24 & 2 & 17 & 1 & 1 & 0.39 & 0 & & & & 0 \\
\hline Stone \& Valentine, 2007 (ii) & 19 & 23 & 2 & 28 & 2 & 17 & 1 & 1 & 0.39 & 0 & & & & 0 \\
\hline 12) Wirth \& Schultheiss, 2007 (i) & 20 & 24 & 2 & 52 & 2 & 12 & 0 & 1 & & 0 & & & & 0 \\
\hline 13) Schultheiss \& Hale, 2007 (i) & 21 & 25 & 1 & 52 & 2 & 12 & 0 & 1 & & 0 & & & & 0 \\
\hline Schultheiss \& Hale, 2007 (ii) & 22 & 26 & 2 & 60 & 2 & 12 & 0 & 1 & & 0 & & & & 0 \\
\hline 14) Carlson \& Reinke, 2008 (i) & 23 & 27 & 1 & 30 & 1 & 33 & 0 & 1 & & 0 & & 6.0 & & 0 \\
\hline Carlson \& Reinke, 2008 (ii) & 24 & 28 & 2 & 30 & 1 & 33 & 0 & 1 & & 0 & & 6.0 & & 0 \\
\hline 15) Monk et al., 2008 (i) & 25 & 29 & 1 & 17 & 2 & 17 & 0 & 1 & & 0 & Generalised Anxiety Disorder & & & 0 \\
\hline Monk et al., 2008 (ii) & 26 & 30 & 1 & 12 & 2 & 17 & 0 & 1 & & 0 & Control Group & & & 0 \\
\hline 16) Carlson et al., 2009a (i) & 27 & 31 & 1 & 12 & 1 & 33 & 1 & 1 & 0.31 & 1 & & & & 0 \\
\hline Carlson et al., 2009a (ii) & 27 & 32 & 2 & l & 1 & 33 & 1 & 1 & 0.31 & 2 & & & & 0 \\
\hline 17) Carlson et al., 2009b (i) & 28 & 33 & 1 & 30 & 5 & 33 & 0 & 1 & & 0 & & 7.0 & & 0 \\
\hline 18) Helzer et al., 2009 (i) & 29 & 34 & 1 & 112 & 4 & 20 & 1 & 1 & & 0 & & & & 0 \\
\hline 19) Fox et al., 2010 (i) & 30 & 35 & 1 & 104 & 5 & 14 & 0 & 2 & & 0 & & 4.0 & 40.1 & 0 \\
\hline 20) Carlson \& Reinke, 2010 (i) & 31 & 36 & 1 & 12 & 1 & 33 & 1 & 1 & & 0 & & 6.0 & & 0 \\
\hline 21) Thomason et al., 2010 (i) & 32 & 37 & 1 & 20 & 1 & 17 & 0 & 1 & & 0 & 11 carriers & & & 1 \\
\hline Thomason et al., 2010 (ii) & 32 & 37 & 1 & 31 & 1 & 17 & 0 & 1 & & 0 & s- allele carriers & & & 1 \\
\hline 22) Sutton \& Altarriba, 2011 (i) & 33 & 38 & 2 & 64 & 4 & 30 & 0 & 2 & & 0 & & & & 0 \\
\hline 23) Carlson et al., 2012 (i) & 34 & 39 & 1 & 40 & 1 & 33 & 1 & 1 & 0.32 & 0 & SS allele & 6.0 & & 2 \\
\hline Carlson et al., 2012 (ii) & 34 & 39 & 1 & 10 & 1 & 33 & 1 & 1 & 0.32 & 0 & L allele & 6.0 & & 2 \\
\hline 24) Carlson et al., 2013a (i) & 35 & 40 & 1 & 40 & 1 & 33 & 1 & 1 & 0.32 & 0 & & 6.0 & & 0 \\
\hline 25) Carlson et al., 2013b (i) & 36 & 41 & 1 & 15 & 1 & 33 & 1 & 1 & 0.32 & 0 & & 6.0 & & 0 \\
\hline 26) Maoz et al., 2013 (i) & 37 & 42 & 1 & 24 & 3 & 17 & 0 & 2 & & 0 & Treatment group & & & 3 \\
\hline Maoz et al., 2013 (ii) & 37 & 42 & 1 & 27 & 3 & 17 & 0 & 2 & & 0 & Control group & & & 3 \\
\hline 27) McCrory et al., 2013 (i) & 38 & 43 & 1 & 40 & 2 & 17 & 0 & 1 & & 0 & & & & 0 \\
\hline 28) Carlson et al., 2014 (i) & 39 & 44 & 1 & 55 & 1 & 33 & 1 & 1 & 0.32 & 0 & & 6.0 & & 0 \\
\hline
\end{tabular}

Note. Dashes indicate that the sample is the same as the preceding row.

Pool ID is a coding variable that indicates the effects that are pooled together into one sample. 
ARE VISUAL THREATS PRIORITISED WITHOUT AWARENESS?

a)

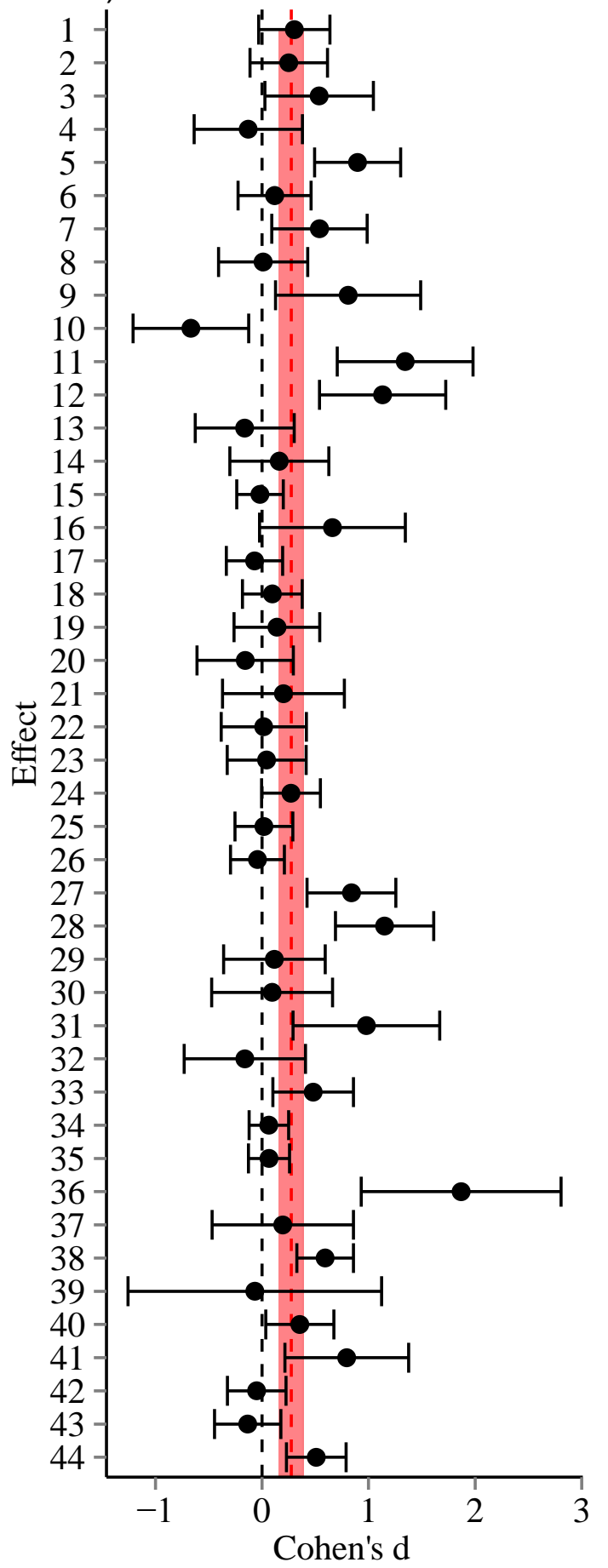

b)

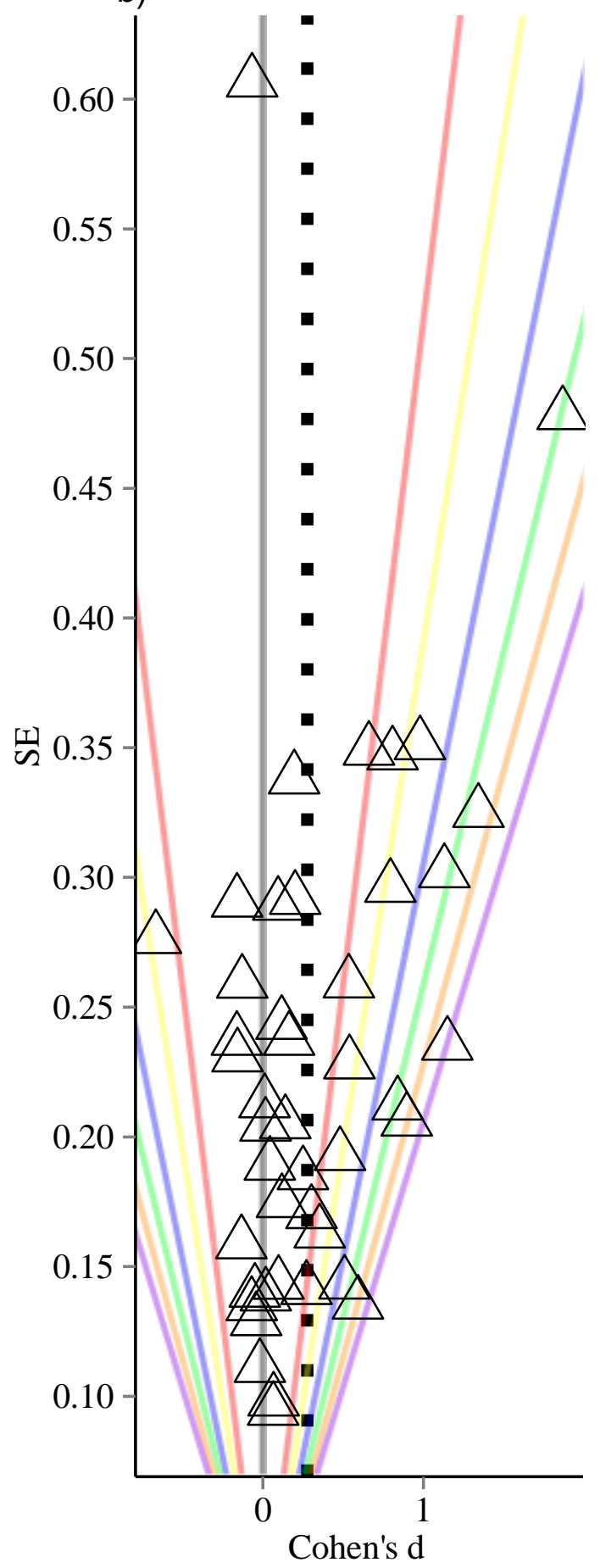




\section{ARE VISUAL THREATS PRIORITISED WITHOUT AWARENESS?}

Figure 5. a): Forest plot of effects from the MVP analyses, error bars are $95 \%$ confidence intervals. Dotted red line is the pooled summary effect, shaded region is the $95 \%$ confidence interval b) Funnel plot. Dotted line is pooled effect size. Coloured contours represent $p$ values $($ Black: $=1$, Red $=.05$, Yellow $=.01$, Blue $=.001$, Green $=.0001$, Orange $=.00001$, Purple $=.000001)$.

Substantial heterogeneity was detected $(Q(43)=151.24, p<.001)$. The $I^{2}$ statistic indicated that $77 \%$ of the heterogeneity between studies could not be accounted for by sampling variability, justifying the use of the random effects model. Fifty-eight percent of heterogeneity was located at the between condition level and only $19 \%$ was located at the between sample level. Moreover, a 3-level, nested model did not provide a better fit to the data than a traditional 2 level model $(L R T=0.249, p=.618)$, suggesting the influence of dependency was limited. To explain this heterogeneity across threat-related biases, we examined the influence of moderators, which are summarized in Table 1.

\section{Regression models with one moderator.}

A summary table of the one-moderator models and plots of all main effects can be found in supplementary material (S8).

An effect of stimulus type was detected $(Q(5)=13.78, p=.017)$ and including this moderator in the model accounted for $24.34 \%$ of the total heterogeneity among effects. There was a large bias for fearful faces $\left(d_{z}=0.58,[0.370 .78], p<.001\right)$ but significant pooled biases were not detected for any other stimulus types (see Figure 6a). Fearful faces yielded larger 


\section{ARE VISUAL THREATS PRIORITISED WITHOUT AWARENESS?}

biases than angry faces, disgust faces and word stimuli $(p s<.05)$. No other significant differences between stimulus types were detected.

The distribution of SOAs between target stimulus and mask was bimodal, so we dummy coded SOAs as either long $(30,33$, or $34 \mathrm{~ms})$ or short $(12,14$, or $17 \mathrm{~ms})$. A main effect of this factor was detected $(Q(1)=9.23, p=.002)$ and this moderator accounted for $29.10 \%$ of the heterogeneity in effects: threat-related biases were significantly larger at longer SOAs (see Figure 6b).

No difference was detected between studies that did vs. did not include an objective awareness check $(Q(1)=0.04, p=.834)$. To assess the statistical power of objective awareness checks, we used the effect size index Cohen's $h$ (the arcsine transformed difference between chance performance and a target level of above-chance performance; Cohen, 1977). To summarize power in a single metric $\left(h^{\mathrm{pwr}}\right)$, we calculated the largest value of $h$ that each awareness check would be underpowered to detect (by assuming power of $79 \%$ to detect at the $a=.05$ level). In other words, this analysis asks, "what is the upper limit of discrimination performance that participants could attain in the awareness check, but still be classified as 'unaware'?". The mean value of $h^{\mathrm{pwr}}$ was $0.37(S D=0.06)$ - a small-to-medium effect size. In practice, this means that, on average, it is accepted that participants are objectively unaware of stimuli if $2 \mathrm{AFC}$ performance is less than $68 \%$, i.e. up to $18 \%$ above chance level.

Meta-regression detected no evidence that $h_{p w r}$ predicted the magnitude of threat related bias $(Q(1)=0.32, p=.856(R I: b=0.02,[-0.080 .12], p=.694, R S I: b=0.02,[-0.09$ $0.12], p=.754)$. Thus, although awareness checks were lacking in statistical power, and threat biases are larger with long SOAs, these data do not provide direct evidence that threat related biases can be attributed to undetected deviations from chance performance. However, 


\section{ARE VISUAL THREATS PRIORITISED WITHOUT AWARENESS?}

given the low variability in $h_{p w r}$ values across studies (range $0.27-0.43$ ), and the limited number of effects that had an associated objective awareness check $(k=26)$, limited power exists to detect this potential relationship.

Trait anxiety levels were reported for 15 effects. Anxiety was entered as a continuous predictor of the corresponding threat-biases via meta-regression (Figure 6c), revealing that elevated anxiety is associated with larger threat bias $\left(b=0.03, R^{2}=37.18 \%, p=.008 ; R I: b=\right.$ $0.02,[0.010 .04], p=.016 ;$ RSI: $b=0.01,[-0.010 .03], p=.234)$. The model indicated that threat-related biases would reduce to statistical non-significance for samples with STAI-T scores below 40. However, when restricting our analyses to samples whose anxiety levels were unreported, a small threat bias was still detected $\left(d_{z}=0.25,95 \%\right.$ CI $[0.12,0.39]$, $p<.001)$.

Across 22 effects, we found no evidence that stimulus size modulated effect sizes $\left(b=0.04, R^{2}=0.00, p=.624, R I: b=0.02,[-0.080 .12], p=.694 ; R S I: b=0.02,[-0.090 .12], p\right.$ $=.754)$. We also found no evidence that probe response modulated effect sizes $(Q(1)=0.14$, $p=.708)$. Pooled effect sizes were of similar magnitude in the 'where' $\left(d_{z}=0.26,[0.120 .40]\right.$, $p<.001)$ and 'what' versions of the task $\left(d_{z}=0.32,[0.070 .57], p=.013\right)$. Five studies split their analyses by visual field, yielding 10 effects. No effect of visual field was detected $(Q(1)=$ $1.93, p=.165)$. However, when left and right visual field were analyzed separately, threatrelated biases were only statistically significant for stimuli presented in the left visual field (left: $d_{z}=0.68,[0.231 .15], p=.003$, right: $d_{z}=0.23,[-0.210 .68], p=.304$ ). 

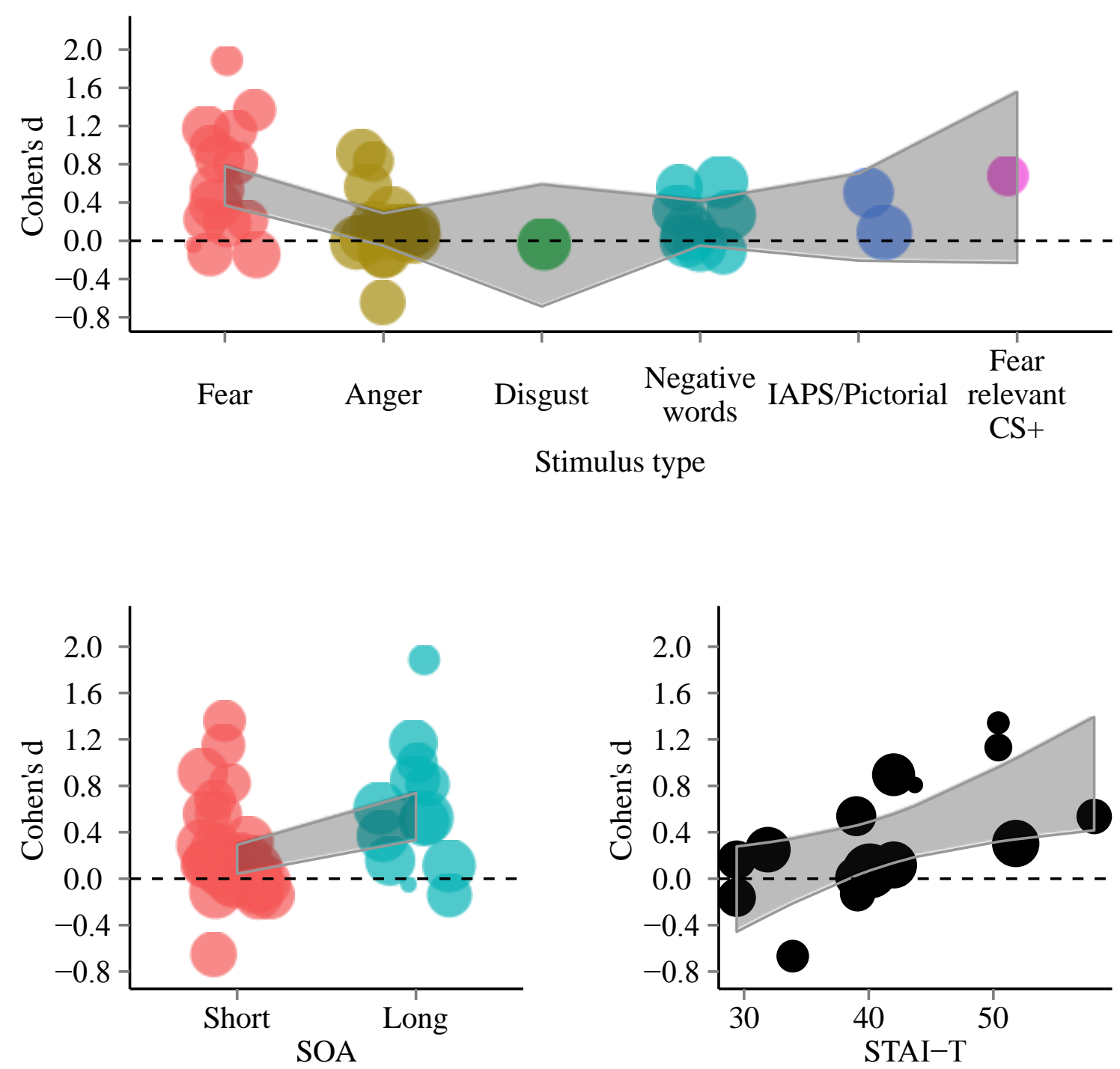

Figure 6. Random effects models with (a) stimulus type, (b) SOA and (c) STAI-T as the sole moderator. Shaded grey region is the $95 \%$ CI. Size of points is inversely proportional to the standard error of the effect (larger $=$ more precision). 


\section{ARE VISUAL THREATS PRIORITISED WITHOUT AWARENESS?}

\section{Models with two-way interactions.}

Models with two-way interactions are summarized in the tables and figures in supplementary material S8. An interaction was detected between stimulus type and STAI-T $(Q(2)=15.13, p<.001)$; the threat biases elicited by all stimuli had a positive association with STAI-T, but the slope was largest for angry faces, then fearful faces and words. The interaction between awareness measure and SOA was marginally significant $(Q(1)=3.73$, $p=.054)$, such that the effect of SOA on threat bias was greater when no awareness check was conducted. We did not test for higher order interactions due to low numbers of observations and empty cells in some moderator categories.

\section{Multiple regression models}

We used multiple regression to determine the model that optimally explained the heterogeneity in effects. Only main effects were included since interactions were either nonsignificant, or involved a substantially reduced number of effects. This also enhanced the interpretability of our final model. We used a backward elimination strategy, starting with a model that contained all moderators, then eliminating moderators consecutively on the basis on their $p$ value. Since competing models differed in terms of the number of coefficients, we used maximum likelihood estimation to compare models via likelihood ratio tests $(L R T)$.

\section{Complete effects models.}

We first analyzed models where moderators were reported for all effects $(k=44$ : complete effects models). These moderators (the only ones with no missing values) were stimulus type, awareness measure, SOA and probe response. The backward elimination 


\section{ARE VISUAL THREATS PRIORITISED WITHOUT AWARENESS?}

strategy revealed that the optimal complete effects model included only stimulus type and SOA as predictors, accounting for $31.72 \%$ of the heterogeneity in effects (see Figure 7).

\section{Reduced effect models.}

We next evaluated the influence of additional moderators that were only reported for a subset of effects, by including only effects for which these moderator values were reported (reduced effects models). The predictors $h^{p w r}(k=26)$ stimulus size $(k=22)$ and visual field $(k=$ 10) did not significantly improve the model fit, but STAI-T $(k=15)$ did $(L R T=9.73, p=.002)$.

\section{Model comparisons with imputed data.}

Using RI to estimate the missing data, the best fitting model included stimulus type, SOA and STAI-T, and accounted for 52.50\% [31.23 74.11] of the heterogeneity among effects. However, with RSI, STAI-T did not significantly improve model fit. 


\section{ARE VISUAL THREATS PRIORITISED WITHOUT AWARENESS?}

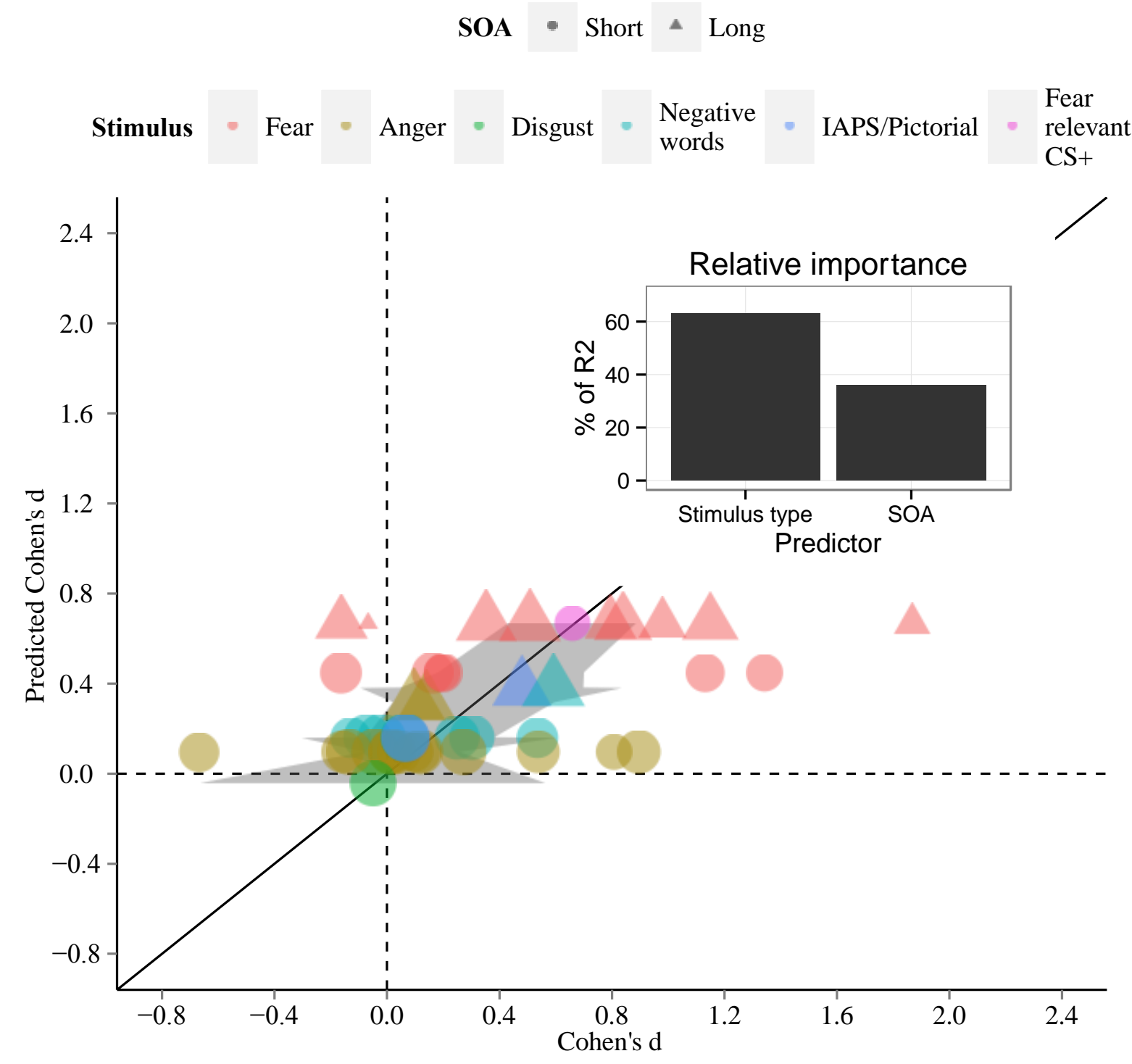

Figure 7. Predicted effect sizes from the final model, plotted as a function of actual (observed) effect sizes. Shaded region is $95 \%$ confidence interval. The panel shows the relative importance of each predictor (normalised contribution to $R^{2}$ across all orderings of regressors). 


\section{ARE VISUAL THREATS PRIORITISED WITHOUT AWARENESS?}

\section{Sensitivity analyses.}

As noted earlier, some of the effects in our model shared a sample with another effect. The outcome of our analyses may therefore be biased if the samples contributing multiple effects were unrepresentative (Greenhouse \& Iyengar, 1994). We therefore constructed two new data sets using random selection procedures such that no independent sample contributed more than one effect size to the model $(k=39)$. The pooled effect sizes were $d_{z}=0.29[0.16$ $0.42], p<.001$ and $d_{z}=0.23$ [0.11 0.34], $p<.001$ for the first and second random selections respectively, and these datasets both resulted in the same final model (including stimulus type and SOA), following multiple regression. This further suggests that the presence of shared samples / dependency did not substantially bias our analyses.

\section{Summary of MVP findings.}

In the MVP paradigm, we detected a small threat bias when effect sizes were pooled. A substantial amount of heterogeneity was explained by the type of stimulus, the SOA between stimulus and mask and the observers' state anxiety.

\section{i) Threat stimuli are not equally prioritised.}

The threat related bias is predominantly attributable to fearful faces. Notably, we detected no threat related bias for any other individual stimulus type. Removing fearful faces from the analysis nearly halved the magnitude of the pooled effect $d_{z}=0.15$ [0.05 0.24], $p=.004$.

\section{ii) Stimulus visibility may modulate threat related biases}

The data provide indirect support for the idea that stimulus visibility moderates threat related biases: effects were substantially larger when the SOA between target and mask was 


\section{ARE VISUAL THREATS PRIORITISED WITHOUT AWARENESS?}

$>30 \mathrm{~ms}$. Importantly, studies using stringent signal detection criteria show that the majority of observers can reliably detect stimuli when they are masked with an SOA of $\sim 30 \mathrm{~ms}$ (Pessoa, Japee, Sturman, \& Ungeleider, 2006). Furthermore, the interaction between awareness measure and SOA approached statistical significance - the effect of SOA on threat-bias was greater when there was no awareness measure. This further suggests that inadequate awareness measures combined with partial stimulus visibility could have contributed to the observed threat effects in several studies. Another interpretation of the moderating effect of SOA is that a brief presentation may degrade processing of a masked stimulus in general, thereby reducing effect sizes, regardless of whether this results in visibility or not. However, irrespective of whether effect sizes are moderated by awareness of the stimuli, or simply by the strength of visual signals, either possibility illustrates the methodological issues associated with using brief presentations to manipulate awareness.

\section{iii) Awareness was not carefully measured in all studies.}

Eighteen effects were not associated with any awareness check to verify the efficacy of the masking procedure and so cannot make strong categorical claims about genuinely 'unconscious' processing. Furthermore, power analyses revealed that objective awareness checks were underpowered to detect small to medium deviations from chance performance. Thus, in many cases, type II errors (failure to detect awareness) may have occurred.

iv) Threat related biases are related to, but not dependent on high anxiety levels.

Our analyses generally support the proposed link between attentional bias to masked threat and anxiety. However, the data do not strongly suggest that preconscious threat-related biases require high anxiety levels - a robust threat-related bias was observed in samples for 
ARE VISUAL THREATS PRIORITISED WITHOUT AWARENESS?

which levels of anxiety were not reported, but are likely to converge around healthy population means. 


\section{Binocular Rivalry}

\section{Summary of included data.}

Fourteen binocular rivalry (BR) studies (comprising 788 subjects in total) were included in our analyses. These studies reported data from 22 independent samples, providing 31 effect size estimates. The coding system and summary of the included effects are displayed in Tables 3 and 4 respectively. Detailed information on each effect size and demographic information can be found in the supplementary material S9.

\section{Dependent measures.}

For the BR paradigm, a positive value of $d$ reflects prioritized perceptual selection of threatening stimuli over neutral stimuli. The first dependent measure we refer to as total dominance, which is defined by the difference between threatening and neutral stimuli in terms of the proportion of total trial time (within rivalry trials) that each was perceptually dominant (e.g. Alpers \& Gerdes, 2007). The second outcome measure is initial dominance, which is summarised by the difference between threat and neutral stimuli in terms of the proportion of rivalry trials on which each was reported as the first percept (e.g. Gray, Adams, \& Garner, 2009).

\section{Overall effect of threat-related bias.}

Figure 8 displays the main meta-analytic results. A medium effect of threat bias was detected $\left(k=31, N=788, d_{z}=0.47,95 \%\right.$ CI $\left.[0.300 .63], p<.001\right)$. After controlling for individual differences, this is consistent with a $68 \%$ [62\% 74\%] chance that a randomly 


\section{ARE VISUAL THREATS PRIORITISED WITHOUT AWARENESS?}

sampled observer will perceive threatening stimuli longer/ more frequently than neutral stimuli. The effect remained statistically significant when any single effect was removed (leave-one-out analyses, all $p s<.001$ ). Rosenthal's fail-safe $N$ indicated that 1559 effects averaging a null result would be required to reduce the pooled effect to non-significance. Trim and fill analyses did not suggest the suppression of null effects (see funnel plot, Figure $8 b)$.

Substantial heterogeneity was detected $(Q(30)=165.33, p<.001)$. The $I^{2}$ statistic indicated that $83 \%$ of the heterogeneity between effects could not be accounted for by sampling variability. The vast majority of heterogeneity $(82 \%)$ was located at the between condition level, and only $1 \%$ was located at the between sample level. Moreover, a 3 level, nested model did not provide a better fit to the data than a traditional 2 level model $(L R T=$ $.001, p=.972$ ), suggesting virtually no influence of dependency on effect sizes. We examined the influence of several moderators to explain this heterogeneity (Table 3). 
ARE VISUAL THREATS PRIORITISED WITHOUT AWARENESS?

Table 3

Coding System for Individual Effects in the BR Paradigm

\begin{tabular}{|c|c|c|c|c|c|}
\hline Moderator & Type & Values & Description / theoretical justification & $\begin{array}{l}\text { Descriptive } \\
\text { statistics }\end{array}$ & $\begin{array}{l}\text { Missing } \\
\text { cases }\end{array}$ \\
\hline $\begin{array}{l}\text { Stimulus } \\
\text { type }\end{array}$ & Categorical & $\begin{array}{l}1=\text { fearful face } \\
2=\text { angry face } \\
3=\text { disgust } \\
4=\text { conditioned } \\
\text { neutral face } \\
\text { (CS+) } \\
5=\text { grating }(\mathrm{CS}+) \\
6=\text { IAPS/ } \\
\text { pictorial }\end{array}$ & $\begin{array}{l}\text { Type of threatening stimulus presented in the rivalry trial. Justification: The magnitude of threat } \\
\text { bias in rivalry may differ as a function of the semantic/physical properties of the stimulus categories }\end{array}$ & $\begin{array}{l}k=31 \\
1=13 \\
2=7 \\
3=4 \\
4=2 \\
5=2 \\
6=3\end{array}$ & 0 \\
\hline $\begin{array}{l}\text { Dominance } \\
\text { measure }\end{array}$ & Dichotomous & $\begin{array}{l}1=\text { total } \\
\text { dominance } \\
2=\text { initial } \\
\text { dominance }\end{array}$ & $\begin{array}{l}\text { Whether the effect reflects initial dominance (which stimulus is perceived first) or total dominance } \\
\text { (which stimulus is perceived for the longest time over the course of a trial). Justification: These are } \\
\text { thought to partially reflect separate processes. In initial dominance, the observer's only response is } \\
\text { the first stimulus they perceive. This initial percept thus reflects only the 'bottom up' early stages of } \\
\text { perceptual selection. However, with total dominance, both stimuli alternate in awareness, thus it is } \\
\text { difficult to infer whether increased perception of threat stimuli is due to unconscious processes (i.e. } \\
\text { processes acting on a suppressed threat stimulus), or contamination from periods of conscious } \\
\text { evaluation during dominance periods (i.e. processes occurring when the threat stimulus is visible; } \\
\text { Carter \& Cavanagh, 2007). }\end{array}$ & $\begin{array}{l}k=31 \\
1=20 \\
2=11\end{array}$ & 0 \\
\hline Design & Dichotomous & $\begin{array}{l}0=\text { offline } \\
1=\text { online }\end{array}$ & $\begin{array}{l}\text { Whether threatening and neutral images competed in rivalry in the same trial (online) or across trials } \\
\text { via a 'baseline' stimulus (offline). Justification: Differences between concurrently presented stimuli } \\
\text { determine rivalry dominance. It is not known whether these effects are transitive, thus the two } \\
\text { designs may produce different effect sizes. }\end{array}$ & $\begin{array}{l}k=31 \\
0=20 \\
1=11\end{array}$ & 0 \\
\hline $\begin{array}{l}\text { Stimulus } \\
\text { size }\end{array}$ & Continuous & $1-11.5$ & $\begin{array}{l}\text { The diameter of the threat stimulus in degrees of visual angle. Justification: Affective processing of } \\
\text { threat images may vary over stimulus size (Codispoti \& Cesarei, 2007). Moreover, larger stimuli } \\
\text { increase the likelihood of piecemeal rivalry (mixed percepts, in which elements of both rivalling } \\
\text { stimuli are visible; Blake, O'Shea, \& Mueller, 1992). }\end{array}$ & $\begin{array}{l}k=26 \\
M=6.09 \\
S D=4.34 \\
\text { Range= } 1-11.5\end{array}$ & 5 \\
\hline
\end{tabular}




\section{ARE VISUAL THREATS PRIORITISED WITHOUT AWARENESS?}

\begin{tabular}{|c|c|c|c|}
\hline $\begin{array}{l}\text { Rivalry } \\
\text { trial length }\end{array}$ & Continuous & $8-60$ & $\begin{array}{l}\text { Variable representing the length of the rivalrous period. Justification: Across shorter trials, } \\
\text { dominance proportion will be more tightly correlated with first percepts. With longer trial lengths, } \\
\text { each stimulus will have be perceived more times, given that the number of perceptual switches are } \\
\text { inversely proportional to the length of the rivalrous period. }\end{array}$ \\
\hline STAI-T & Continuous & $27.9-50.5$ & $\begin{array}{l}\text { The sample's mean trait anxiety level, as assessed by the Spielberger state-trait anxiety scale (ref). } \\
\text { Justification: Anxiety is consistently linked with processing biases towards threatening stimuli (Bar } \\
\text { Haim et al., 2007). }\end{array}$ \\
\hline
\end{tabular}

Variable representing the length of the rivalrous period. Justification: Across shorter trials,

The sample's mean trait anxiety level, as assessed by the Spielberger state-trait anxiety scale (ref).

Whether the threat stimulus is presented upright, or spatially inverted. Justification: Spatial inversion can impair recognition of the emotional content of stimuli, but leave low-level properties such as 
ARE VISUAL THREATS PRIORITISED WITHOUT AWARENESS?

Table 4

Summary of Effects Included in the BR Analyses

\begin{tabular}{|c|c|c|c|c|c|c|c|c|c|c|c|c|}
\hline Study/Effect & $\begin{array}{l}\text { Samp } \\
\text { le } \\
\text { code }\end{array}$ & $\begin{array}{l}\text { Cond } \\
\text { ition } \\
\text { code }\end{array}$ & Exp & $N$ & Stim & $\begin{array}{l}\text { Dom } \\
\text { meas }\end{array}$ & $\begin{array}{l}\text { Ret } \\
\text { Size }\end{array}$ & $\begin{array}{l}\text { Tria } \\
1 \text { len }\end{array}$ & Online & Group & $\begin{array}{l}\text { STAI- } \\
\mathrm{T}\end{array}$ & Stim inv \\
\hline 1) Alpers et al., 2005 (i) & 1 & 1 & 1 & 31 & 4 & 1 & 1.31 & 8 & 0 & & 42.60 & 1 \\
\hline Alpers et al., 2005 (ii) & 2 & 2 & 2 & 30 & 4 & 1 & 3.00 & 14 & 0 & & 40.70 & 1 \\
\hline 2) Alpers \& Pauli, 2006 & 3 & 3 & 1 & 46 & 5 & 1 & 9.50 & 30 & 1 & & 40.58 & 1 \\
\hline 3) Alpers \& Gerdes, 2007 (i) & 4 & 4 & 1 & 30 & 1 & 1 & 9.05 & 15 & 1 & & 39.90 & 1 \\
\hline Alpers \& Gerdes, 2007 (ii) & 4 & 5 & 1 & l & 2 & 1 & 9.05 & 15 & 1 & & & 1 \\
\hline Alpers \& Gerdes, 2007 (iii) & 5 & 6 & 2 & 22 & 2 & 1 & 1.00 & 8 & 1 & & & 1 \\
\hline 4) Bannerman et al., 2008 (i) & 6 & 7 & 1 & 27 & 1 & 1 & 11.50 & 60 & 1 & & & 1 \\
\hline Bannerman et al., 2008 (ii) & 7 & 8 & 3 & 20 & 1 & 1 & 11.50 & 60 & 0 & & & 1 \\
\hline Bannerman et al., 2008 (iii) & 7 & $\mathrm{I} 1$ & 3 & I & 1 & 1 & 11.50 & 60 & 0 & & & 2 \\
\hline 5) Yoon et al., 2009 (i) & 8 & 9 & 1 & 38 & 3 & 1 & 1.90 & 60 & 1 & & & 1 \\
\hline Yoon et al., 2009 (ii) & 9 & 10 & 2 & 78 & 3 & 1 & 1.90 & 60 & 1 & & & 1 \\
\hline Yoon et al., 2009 (iii) & 9 & 11 & 2 & I & 3 & 2 & 1.90 & & 1 & & & 1 \\
\hline 6) Gray et al., 2009 (i) & 10 & 12 & 1 & 19 & 1 & 2 & 2.15 & & 1 & & 42.95 & 1 \\
\hline Gray et al., 2009 (ii) & 10 & 13 & 1 & l & 2 & 2 & 2.15 & & 1 & & & 1 \\
\hline Gray et al., 2009 (iii) & 10 & $\mathrm{I} 2$ & 1 & l & 1 & 2 & 2.15 & & 1 & & & 2 \\
\hline Gray et al., 2009 (iv) & 10 & $\mathrm{I} 3$ & 1 & / & 2 & 2 & 2.15 & & 1 & & & 2 \\
\hline 7) Amting et al., 2010 (i) & 11 & 14 & 1 & 16 & 1 & 2 & & & 1 & & & 1 \\
\hline Amting et al., 2010 (ii) & 11 & 15 & 1 & l & 3 & 2 & & & 1 & & & 1 \\
\hline 8) Anderson et al., 2011 (i) & 12 & 16 & 1 & 57 & 6 & 1 & 1.50 & 10 & 0 & & & 1 \\
\hline Anderson et al., 2011 (ii) & 13 & 17 & 2 & 41 & 6 & 1 & 1.50 & 10 & 0 & & & 1 \\
\hline \multirow{4}{*}{ 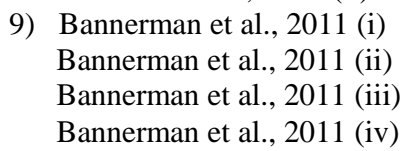 } & 14 & 18 & 1 & 30 & 2 & 1 & 3.25 & 60 & 0 & Younger adults & & 1 \\
\hline & 14 & I4 & 1 & I & 2 & 1 & 3.25 & 60 & 0 & Younger adults & & 2 \\
\hline & 14 & 19 & 1 & 30 & 2 & 1 & 3.25 & 60 & 0 & Older adults & & 1 \\
\hline & 14 & I5 & 1 & l & 2 & 1 & 3.25 & 60 & 0 & Older adults & & 2 \\
\hline 10) Ritchie et al., 2012 (i) & 15 & 20 & 1 & 18 & 1 & 1 & 5.95 & 60 & 0 & & & 1 \\
\hline Ritchie et al., 2012 (ii) & l & I6 & 1 & 5 & 1 & 1 & 5.95 & 60 & 0 & & & 2 \\
\hline 11) Lerner et al., 2012 (i) & 16 & 21 & 1 & 11 & 1 & 1 & & 36 & 0 & & & 1 \\
\hline 12) Singer et al., 2012 (i) & 17 & 22 & 1 & 16 & 1 & 2 & 11.50 & & 0 & Control group & 27.90 & 1 \\
\hline Singer et al., 2012 (ii) & 17 & 23 & 1 & l & 1 & 1 & 11.50 & 40 & 0 & & & 1 \\
\hline Singer et al., 2012 (iii) & 18 & 24 & 1 & 16 & 1 & 2 & 11.50 & & 0 & Social anxiety group & 50.50 & 1 \\
\hline
\end{tabular}


ARE VISUAL THREATS PRIORITISED WITHOUT AWARENESS?

\begin{tabular}{|c|c|c|c|c|c|c|c|c|c|c|c|c|}
\hline Singer et al., 2012 (iv) & 18 & 25 & 1 & I & 1 & 1 & 11.50 & 40 & 0 & & & 1 \\
\hline Singer et al., 2012 (v) & 19 & 26 & 1 & 14 & 1 & 2 & 11.50 & & 0 & Panic disorder group & 43.11 & 1 \\
\hline Singer et al., 2012 (vi) & 19 & 27 & 1 & l & 1 & 1 & 11.50 & 40 & 0 & & & 1 \\
\hline Anderson et al., 2013 (i) & 20 & 28 & 1 & 152 & 2 & 1 & & 10 & 0 & & 38.52 & 1 \\
\hline Anderson et al., 2013 (ii) & 20 & 29 & 1 & I & 2 & 2 & & & 0 & & & 1 \\
\hline Gerdes \& Alpers., 2014 (i) & 21 & 30 & 1 & 20 & 5 & 2 & 4.00 & & 0 & Control group & 37.35 & 1 \\
\hline Gerdes \& Alpers., 2014 (ii) & 22 & 31 & 1 & 21 & 5 & 2 & 4.00 & & 0 & Phobic group & 41.47 & 1 \\
\hline
\end{tabular}



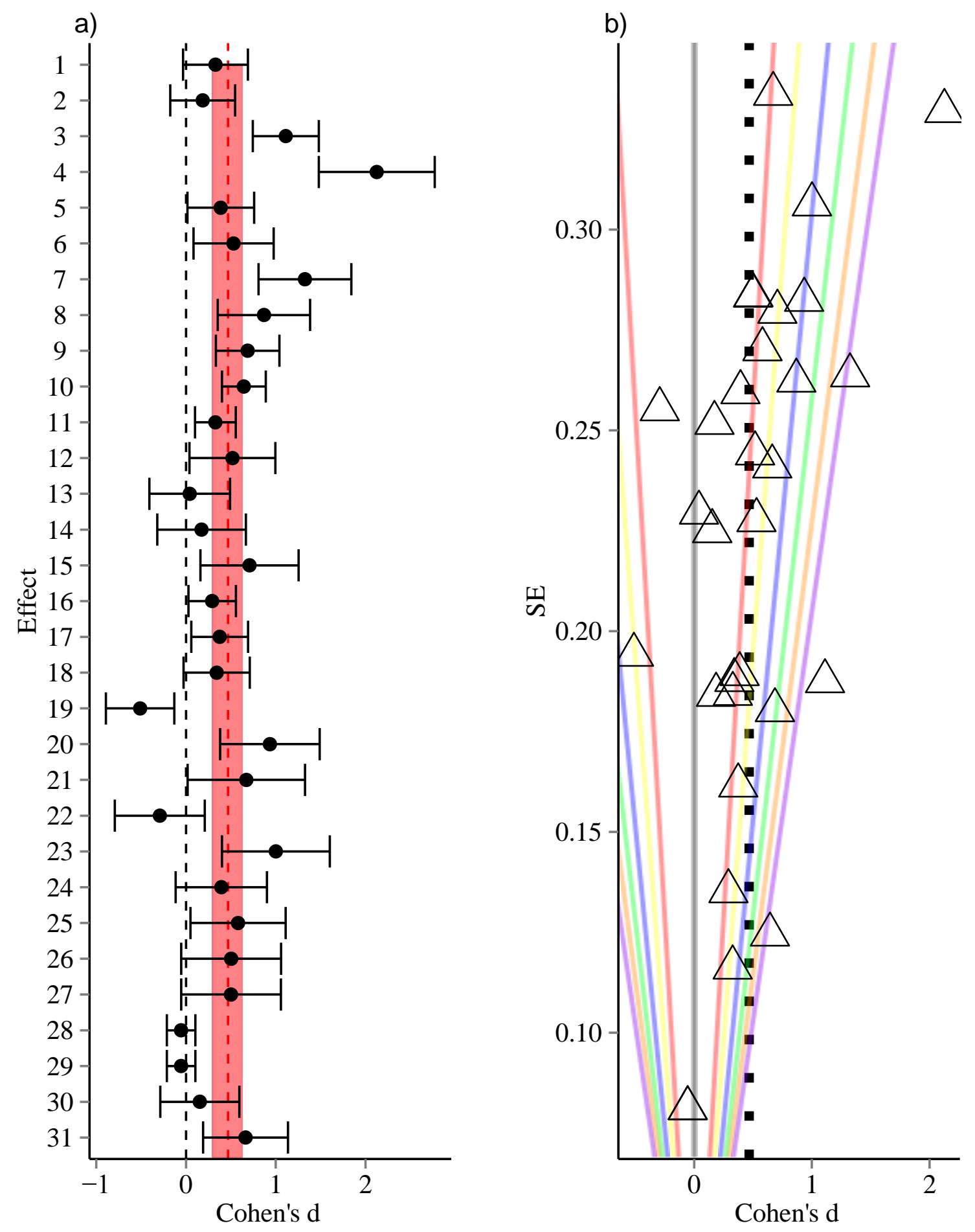

Figure 8. a): Forest plot of effects from the BR analyses, error bars are $95 \%$ confidence intervals. Red dotted line is the pooled summary effect, shaded red region is the $95 \%$ 


\section{ARE VISUAL THREATS PRIORITISED WITHOUT AWARENESS?}

confidence interval b) Funnel plot. Coloured contours represent $p$ values (Black: $=1$, red=.05, yellow $=.01$, Blue $=.001$, Green $=.0001$, Orange $=.00001$, Purple $=.000001)$.

\section{Regression models with one moderator.}

A table and figure summary of all main effects can be found in the supplementary material S10.

Stimulus type (including fearful, angry and disgust faces, international affective picture system (IAPS; Lang, Bradley, \& Cuthbert, 2008) images, conditioned neutral faces and conditioned gratings) was detected as a significant moderator of threat related biases $(Q(5)=13.24, p=.021)$, accounting for $29.92 \%$ of the total heterogeneity among effects (see Figure 9a). Moderate to large effects for fearful faces $\left(d_{z}=0.73,[0.500 .97], p<.001\right)$, disgust faces $\left(d_{z}=0.47,[0.110 .83], p=.014\right)$ and IAPS images $\left(d_{z}=0.66,\left[\begin{array}{lll}0.20 & 1.12\end{array}\right], p=.005\right)$ were detected. Fearful faces and IAPS images yielded larger threat-related biases than angry faces ( $p s<.050)$. No other differences between stimulus type were detected.

The dominance measure (total, initial) was a marginally significant moderator of threat-related bias $(Q(1)=3.08, p=.079$, see Figure $9 \mathrm{~b})$ accounting for $6.86 \%$ of heterogeneity. A moderate effect for total dominance was detected $\left(d_{z}=0.57,[0.370 .77]\right.$, $p<.001)$, whereas initial dominance effects were small $\left(d_{z}=0.27,[0.000 .54], p=.048\right)$.

An effect of design was also detected $(Q(1)=4.01, p=.045$, see Figure 9c), accounting for $12.96 \%$ of heterogeneity, such that online designs $\left(d_{z}=0.68,[0.410 .95]\right.$, $p<.001)$ yielded larger threat-related biases than offline designs $\left(d_{z}=0.35,[0.150 .54]\right.$, $p=.001)$. 


\section{ARE VISUAL THREATS PRIORITISED WITHOUT AWARENESS?}

We were able to determine stimulus size for 26 effects. This predictor was marginally significant (see Figure 9d): larger stimuli produced larger threat related biases (observed: $b=0.039, R^{2}=12.81 \%, p=.058 ; R I: b=0.038[-0.0040 .081], p=.075 ; R S I: b=0.032,[-0.011$ 0.076], $p=.140)$.
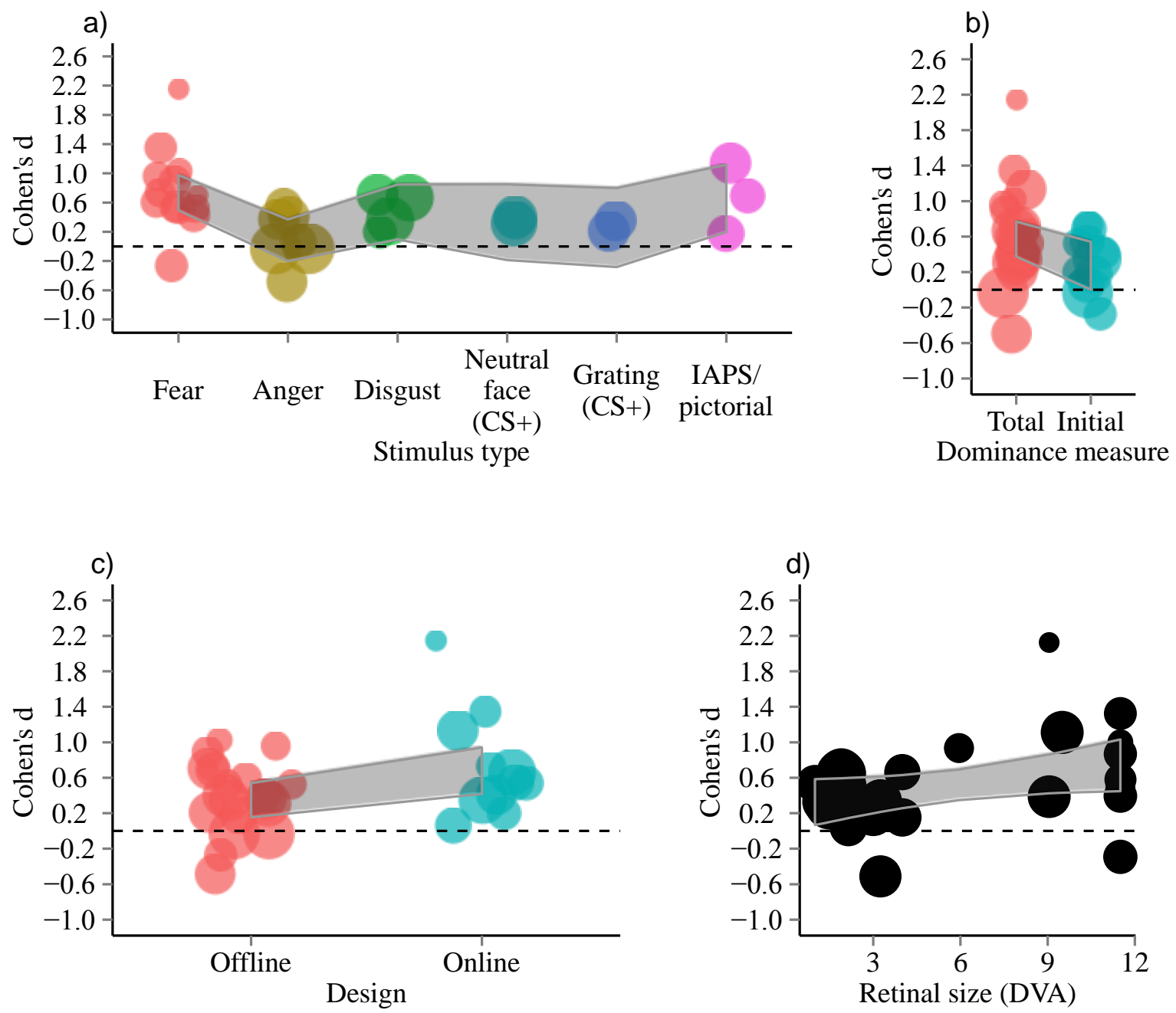

Figure 9. Main effects for the BR paradigm. Random effects models with (a) stimulus type

(b) dominance measure (c) design (d) or stimulus size as the sole moderator. 


\section{ARE VISUAL THREATS PRIORITISED WITHOUT AWARENESS?}

Trait anxiety levels were available for 17 effects. No effect of anxiety on the size of the threat bias was detected (observed: $b=0.008, R^{2}=0.00, p=.657 ; R I: b=0.007,[-0.033$, 0.047], $p=.716 ;$ RSI: $b=0.006,[-0.031,0.043], p=.744)$. Across the 20 total dominance effects, no effect of trial length on the magnitude of threat-related bias was detected $\left(b=0.003, R^{2}=0.00, p=.525\right)$.

\section{Models with two-way interactions.}

Plots and tables summarizing all interactions can be found in supplementary material S10. An interaction between trait anxiety and design was detected, such that anxiety was more strongly associated with threat bias in offline designs $(b=-0.30, Q(1)=4.25, p=.039)$. The interaction between stimulus size and BR task was marginally significant $(b=-0.07$, $Q(1)=3.40, p=.065)$ such that the positive association between stimulus size and threat related bias was larger in total than initial dominance effects.

To examine the effect of spatial inversion on threat related bias, in a separate model we combined data from conditions where threat-related biases were reported for both upright and spatially inverted stimuli ( $k=12$, only available for fearful and anger stimulus types). Although inversion reduced the threat bias (upright: $d_{z}=0.32$, inverted: $d_{z}=0.13$ ), this was not a significant main effect $(Q(1)=0.68, p=.409)$. Critically, however, we detected an interaction between stimulus type and inversion $(Q(1)=3.93, p=.047)$; contrasts revealed that inversion significantly reduced biases for fearful faces $(Q(1)=4.55, p=.033)$ but not angry faces $(Q(1)=0.31 p=.580)$. 
ARE VISUAL THREATS PRIORITISED WITHOUT AWARENESS?

\section{Multiple regression models.}

\section{Complete effects models.}

Our full model contained three predictors: stimulus type, dominance measure and design, since these were the only moderators with no missing values. The backward elimination strategy and likelihood ratio tests indicated that this model was significantly better than models with any of these predictors removed and was thus retained as the final model (See Figure 10). The model accounted for $74.70 \%$ of the heterogeneity in effects.

Reduced effects models.

Reduced effect models that included stimulus size $(k=26)$, trial length $(k=20)$ or state anxiety $(k=17)$ were not significantly better than the full model with three predictors. 


$$
\begin{aligned}
& \text { Stimulus - Fear - Anger - Disgust } \begin{array}{l}
\text { Neutral } \\
\text { face } \\
(\mathrm{CS}+)
\end{array} \cdot \begin{array}{l}
\text { Grating } \\
(\mathrm{CS}+)
\end{array} * \begin{array}{l}
\text { IAPS/ } \\
\text { pictorial }
\end{array} \\
& \text { Design - Offline ^ Online }
\end{aligned}
$$

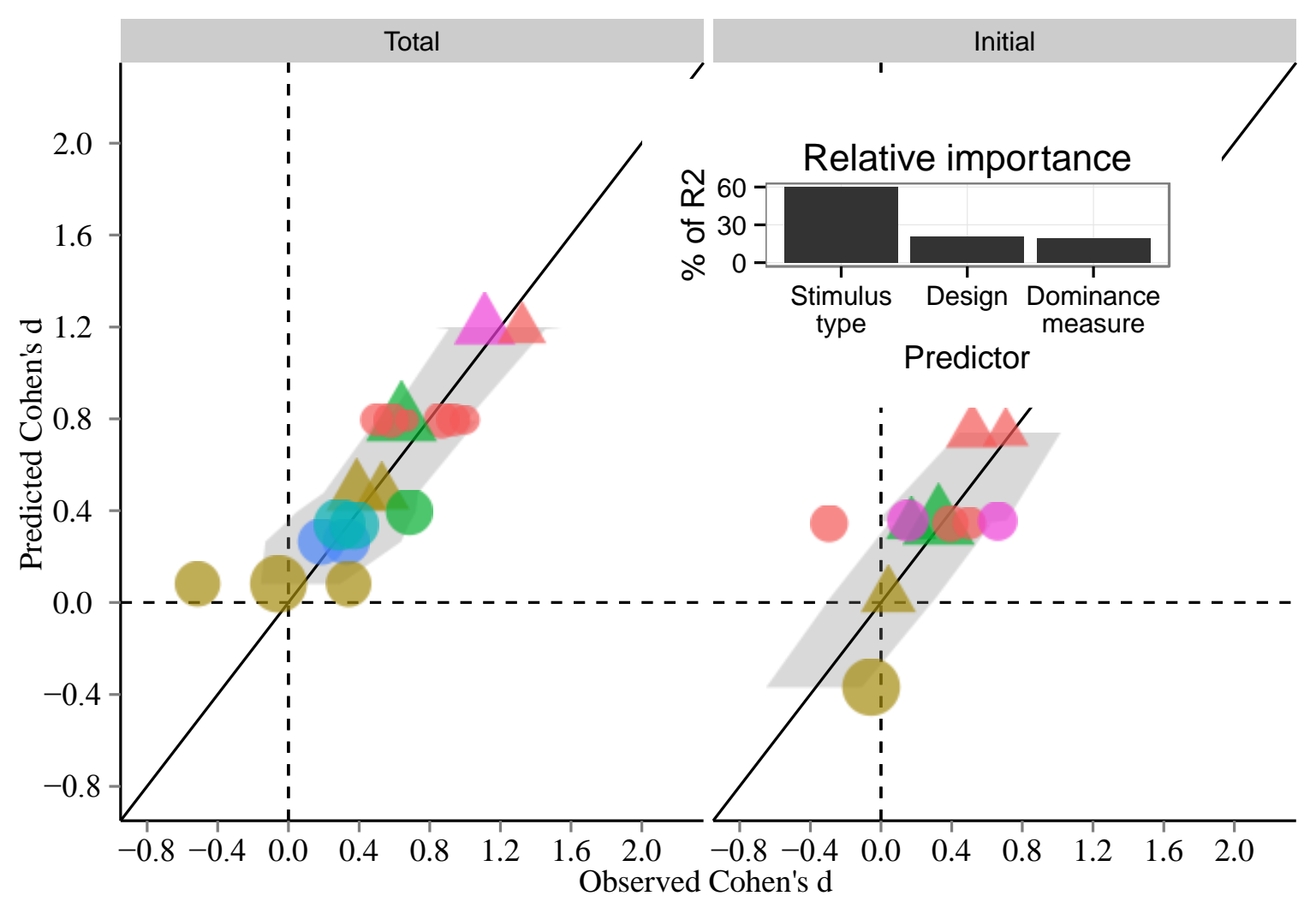

Figure 10. Predicted values from the final model, plotted as a function of actual (observed) data. Shaded region is $95 \%$ confidence interval. The panel shows the relative importance of each predictor (normalised contribution to $R^{2}$ across all orderings of regressors). 


\section{ARE VISUAL THREATS PRIORITISED WITHOUT AWARENESS?}

\section{Model comparisons with imputed data.}

After using both RI and RSI to estimate the missing values for stimulus size, trial length and state anxiety, the best fitting model was unchanged.

\section{Sensitivity analyses.}

We constructed two new data sets using random selection procedures such that no sample contributed more than one effect size to the model $(k=22)$. The pooled effect sizes were $d_{z}=0.60,[0.410 .78], p<.001$ and $d_{z}=0.56,[0.370 .75], p<.001$ for the first and second random selections respectively, and these resampled datasets resulted in the same final model, following multiple regression. This suggests that the presence of shared samples did not substantially bias our analyses.

\section{Summary of BR findings.}

For the BR paradigm, we detected a moderately-sized overall threat bias that was larger than that found with the MVP paradigm. A model containing the type of stimulus, the dominance measure and design as moderators provided a good fit to the data.

\section{i) Stimulus type.}

Similarly to the MVP paradigm, the size of the threat bias depended on the type of stimulus; in both the MVP and BR paradigms, fearful faces produced a large and highly reliable effect. Strikingly, in both MVP and BR paradigms, the effect produced by angry faces was significantly smaller, and not significantly different from zero.

Fearful faces were the most widely used threat stimulus in the BR paradigm (contributing $42 \%$ of our analyzed effects), whilst some other stimulus categories (e.g. IAPS) were sparsely represented, limiting the precision of their effect size estimates. 


\section{ARE VISUAL THREATS PRIORITISED WITHOUT AWARENESS?}

\section{ii) Effects are smaller for initial than total dominance.}

The initial dominance is thought to be a more objective measure of the unconscious perceptual selection of stimuli in the competition for awareness than total dominance (Berry, 1969; Gray et al., 2009; Ooi \& He, 1999). Because total dominance is quantified from alternating perception of threatening and neutral stimuli, both conscious (during dominance of threat) and unconscious processes (during suppression of threat) could contribute to these effects. Our analyses revealed that total dominance effects were larger than initial dominance, suggesting that threat related biases in BR are strongly modulated by conscious processing.

\section{iii) Stimulus size.}

There is good evidence that rivalry occurs within spatially localized regions (e.g. Kovacs et al., 1996). This can lead to piecemeal rivalry for larger stimuli: perception is not exclusively of one stimulus or other, but a mixed patchwork of the two. Piecemeal rivalry may actually become more prevalent than global rivalry when stimuli are large; the optimum stimulus size for whole-image rivalry is less than 1 degree of visual angle (DVA; Blake et al., 1992). Generally, the stimuli presented in the BR studies were considerably larger than this (the mean stimulus size was 6 DVA in diameter), suggesting that piecemeal rivalry may have occurred frequently. This, in turn, increases the risk of response biases and criterion effects, since these are more likely to come into play during the ambiguous, mixed perceptual states in piecemeal rivalry. For instance, a threatening stimulus may be reported as the dominant percept because it has more behaivoural relevance and is more noticeable to an observer, when in fact local regions of both threat and neutral stimuli are visible. Our data provide some support for this - there was a marginally significant association between stimulus size and threat related bias. Moreover, stimulus size was more predictive of threat related bias in 


\section{ARE VISUAL THREATS PRIORITISED WITHOUT AWARENESS?}

total dominance tasks than initial dominance tasks (stimulus size $\mathrm{x}$ dominance measure interaction). This further suggests that mixed perception may play a role; mixed perception often occurs at the time of perceptual switches, which are lacking in paradigms that only measure the first percept (i.e. initial dominance).

\section{iv) Experimental design}

The design (offline vs. online) was predictive of threat related biases: online designs yielded larger effects than offline designs. Importantly, in online designs, when competing images (e.g. a fearful face and neutral face) are presented simultaneously, they may not satisfy a necessary condition of binocular rivalry: that the images presented to each eye are sufficiently different. In particular, if the faces are matched in terms of identity and, more importantly, orientation (as in, for example, Alpers \& Gerdes, 2007, Amting et al., 2010) they may be binocularly fused, with the resultant percept differing from neutral. Thus, fusion may prompt an observer to report that a threatening stimulus is dominant, when in fact no rivalry occurred at all. Indeed, one experiment with an online design (Bannerman et al., 2008, Experiment 2a-which we excluded from our analyses) reported that when aligned fearful and neutral faces were presented dichoptically, observers did not experience any rivalry.

\section{v) Binocular rivalry and anxiety.}

Some studies included in our analyses have suggested a positive association between anxiety and threat bias in BR (Gray et al., 2009; Singer et al., 2012). This was not consistent across all studies, and unlike the MVP analyses, our meta-regression did not detect a relationship between trait anxiety and threat dominance overall. Some studies reported no difference in threat bias between anxious and non-anxious populations (Alpers \& Gerdes, 2007; Anderson et al., 2013). Another showed larger threat biases for anxious populations, 
ARE VISUAL THREATS PRIORITISED WITHOUT AWARENESS?

relative to controls in initial dominance, but effects in both directions in total dominance, depending on the specific diagnosis (Singer et al., 2012). Although our analyses detected no main effect of anxiety, the relationship between anxiety and rivalry may be a function of the dominance measure, stimulus type, and specific diagnosis. More data will be needed to clarify this relationship.

\section{Breaking Continuous Flash Suppression}

\section{Summary of included data.}

Fourteen bCFS studies (comprising 501 subjects) were included in the analyses. These studies reported data from 18 independent samples, providing 27 effect size estimates. The coding system and summary of the included effects are displayed in Tables 5 and 6 respectively. Details of how each effect size was computed can be found in the supplementary material S11. 


\section{ARE VISUAL THREATS PRIORITISED WITHOUT AWARENESS?}

\section{Dependent measures.}

For the bCFS paradigm, a positive value of $d$ indicates prioritized detection of threatening stimuli from CFS. In almost all cases, the dependent measure was response time, where a positive value indicates faster detection of threatening stimuli (e.g. Yang et al., 2007). In other cases, a positive value indicates more accurate localization of threat stimuli following shorter, fixed duration CFS trials (indexed by accuracy in forced choice responsessee Hedger, Adams, \& Garner, 2015; Oliver, Mao \& Mitchell, 2014).

\section{Overall effect of threat-related bias.}

Figure 11 displays the main meta-analytic results for the bCFS paradigm. Across all effects, the pooled effect size was small, negative and non-significant $\left(k=27, N=501, d_{z}=\right.$ $0.14,[-0.450 .17], p=.376)$. After controlling for individual differences, this is consistent with a $44 \%$ chance that a randomly sampled observer will perceive threatening stimuli faster/ more efficiently than neutral stimuli. Trim and fill analyses did not suggest the suppression of any unpublished effects (see funnel plot, Figure 11b). The test for heterogeneity was significant $\left(Q(26)=252.56, p<.001\right.$ and the $I^{2}$ statistic indicated that nearly all the heterogeneity across effects (94\%) was due to factors other than sampling variability. For heterogeneity, $33 \%$ was located at the between condition level and $61 \%$ was located at the between sample level. However, a 3 level nested model did not provide a significantly better fit than a traditional two level model ( $L R T=2.61, p=.187)$. We examined the influence of several moderators to explain this heterogeneity (Table 5). 
ARE VISUAL THREATS PRIORITISED WITHOUT AWARENESS? 


\section{ARE VISUAL THREATS PRIORITISED WITHOUT AWARENESS?}

Table 5

Coding System for Individual Effects in the bCFS Paradigm

\begin{tabular}{|c|c|c|c|c|c|}
\hline Moderator & Type & Values & Description / theoretical justification & $\begin{array}{l}\text { Descriptive } \\
\text { statistics }\end{array}$ & $\begin{array}{l}\text { Missing } \\
\text { cases }\end{array}$ \\
\hline $\begin{array}{l}\text { Stimulus } \\
\text { type }\end{array}$ & Categorical & $\begin{array}{l}1=\text { Fearful face } \\
2=\text { Angry face } \\
3=\text { Disgust face } \\
4=\text { Dominant face } \\
5=\text { Untrustworthy } \\
\text { face } \\
6=\text { Word } \\
7=\text { Pictoral/ IAPS }\end{array}$ & $\begin{array}{l}\text { Type of threatening stimulus presented in the CFS trial. Justification: The magnitude of threat bias } \\
\text { in CFS may differ as a function of the semantic/physical properties of the stimulus categories }\end{array}$ & $\begin{array}{l}k=27 \\
1=10 \\
2=3 \\
3=3 \\
4=4 \\
5=4 \\
6=2 \\
7=1\end{array}$ & 0 \\
\hline $\begin{array}{l}\text { Stimulus } \\
\text { size }\end{array}$ & Continuous & Range $=1.15-5.20$ & $\begin{array}{l}\text { The diameter of the threat stimulus in degrees of visual angle. Justification: Affective processing of } \\
\text { threat images may vary over stimulus size (Codispoti \& Cesarei, 2007). Moreover, a large stimulus } \\
\text { size increases the likelihood of piecemeal rivalry (mixed percepts, in which elements of both } \\
\text { stimulus and mask are visible; Blake et al., 1992). }\end{array}$ & $\begin{array}{l}k=22 \\
M=3.03 \\
S D=0.92 \\
\text { Range }=1.7 \\
5.20\end{array}$ & 7 \\
\hline $\begin{array}{l}\text { Awareness } \\
\text { measure }\end{array}$ & Dichotomous & $\begin{array}{l}1=\text { Response time } \\
2=\text { Localisation } \\
\text { accuracy }\end{array}$ & $\begin{array}{l}\text { The measure by which an observer's detection of stimuli from CFS is identified Justification: } \\
\text { Response times may comprise multiple components- a motor component (i.e. the time taken to press } \\
\text { a button), a perceptual component (the time it takes for a stimulus to reach awareness) and a } \\
\text { decisional component (the time it takes to use the available information to determine that the } \\
\text { stimulus is visible). Un-speeded forced-choice localisation tasks are less affected by the motor and } \\
\text { decisional components, since response latencies are not diagnostic. }\end{array}$ & $\begin{array}{l}k=27 \\
1=24 \\
2=3\end{array}$ & 0 \\
\hline $\begin{array}{l}\text { Stimulus } \\
\text { inversion }\end{array}$ & Dichotomous & $\begin{array}{l}1=\text { Upright } \\
2=\text { Inverted }\end{array}$ & $\begin{array}{l}\text { Whether the threat stimulus is presented upright, or spatially inverted. Justification: Spatial inversion } \\
\text { can impair recognition of the emotional content of stimuli, but leave low-level characteristics such as } \\
\text { contrast, luminance and spatial frequency unchanged (Gray et al., 2013). The logic of this } \\
\text { manipulation is that if low-level properties were the cause of a threat bias, one might expect a similar } \\
\text { sized bias for upright and inverted stimuli. Conversely, if threat sensitive processes were the cause of } \\
\text { a threat bias, we would expect a threat bias in an upright configuration, but not in an inverted } \\
\text { configuration. }\end{array}$ & $\begin{array}{l}k=18 \\
1=9 \\
2=9\end{array}$ & 0 \\
\hline
\end{tabular}


ARE VISUAL THREATS PRIORITISED WITHOUT AWARENESS?

Table 6

Coding System for Individual Effects in the bCFS Paradigm

\begin{tabular}{|c|c|c|c|c|c|c|c|c|c|}
\hline Study/Effect & $\begin{array}{l}\text { Samp } \\
\text { le } \\
\text { code } \\
\end{array}$ & $\begin{array}{l}\text { Cond } \\
\text { ition } \\
\text { code }\end{array}$ & Exp & $N$ & Stim & $\begin{array}{l}\text { Ret } \\
\text { Size }\end{array}$ & Aw meas & Group & Stim inv \\
\hline 1) Yang et al., 2007 (i) & 1 & 1 & 1 & 12 & 1 & 1.9 & 1 & & 1 \\
\hline Yang et al., 2007 (ii) & 1 & I1 & 1 & / & 1 & 1.9 & 1 & & 2 \\
\hline Yang et al., 2007 (iii) & 2 & 2 & 2 & 12 & 1 & 1.9 & 1 & & 1 \\
\hline Yang et al., 2007 (iv) & 2 & I2 & 2 & I & 1 & 1.9 & 1 & & 2 \\
\hline 2) Sterzer et al.,2011 (i) & 3 & 3 & 1 & 20 & 1 & 2.0 & 1 & Control group & 1 \\
\hline 3) Sylvers et al., 2011 (i) & 4 & 4 & 1 & 87 & 1 & 3.4 & 1 & & 1 \\
\hline Sylvers et al., 2011 (ii) & 4 & 5 & 1 & / & 3 & 3.4 & 1 & & 1 \\
\hline 4) Yang \& Yeh, 2011 (i) & 5 & 6 & 1 & 12 & 6 & 2.0 & 1 & & 1 \\
\hline Yang \& Yeh, 2011 (ii) & 5 & I3 & 1 & I & 6 & 2.0 & 1 & & 2 \\
\hline Yang \& Yeh, 2011 (iii) & 6 & 7 & 2 & 12 & 6 & & 1 & & 1 \\
\hline Yang \& Yeh, 2011 (iv) & 6 & I4 & 2 & / & 6 & & 1 & & 2 \\
\hline 5) Chen \& Yeh., 2012 (i) & 7 & 8 & 1 & 30 & 1 & 5.2 & 1 & & 1 \\
\hline 6) Stein \& Sterzer, 2012 (i) & 8 & 9 & 1 & 16 & 2 & 2.0 & 1 & & 1 \\
\hline 7) Stewart et al., 2012 (i) & 9 & 10 & 1 & 23 & 4 & 3.4 & 1 & & 1 \\
\hline Stewart et al., 2012 (ii) & 9 & 11 & 1 & I & 5 & 3.4 & 1 & & 1 \\
\hline Stewart et al., 2012 (iii) & 10 & 12 & 2 & 21 & 4 & 3.4 & 1 & & 1 \\
\hline Stewart et al., 2012 (iv) & 10 & 13 & 2 & l & 5 & 3.4 & 1 & & 1 \\
\hline Stewart et al., 2012 (v) & 11 & 14 & 3 & 28 & 4 & 3.4 & 1 & & 1 \\
\hline Stewart et al., 2012 (vi) & 11 & 15 & 3 & I & 5 & 3.4 & 1 & & 1 \\
\hline 8) Gray et al., 2013 (i) & 12 & 16 & 3 & 41 & 2 & 2.5 & 1 & & 1 \\
\hline Gray et al., 2013 (ii) & 12 & 17 & 3 & / & 1 & 2.5 & 1 & & 1 \\
\hline Gray et al., 2013 (iii) & 12 & I5 & 3 & l & 2 & 2.5 & 1 & & 2 \\
\hline Gray et al., 2013 (iv) & 12 & I6 & 3 & I & 1 & 2.5 & 1 & & 2 \\
\hline
\end{tabular}


ARE VISUAL THREATS PRIORITISED WITHOUT AWARENESS?

9) Stein et al., 2014a (i)

Stein et al., 2014a (ii)

10) Capitao et al., 2014 (i)

11) Oliver et al., 2014 (i)

Oliver et al., 2014 (ii)

Oliver et al., 2014 (iii)

Oliver et al., 2014 (iv)

12) Getov et al., 2014 (i)

Getov et al., 2014 (ii)

13) Jusyte et al., 2015 (i)

Jusyte et al., 2015 (ii)

Jusyte et al., 2015 (iii)

14) Hedger et al. 2015 (i)

$\begin{array}{lll}13 & 18 & 1 \\ 13 & \mathrm{I} 7 & 1 \\ 14 & 19 & 1 \\ 15 & 20 & 1 \\ 15 & 21 & 1 \\ \mathrm{I} 1 & \mathrm{I} 9 & 2 \\ \mathrm{I} 2 & \mathrm{I} 10 & 2 \\ 16 & 22 & 1 \\ 16 & 23 & 1 \\ 17 & 24 & 1 \\ 17 & 25 & 1 \\ 17 & 26 & 1 \\ 18 & 27 & 1\end{array}$

3.5
3.5
1.7





2.7
2.7
2.7
5.2

$\begin{array}{ll} & 1 \\ & 2 \\ 1 \\ 1 \\ 1 \\ \text { Control Group } & 2 \\ & 2 \\ & 1 \\ & 1 \\ & 1 \\ & 1 \\ & 1\end{array}$




\section{ARE VISUAL THREATS PRIORITISED WITHOUT AWARENESS?}

\section{Regression models with one moderator.}

A table and figure summary of all main effects can be found in the supplementary material S12. Stimulus type (including fearful, angry and disgust, dominant and untrustworthy faces, negative words and IAPS images) was detected as a moderator of threat related biases $(Q(6)=41.32, p<.001)$, accounting for $65.38 \%$ of the total heterogeneity among effects (see Figure 11a). A moderate positive bias was detected for fearful faces $\left(d_{z}=\right.$ $0.49,[0.170 .82], p<.001)$, whereas large, negative biases were detected for dominant faces $\left(d_{z}=-0.96,[-1.47-0.44], p<.001\right)$, untrustworthy faces $\left(d_{z}=-0.68,[-1.18-0.17], p=.008\right)$, and negative words $\left(d_{z}=-1.69,[-2.58-0.79], p<.001\right)$. Fearful faces yielded larger biases than dominant and untrustworthy faces and negative words (all $p s<.001$ ). The pooled effect for negative words was significantly smaller than for angry faces, disgust faces and IAPS images (all $p s<.002)$. 

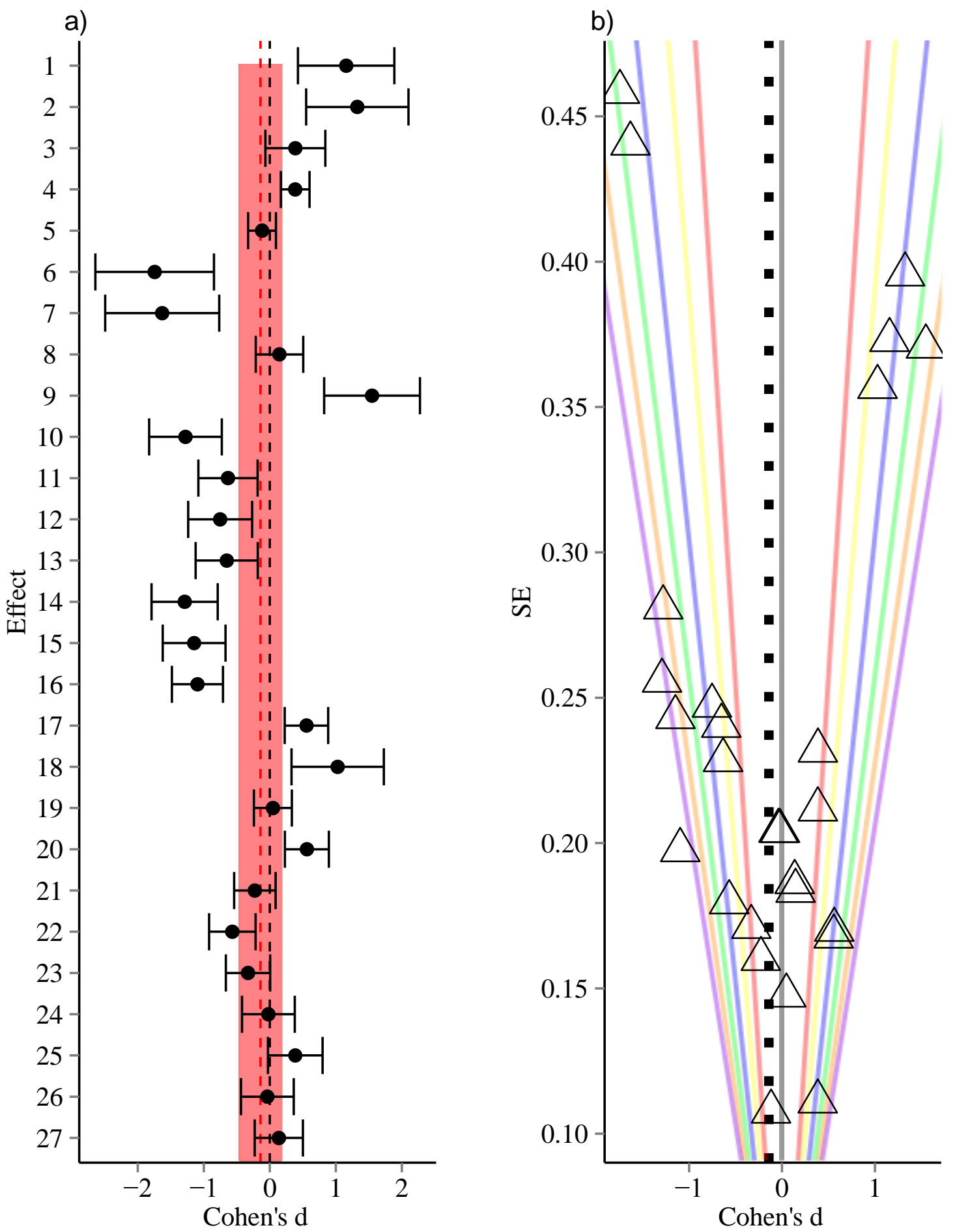

Figure 11. Forest plot of effects, error bars are $95 \%$ confidence intervals. Red dotted line is the pooled summary effect, shaded red region is the $95 \%$ confidence interval b) Funnel plot. 


\section{ARE VISUAL THREATS PRIORITISED WITHOUT AWARENESS?}

Coloured contours represent $p$ values $($ Black: $=1$, red $=.05$, yellow $=.01$, Blue $=.001$, Green $=$ .0001 , Orange $=.00001$, Purple $=.000001)$.

No effect of stimulus size (observed: $b=-0.180, R^{2}=0.00, p=.379 ; R I: b=0.007$, $[-$ 0.033, 0.047], $p=.716 ; R S I: b=0.006,[-0.031,0.043], p=.744)$ or awareness measure was detected $(Q(1)=0.192, p=.661)$.

\section{Models with two-way interactions.}

Plots and tables summarising all interactions can be found in supplementary material S12. No interactions involving stimulus type, stimulus size or awareness measure were detected. To observe the effect of spatial inversion on threat related bias, in a separate model, we combined data from conditions where threat-related biases were reported for both upright and spatially inverted stimuli $(k=18)$. Inverted stimuli actually yielded larger threat related biases (upright: $d_{z}=0.15$, inverted: $d_{z}=0.34$ ) although the main effect of inversion was not significant $(Q(1)=0.816, p=.367)$. Critically, we detected an interaction between stimulus type and inversion $(Q(1)=12.811, p=.005$, see Figure $12 \mathrm{~b})$, i.e. inversion had a differential effect on threat-related bias depending on the stimulus type. Contrasts revealed that threatrelated biases for fear $(p=.837)$ and anger $(p=.372)$ faces did not differ significantly between upright and inverted configurations, but inversion was associated with significantly larger effect sizes for disgust faces $(p=.044)$ and negative words $(p<.001)$. 


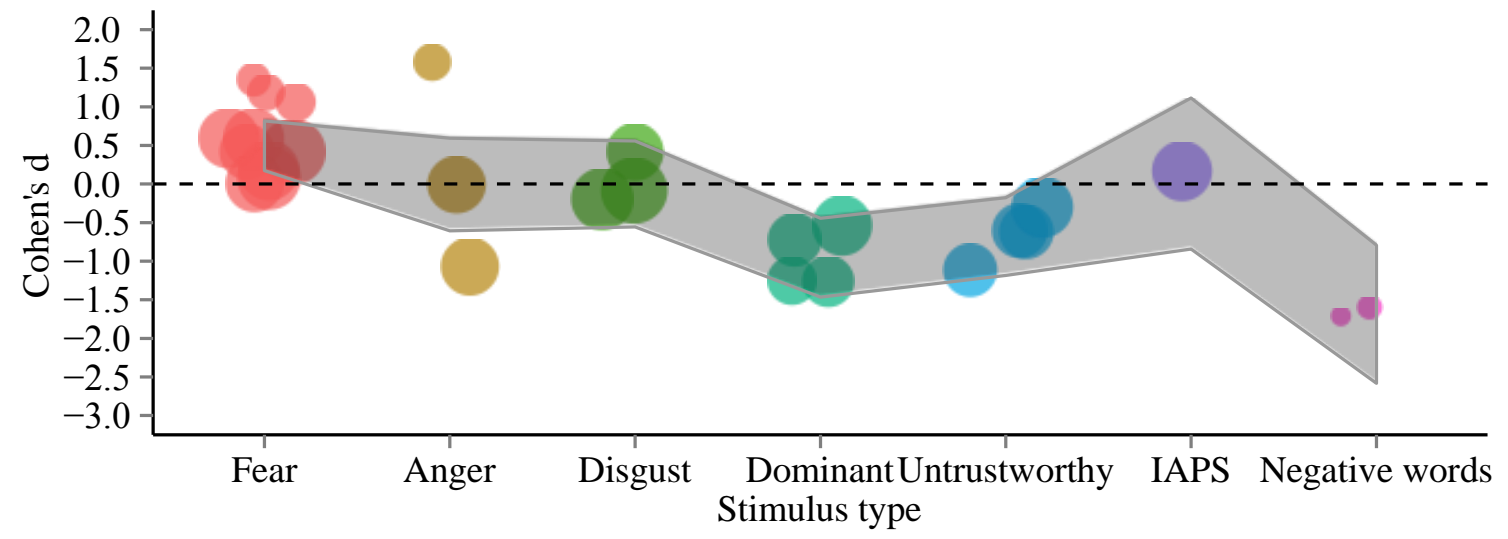

Stimulus type - Fear - Anger $=$ Disgust $=$ Negative words

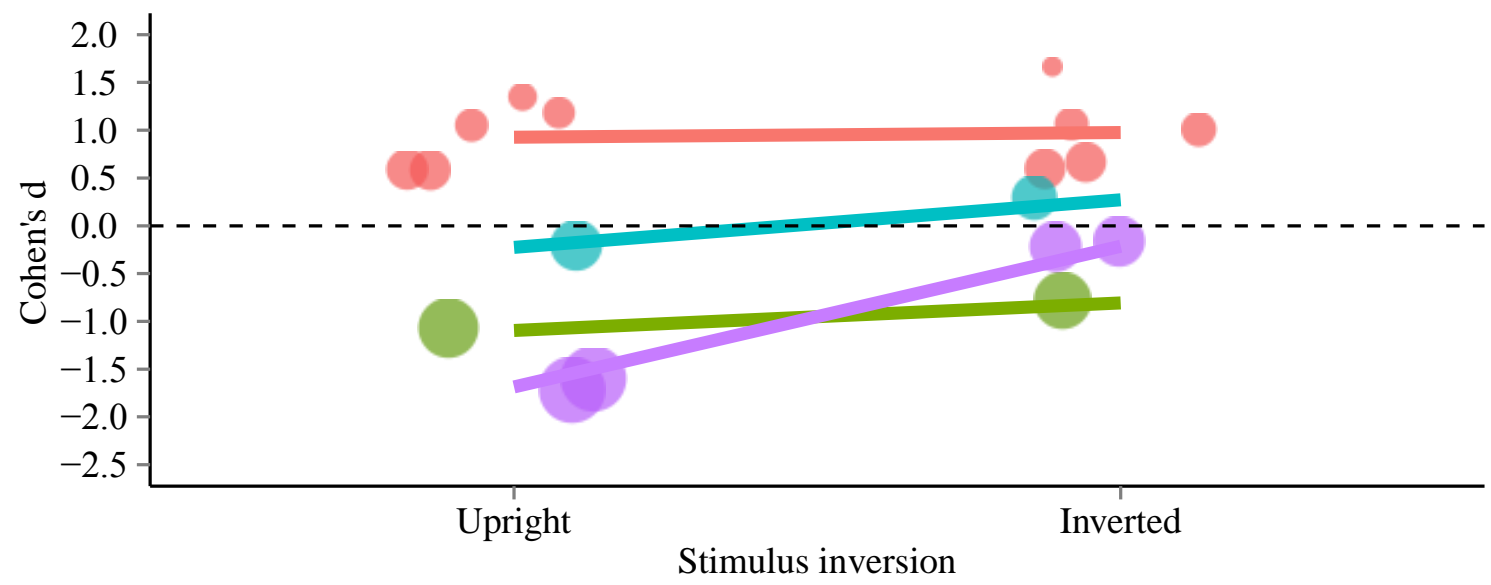

Figure 12. a) Random effects model with stimulus type as the sole moderator. b) Model depicting the interaction between stimulus type and stimulus inversion.

\section{Models with multiple moderators.}

Complete effects models. 


\section{ARE VISUAL THREATS PRIORITISED WITHOUT AWARENESS?}

Our full model contained two predictors: stimulus type and awareness measure, since these were the only moderators with no missing values. The backward elimination strategy eliminated awareness measure, meaning that the best fitting model included only stimulus type, as described above (Figure 12a).

\section{Reduced effects models.}

A reduced effect model that included stimulus size $(k=22)$ did not significantly improve the model fit.

\section{Model comparisons with imputed data.}

Using both imputation methods, the best-fitting model remained unchanged.

\section{Sensitivity analyses.}

We constructed two new data sets using random selection procedures such that no sample contributed more than one effect size to the model $(k=22)$. The pooled effect sizes were $d_{z}=0.09,[-0.270 .47], p=.618$ and $d_{z} 0.06,[-0.300 .43], p=.725$ for the first and second random selections respectively, and these resampled datasets resulted in the same final model (including just stimulus type), following multiple regression. This suggests that the presence of shared samples did not substantially bias our analyses.

\section{Summary of bCFS findings.}

In our analysis of the $b$ CFS literature, we estimated a very small, negative, nonsignificant effect of threat related bias. Although many studies provided significant effects, there was substantial heterogeneity, with many effect sizes being strongly positive or strongly negative.

\section{i) Evidence for reversed threat biases.}




\section{ARE VISUAL THREATS PRIORITISED WITHOUT AWARENESS?}

Some aspects of the data were similar to the MVP and BR paradigms. Again, fearful faces yielded threat-biases that were substantially larger than other stimulus categories. However, unlike these paradigms, a striking discrepancy was observed in that we found evidence for substantial reversed biases for some threat stimuli: negative word stimuli, and dominant and untrustworthy faces were slower to break suppression than their neutral counterparts. In addition to conflicting with the data from other paradigms, these findings conflict with the basic notion that unconscious threat processing is concerned with expediting the processing and perception of threatening stimuli to promote survival.

\section{ii) Low-level confounds may explain some threat-related biases.}

Contrary to our findings for the BR paradigm, we found that biases for fear and angry faces were indistinguishable between upright and inverted configurations. In fact, the pooled effect was slightly larger for inverted configurations. Given that inversion reduces the recognizable threat content of facial expressions, but maintains their low-level image properties (Gray et al., 2013), this provides good evidence that detection advantages/disadvantages for these stimuli may be mainly attributed to low-level properties such as contrast and spatial frequency content - factors known to affect rivalry dominance (Baker \& Graf, 2009), rather than threat sensitive processes. 


\section{Discussion}

\section{Summary of outcomes}

The primary goal of our meta-analysis was to examine the extent to which unconsciously presented threatening stimuli are prioritized in visual processing, relative to neutral stimuli. Our analyses revealed evidence for a small pooled threat-prioritization effect in the MVP paradigm, a medium effect in the BR paradigm and inconsistent effects in the bCFS paradigm.

\section{Differences between paradigms}

The three paradigms we reviewed did not only yield pooled effects of different magnitude, they were also modulated by different variables, affirming our decision to analyse them separately. This is perhaps unsurprising, because the three paradigms differ with respect to how they disrupt normal visual processing (Breitmeyer, 2015). Research indicates that brief, masked presentations interfere with awareness by impeding the temporal integration of neural responses to successive stimuli (Kovacs, Vogels, \& Orban, 1995). In contrast, BR is a complex multi-stage phenomenon, comprising of low-level, interocular inhibitory components (Tong \& Engel, 2001; Tong, Meng, \& Blake, 2006) and higher-level effects that increase the depth of suppression along the ventral processing stream (Nguyen, Freeman, \& Alais, 2003). The strength of suppression induced by CFS is also more potent than BR, as demonstrated by sensitivity measurements (Yang \& Blake, 2012). Moreover, masking and CFS differ with respect to how they attenuate neural responses in the dorsal and ventral processing streams (Almeida, Mahon, Nakayama, \& Caramazza, 2008). For instance, there is 


\section{ARE VISUAL THREATS PRIORITISED WITHOUT AWARENESS?}

an ongoing discussion about whether CFS spares processing via the dorsal 'vision for action' pathway relative to masking (Hebart \& Hesselman, 2012). Such a difference might provide an a priori expectation that stimuli presented under CFS are more likely to elicit behavioral responses. These different suppression mechanisms should therefore be expected to differ with respect to how they restrict the neural representation of threat-relevant stimuli.

It is also important to consider that the MVP paradigm may reflect a different visual selection process to BR and bCFS. During BR, awareness alternates between two retinally co-located images presented to the two eyes. In contrast, in attentional cuing tasks, attending to a stimulus at one location impairs discrimination of a stimulus at another location, but does not, in itself, cause it to disappear from awareness. However, although selective attention and interocular suppression clearly have different perceptual consequences, they may engage common competitive mechanisms. For instance, Mitchell, Stoner and Reynolds (2004) found that cuing attention to a surface engaged in rivalry enhanced its dominance. Similarly, Ooi and $\mathrm{He}(1999)$ found that a stimulus is more likely to become dominant if accompanied by a salient 'pop out' cue. Human brain imaging also shows that the activation of regions involved in attentional switching and perceptual switching in BR are similar (Knapen, Brascamp, Pearson, van Ee \& Blake, 2011). Indeed, behavioural evidence shows that in the absence of attention there are no variations in consciousness that define binocular rivalry (Brascamp \& Blake, 2012). Thus, despite apparent differences, biases observed in BR and MVP paradigms may be governed by a similar neural competition process that is prompted by rival stimulus representations. In this context, it is notable that when controlling for the differences in stimuli that have been used in each paradigm, the data are broadly consistent. When considering only those stimuli that have been used in all three paradigms (fear faces, andgry 


\section{ARE VISUAL THREATS PRIORITISED WITHOUT AWARENESS?}

faces, disgust faces, and IAPS images), effect sizes are not moderated by paradigm $(Q(2)=$ $2.37, p=.036)$ and there is no interaction between stimulus and paradigm $(Q(6)=2.48, p=$ $.870)$.

\section{Which threat stimuli receive prioritized processing?}

One other interesting finding was the existence of strong reversed biases for some threatening stimuli in the bCFS paradigm: neutral stimuli were consistently prioritized over negative words, untrustworthy and dominant faces. These findings conflict with the basic notion that when encountering threat, its privileged processing is beneficial (Nesse, 1999). Stewert and colleagues (2012) propose a framework to account for these discrepancies by suggesting that indirect threats (e.g. fearful faces) may induce fight or flight responses and heighten cortical arousal to reduce suppression of threat stimuli, whereas direct threats (e.g. angry faces, dominant faces) may also produce passive responses, characterized by 'freezing' and reduced cortical arousal, which may prolong suppression of threat. However, this framework cannot accommodate the reversed bias for negative words, which are not direct threats, nor can it accommodate for the lack of reversed biases for directly threatening stimuli in the BR and MVP paradigms. At any rate, whereas freezing behaviors and physiological changes have adaptive properties in the context of threat (reducing detection by predators, conserving energy) these should not be conflated with actively suppressing the perception of threatening stimuli, which seems maladaptive. In fact, freeze responses in many mammals are associated with hypervigilance to threat cues that prime a subsequent fight or flight reaction (Campbell, Wood \& McBride, 1997). 


\section{ARE VISUAL THREATS PRIORITISED WITHOUT AWARENESS?}

One finding that was consistent across all three paradigms was that fearful faces elicited the largest, most reliable threat related biases (MVP: $\mathrm{dz}=0.56, \mathrm{BR}: \mathrm{dz}=0.58, \mathrm{bCFS}$ : $\mathrm{dz}=0.49)$. In fact, it is worth noting that removing fearful faces from the analysis substantially reduced the pooled effect size in each paradigm (MVP: 0.28 to 0.15 , BR: 0.47 to 0.31, bCFS: -0.04 to -0.50 ). This sensitivity to fear is consistent with a large body of neuroimaging literature which has demonstrated that fear faces elicit responses in threat sensitive brain regions, even when suppressed by masking (Whalen et al., 2004), BR (Pasely, Mayes, \& Schultz, 2004) and CFS (Jiang \& He, 2006). Another commonality worth noting is that in all three paradigms, angry faces produced substantially smaller, non-significant, and even negative effects (MVP: 0.11, BR: 0.08, bCFS: -0.07). This is somewhat surprising, given that angry faces signal a direct threat to an observer ("I am angry"), whereas fearful faces only indicate the presence of a threat ("I am afraid"). It is hard to explain why an effective threat detection system would have the capacity to prioritise an indicator of threat in the environment (a fearful face), without similar sensitivity to stimuli that are directly threatening (an angry face). One possibility is that fearful faces are more salient on a purely sensory level, and that this is a better predictor of their enhanced processing than their effect on threat sensitive processes (Gray et al., 2013; Lee, Susskind \& Anderson, 2013). We discuss to this possibility in the following section.

\section{Low level confounds}

In our bCFS analyses, we found that biases for some stimulus categories (e.g. fearful faces) did not differ between upright and inverted configurations. Recent reports have shown that inverted facial expression, while retaining luminance, contrast and spatial frequency profile, have vastly reduced recognizable emotional content, according to signal detection 


\section{ARE VISUAL THREATS PRIORITISED WITHOUT AWARENESS?}

and implicit measures (Gray et al., 2013) and also valence, arousal and dominance ratings (Hedger, Adams, \& Garner, 2015b). Therefore, the fact that the detection advantage for fearful over neutral faces is equivalent in magnitude between upright and inverted configurations suggests that simple low-level variability between expressions may drive this effect.t Given that i) inversion reduces the recognizable emotional content of stimuli, and ii) it does not alter low-level stimulus properties (contrast, luminance, spatial frequency profile), the similar magnitude of threat bias in upright and inverted configurations suggests that simple low-level variability between fearful and neutral faces may explain the threat related bias. This more parsimonious explanation negates the need to invoke unconscious threat sensitive processes. It is notable that very few MVP studies have attempted to control for low-level stimulus properties (the exceptions being Carlson \& Reinke, 2008; and Fox, 2002). This is important, since if stimuli differ on some other dimension other than their perceived threat, it cannot unequivocally be claimed that perceived threat is the cause of the processing bias unless adequate controls are implemented.

Recently, it has been reported that the prioritised detection of fearful faces from backward masking and CFS is poorly explained by perceived threat (valence arousal and dominance ratings) and is better explained by low-level stimulus characteristics - the distribution of luminance contrast across spatial frequency in relation to the human contrast sensitivity function (Hedger et al., 2015b). In particular, several authors have noted that the increased luminance contrast associated with the greater exposure of iris and scleral field in the fear expression may be a good predictor of their prioritized detection over neutral faces (Lee, Susskind, \& Anderson, 2013). Notably, this suggests a purely sensory detection advantage that can occur independently of threat, or emotion sensitive processes. Given that 


\section{ARE VISUAL THREATS PRIORITISED WITHOUT AWARENESS?}

i) fearful faces were the most commonly used stimuli in conditions contributing to our analyses and ii) these conditions contributed the largest effect sizes to the pooled estimate, this is a non-trivial issue.

\section{Assessment of awareness and response criteria.}

In the MVP analyses, we found evidence that awareness moderates threat related biases: effects were substantially larger when the SOA between target and mask was increased to $>30 \mathrm{~ms}$. This is particularly important, given evidence that observers can reliably detect stimuli that are presented for this duration when stringent, signal detection criteria are used to assess awareness (Pessoa, Japee, \& Ungerleider, 2005; Pessoa, Japee, Sturman \& Ungerleider, 2006). Furthermore, many MVP studies did not include any explicit awareness check to verify the efficacy of the masking procedure, which substantially limits the validity of strong conclusions about 'unconscious' processing on the basis of these observations.

Related, but separable concerns are applicable to the assessment of awareness in the BR and bCFS paradigms. In BR, the perceptual switches between stimuli are not always well defined and discrete, making it difficult to reliably measure which stimulus is dominant at any one time. Although some studies have included a 'mixed-percept' response option to address this issue (Alpers \& Gerdes, 2007; Lerner et al., 2012), the boundary between perception of one image and another in rivalry is often graded and temporally uncertain (Knapen et al., 2011). Thus, regardless of the available response options, perceptual reports are still heavily reliant on an observer's individual criteria in classifying when one image is (primarily) dominant or the percept is mixed (Pessoa, 2005). It is possible, for example, that 


\section{ARE VISUAL THREATS PRIORITISED WITHOUT AWARENESS?}

response biases could inflate effect sizes, if a threatening stimulus is reported when elements of both threatening and neutral images are visible.

Similarly, response times in $b$ CFS tasks reflect a 'pure' suppression duration, during which none of the target stimulus is visible, but can also reflect the time taken, and criterion used, to report that a stimulus has become visible. This concern is particularly pertinent when one considers that several studies included in our analysis did not include a non-CFS control condition to verify that there were no inherent differences in detectability of threatening vs. non-threatening stimuli under suprathreshold conditions (Capitao et al., 2014; Chen \& Yeh, 2012; Gray et al., 2013; Justyte et al., 2015; Stein et al., 2013; Sylvers et al., 2011). Furthermore, even in the cases where such a control has been included, this typically consists of presenting identical stimuli to both eyes (Sterzer et al., 2011; Stewart et al., 2012), which may not be perceptually comparable. For instance, response times are highly variable in a bCFS task, due to the stochastic temporal dynamics of BR (Lahky, 1995), whereas in a nonCFS control condition, the appearance of a target whose contrast is linearly increased is more easily anticipated (Stein, Hebart, \& Sterzer, 2011). Since the target stimulus and mask are simply superimposed in control tasks, there is also the absence of partial stimulus visibility that can occur during perceptual switches in binocular rivalry, including CFS. Thus, such control tasks are not comparable and may not be equipped to rule out the influence of response biases. We must be cautious, therefore, in interpreting differential response times in $b$ CFS studies as solely reflecting unconscious processing.

\section{Threat-related biases and anxiety}

Evidence for a relationship between anxiety and threat-related bias varied across paradigms. We found strong evidence for a relationship between trait anxiety and threat bias 


\section{ARE VISUAL THREATS PRIORITISED WITHOUT AWARENESS?}

in the MVP paradigm, but evidence for this association in the BR paradigm was more mixed, with both affirmative (Gray et al., 2009, Singer et al., 2012) and null findings (Alpers \& Gerdes, 2007; Anderson et al., 2013). In the bCFS paradigm, we identified only one study that included an anxiety measure, which prevented meta-analytic examination. Measurement of threat biases in anxious populations could be complicated by the fact that anxious observers are less capable of discriminating between threatening and neutral signals (Lissek et al., 2009) and often interpret ambiguous stimuli as threatening (Clark \& McManus, 2002) as a consequence of a lowered threshold for perceiving threat (Mogg \& Bradley, 1998). Indeed, Lee, Kang, Kim, and An (2008) note that neutral faces may provide an inappropriate baseline in studies of emotion processing, since they may be evaluated as negative, depending on the experimental context and the observer.

Another possibility is that anxiety is only associated with enhanced threat biases when stimulus presentation is brief; our BR analyses revealed that the association between anxiety and threat bias was stronger in the initial dominance measure (although the anxiety $\mathrm{x}$ dominance measure interaction did not reach significance). In keeping with this, evidence from the visual probe paradigm has suggested an anxiety-enhanced bias towards threat at short presentations, but this is less reliable at longer stimulus presentations (Mogg \& Bradley, 2006; Mogg, Philppot, \& Bradley, 2004). Moreover, in clinically anxious populations, threat related biases have been found to be larger in subliminal than supraliminal versions of the emotional Stroop task (Bar Haim et al., 2007). Eye movement data also indicate that threat biases in anxiety are typically observed during the initial phases of stimulus presentation (e.g. first fixations; Calvo \& Avero, 2005; Mogg, Garner, \& Bradley, 2007). These observations are broadly consistent with cognitive models of anxiety, which posit that selective attention 


\section{ARE VISUAL THREATS PRIORITISED WITHOUT AWARENESS?}

for threat is mediated by mechanisms operating early in information processing (Williams, Watts, Macleod, \& Mathews, 1997).

\section{Future directions}

Our review reveals a number of topics that, in our view, warrant further investigation.

\section{Dissociating awareness, stimulus degradation and suppression.}

Firstly, there is a need for a more refined, systematic investigation of the representation of subliminal stimuli. To optimally study unconscious threat processing, a paradigm should manipulate awareness and not any other aspect of visual processing. However, all known methods for rendering stimuli invisible do so by making them drastically different from a consciously viewed counterpart. Thus although suppression methods allow experimenters to 'switch awareness off', they likely do so by attenuating the gain of neural responses and degrading the strength of visual signals, relative to consciously viewed stimuli (Yuval-Greenberg \& Heeger, 2013). It has been argued, for instance, that binocular rivalry may not be optimally suited for studying visual consciousness, since it may have unique neural mechanisms that do not generalize to other stimulus conditions and perceptual phenomena (Blake, Brascamp \& Heeger, 2014). Therefore, it remains possible that other paradigms may eliminate awareness, but spare visual processing to the extent that threat responses remain effective. Testing a range of suppression paradigms that rely on different mechanisms, will allow more reliable dissociation of null effects resulting from the genuine absence of unconscious threat-sensitive process from those resulting from methodological limitations (e.g. Faivre, Berthet \& Koudier, 2012).

On a related note, the extent to which 'dominance' and 'suppression' in BR and CFS are functionally the same as 'awareness' and 'unawareness' remains an empirical question. 


\section{ARE VISUAL THREATS PRIORITISED WITHOUT AWARENESS?}

Under some conditions, participants may retain some residual sensitivity to, or phenomenal awareness of stimuli in the suppression phase. For instance, colors of objects suppressed under rivalry can nonetheless appear as a diffuse "cloud" superimposed on the dominant image (Hong \& Blake, 2009), and suppressed, drifting grating can still give an impression of movement, when only the dominant image is visible (Zabood, Lee \& Blake, 2011). Moreover, when two flickering forms engage in rivalry, they can be temporally integrated into 'beats', despite observers only being conscious aware of one form (Carlson \& He, 2000). These examples of 'stimulus fractionation' are widespread in the rivalry literature and suggest that fusion and rivalry can co-occur, such that some aspects of a stimulus may be suppressed (form) but other may be fused (color, motion, temporal information).

\section{Are threat stimuli comparable?}

A common criticism of meta analyses is that researchers combine different types of studies in a single analysis (i.e. the problem of "apples and oranges", Bornstein, 2009). For instance, combining the data from individual studies that use either fearful or dominant faces (as in the case of the bCFS analyses) yields a threat related bias that is near zero, but the does not adequately characterize the effect elicited by each stimulus. However, meta analyses allow us to quantify these differences despite the fact that these stimuli were not directly compared within the same empirical study. Given the substantial heterogeneity explained by stimulus type in all three paradigms, we should question the extent to which all stimuli defined as threatening are truly comparable.

Though both fearful and dominant faces may be threatening, fearful faces may be perceived as a salient threat of physical harm in the mearby environment, whereas dominant faces may be perceived as more nuanced threat to social status. At the behavioral level, 


\section{ARE VISUAL THREATS PRIORITISED WITHOUT AWARENESS?}

reacting to a fearful face may require a fast behavioral response, whereas responding to a dominant face may promote submissive withdrawal and behavioral adjustments related to longer term risk assessment. Indeed, at the neural level, researchers have differentiated between systems for responding to 'potential threat' and 'imminent danger' (Fiddick, 2011). As a result, a more refined characterization of threatening stimuli is required in future research. This could include a number of important dimensions that may modulate the threat response, such as the proximity (Mobbs et al., 2007), predictability (Whalen et al., 2007) or directness (Adams et al., 2011) of the threat and the psychological state of the observer (Bishop 2007).

A related recommendation is that experimental methods should routinely test the crucial possibility that stimuli intended to be threatening or neutral may simply not be perceived as such by participants. This problem may arise because self-report rating can be influenced by distortions such as social norms and the investigators' expectations (Dagleish \& Power, 1999). Indeed, implicit measures of valence have been shown to be inconsistent with self report measures and may reveal that observers judge both 'neutral' and 'threatening' categories as being broadly similar in valence (e.g. Lee et al., 2008). As implicit measures are relatively immune to response bias, they could be used in place of, or in conjunction with self report measures.

\section{What kind of awareness matters?}

The research literature that we have reviewed consists of paradigms that disrupt normal visual processing so that awareness can be studied. It has been argued that although this type of awareness is interesting, it is not particularly relevant to understanding the impact of threatening stimuli on behavior and clinical conditions such as anxiety (Pessoa, 2013). The 


\section{ARE VISUAL THREATS PRIORITISED WITHOUT AWARENESS?}

primary reason cited for this position is that "subliminal stimuli do not occur naturally" (Bargh \& Morsella, 2008, p. 78). Whilst this claim seems unfalsifiable, it is clear that we do not, outside of the lab, often encounter a $10 \mathrm{~Hz}$ stimulus presented to just one eye, or isolated faces images that are masked after only 17 milliseconds. For this reason, Bargh and Morsella propose that studying unawareness of the influence of a stimulus is more important to understanding human behavior than the unawareness of a stimulus itself. Although a reasonable concern, it is also true that stimuli can also be rendered invisible in more typical circumstances than those induced by BR and masking. For instance, the majority of traffic accidents can be attributed to inattention and forms of perceptual blindness (Chun \& Marois, 2002). Visual crowding and motion-induced blindness are other instances where stimuli are rendered invisible, but under conditions that are likely to occur frequently in cluttered and dynamic natural scenes (Bonneh, Cooperman, \& Sagi, 2001; Koudier, Berthet, \& Faivre, 2011). Using these paradigms may prove informative and allow conclusions to more readily be generalized to typical viewing conditions.

\section{Interocular suppression and anxiety}

Although there have been studies into the efficacy of pharmacological and cognitive interventions to modulate threat related biases in anxious individuals using the MVP paradigm (Maoz et al., 2013; Murphy et al, 2008), this has not been done using BR and bCFS. This is somewhat surprising, since there is good evidence that perceptual switches in binocular rivalry are linked to the balance of inhibitory neurotransmitters (van Loon et al., 2013), prefrontal cortex activity (Amting et al., 2010) and attentional control (Carter et al., 2005; Paffen \& Alais, 2011); all of which have been implicated in maladaptive perceptual biases in anxiety and considered therapeutic treatment targets (Bishop, 2009; Eysenck, 


\section{ARE VISUAL THREATS PRIORITISED WITHOUT AWARENESS?}

Derakshan, Santos, \& Calvo, 2007). There are therefore, potential gains from applying well controlled versions of these tasks to investigate maladaptive biases in threat processing in anxiety. For instance, early investigations with the bCFS paradigm appear to show some sensitivity to self-reported anxiety (Capitao et al., 2014) and other social trait characteristics (Stewart et al., 2012).

\section{What drives threat-related biases?}

A major limitation of the 'threat' literature is that it is often unclear whether sensory or affective dimensions of stimuli drive their prioritised processing (Adams, Gray, Garner \& Graf, 2011). The claim that perceived threat is the cause of a processing bias is crucial to the logic of many of studies, but is often based on assumption, rather than empirical evidence. It is important to control for, or at least explicitly characterize, the influence of low-level stimulus properties. One way to circumvent the issue of low-level confounds is to pair perceptually similar stimuli (pairs of neutral faces, simple gratings) with negative and neutral valences, via fear conditioning/ affective learning. Two studies in our meta analysis employed this technique (Alpers et al., 2005; Anderson et al., 2011) and observed evidence for a threat-related bias even when low-level confounds were eliminated via this method. Similarly, we would suggest that control stimuli (such as spatially and contrast inverted faces) provide a good means of dissociating sensory and affective factors (e.g. Gray et al., 2013). In addition to controlling for low-level stimulus properties, future studies could systematically measure affective dimensions of stimuli, via perceived valence, arousal and dominance ratings (Hedger et al., 2015b). This would allow a more detailed, precise and standardized examination of the relative contribution of low-level and affective factors. 


\section{ARE VISUAL THREATS PRIORITISED WITHOUT AWARENESS?}

\section{Relating behavioral and neuroimaging measures}

Neuroimaging techniques have the potential to reveal the neural signatures and brain regions underlying unconscious threat processing. For instance, there is considerable evidence that the amygdala is an important component of the neural circuitry involved in threat processing (for a review see Adolphs, 2008). However, patients with amygdala lesions nonetheless show prioritized processing of threat stimuli in a wide range of behavioral tasks (Tsuchiya, Moradi, Felsen, Yamazaki, \& Adolphs, 2009; Piech et al., 2010; Piech et al., 2011). It therefore remains an interesting question as to whether amygdala activity to unconsciously presented faces has a causal role in driving threat responses, or whether it is simply correlated with the processing of threatening stimuli. Thus, whilst these neuroimaging findings are invaluable in many respects, they are more easily interpretable when combined with sensitive, well-controlled behavioral measures of enhanced threat processing.

When a procedure (e.g. masking) prevents conscious awareness, but behavioral evidence for threat processing is detected, it is often concluded that threat processing temporally precedes awareness, or that it is 'preconscious' (Fox et al., 2010; Mogg et al., 1995, Sylvers et al., 2011). However, the rapidity of stimulus presentation is not related to the rapidity of processes under study (Vanrullen, 2011). Restricting presentation time directly affects the quality of visual input or equivalently, the signal to noise ratio. It is possible that conscious awareness requires more robust visual input than threat processing, but the two processes occur at similar latencies when the signal to noise ratio is sufficient. Thus, effects generated by subliminal stimuli do not shed light on the relative speeds of the two processes. This is important, given that one of the proposed advantages of unconscious threat processing is that it is faster than general purpose visual processing (Tamietto \& deGelder, 2010), but the 


\section{ARE VISUAL THREATS PRIORITISED WITHOUT AWARENESS?}

evidence for this component of the standard hypothesis is very mixed (Pessoa, 2010). This issue may be investigated with further studies using electrophysiological methods with fine temporal resolution, although it is currently unclear whether responses at 'deep' (subcortical) brain structures can be reliably estimated via EEG or MEG (Baumgartner, Pataraia, Lindinger, \& Deecke, 2000).

\section{Awareness measures and response bias}

To clarify whether threat related biases are genuinely independent of awareness, future MVP studies could assess the relationship between stimulus visibility and threat bias by parametrically varying the SOA between target and mask. Recent work applying this logic to studying explicit and implicit measures of affective processing has revealed that these are strongly dependent on visibility/ the SOA (Lahteenmaki, Hyona, Koivisto, \& Nummenmaa, 2015). Ideally, signal detection awareness measures would be employed concurrently with the visual probe trials in a manner that corrects for individual response bias. Researchers could also conduct a priori power calculations to determine the number of trials required for a sensitive awareness check. At a minimum, this could be calculated post hoc to assess the likelihood of type two errors.

Response biases were identified as an issue for BR and bCFS studies. To combat the issue of response biases, some researchers have implemented non-rivalrous simulations that attempt to mimic piecemeal rivalry, by alternating the transparency of regions of superimposed images, with the temporal dynamics of these alternations drawn from rivalry data (Baker \& Graf, 2009; Lee \& Blake, 2004). Since no rivalry is involved, similar simulations could be used to characterize observers' tendency to report visibility of a 


\section{ARE VISUAL THREATS PRIORITISED WITHOUT AWARENESS?}

threatening stimulus as a function of its quantifiable visibility, under conditions that mimic rivalry. This would provide an effective way to estimate the extent of response bias under rivalry-like conditions of partial visibility.

\section{Do threat-related biases generalise?}

All three paradigms that we reviewed revealed some evidence of threat-related bias under certain conditions. It is possible, however, that even the shared findings (e.g. a processing advantage of fearful over neutral faces) rely on the particular (and arguably unusual) stimulus conditions common to all tasks. All paradigms involve simple displays of no more than two isolated, static stimuli, with a high probability that a threatening stimulus will appear in one of a limited number of locations. More commonly, the human observer needs to select a subset of stimuli for further processing from a complex, dynamic scene, after, or in parallel with image segmentation, and often solving for partial occlusion. Novel behavioral paradigms that manipulate the number, predictability and location of threatening stimuli in more complex displays could be implemented to place more real-world demands on the capacity limits and physiological constraints of the visual system. After all, unconscious threat processing is of little functional benefit if it only operates in very simple environments.

\section{Summary and Conclusions}

Our meta analysis and critical review together makes a number of important empirical, methodological and theoretical contributions. At the empirical level, we have quantitatively combined data from a large and diverse research field, in which there was little oversrching consensus. This has allowed us to identify and precisely quantify relationships 


\section{ARE VISUAL THREATS PRIORITISED WITHOUT AWARENESS?}

between threat bias and stimulus, paradigm and observer parameters, in a way not possible by considering the results of individual studies alone. At the stimulus level, we have shown that fearful faces are the only stimuli that reliably elicit a threat effect across paradigms. However, the threat bias elicited by fearful faces may be attributable to low-level confounds; fearful faces also reliably elicit equivalent bCFS effects (relative to neutral faces) in a spatially inverted configuration. At the paradigm level, we note that within the MVP paradigm, threat biases are strongly modulated by SOA. This effect of SOA was also strongest in studies where no awareness check was conducted. We should therefore be cautious in interpreting data from the MVP literature, since effects may be accounted for, to some extent, by partial visibility that was undetected due to insufficient awareness measures. We also found evidence that prioritization of threat may be quite limited at the early stages of perceptual selection as indexed by small initial dominance effects in the BR paradigm. At the observer level, our analyses suggest that anxiety may modulate threat biases, but only under specific presentation conditions.

We can think of our methodological contribution in two ways. Firstly, our analysis of the literature has direct implication for the design of future experiments an which methods may form the basis for interesting new research questions. Secondly, in terms of our meta analysis itself, we have applied rigorous methods to tackle important issues, for example by using a novel combination of recent approaches to tackle dependency between effects and missing data.

At the theoretical level, we have raised important questions about how awareness is measured and the ecological validity of different methods used to manipulate awareness. We have also evaluated evidence for the notion that anxious individuals have an unconscious bias 


\section{ARE VISUAL THREATS PRIORITISED WITHOUT AWARENESS?}

for threat across several different paradigms. This novel analysis invites the field to revisit conclusions drawn from studies that have only employed masking ot manipulate awareness (e.g. Bar Haim et al., 2007). Lastly, at the most basic level, our analyses may call for a redefinition of the scope and limits of visual processing that transpire without awareness, which has been discussed alongside some recent theoretical frameworks (e.g. Hassin, 2013;

Tamietto \& deGelder, 2013) and narrative reviews with no quantitative component (e.g. Axelrod, Bar \& Rees, 2015).

Considering our meta-analyses and critical review together, we suggest that uncritical acceptance of the standard hypothesis, which states that threat stimuli can be identified and prioritized without awareness, is premature. We emphasize the significant methodological issues surrounding the assessment of awareness, response bias and low-level confounds. Tackling these substantial issues will require rigorous measures of awareness and combining evidence across carefully controlled, novel and ecologically valid experimental designs. 


\section{ARE VISUAL THREATS PRIORITISED WITHOUT AWARENESS?}

\section{References}

* References marked with an asterisk were included in the meta-analysis.

Adolphs, R. (2008). Fear,faces, and the human amygdala. Current Opinion in Neurobiology,18(2), 166-172. http://doi.org/10.1016/j.conb.2008.06.006

Alais, D., Cass, J., O’Shea, R. P., \& Blake, R. (2010). Visual Sensitivity Underlying Changes in Visual Consciousness. Current Biology, 20(15), 1362-1367. http://doi.org/10.1016/j.cub.2010.06.015

Algom, D., Chajut, E., \& Lev, S. (2004). A rational look at the emotional stroop phenomenon: a generic slowdown, not a stroop effect. Journal of Experimental Psychology. General, 133(3), 323-338. http://doi.org/10.1037/0096-3445.133.3.323

Almeida, J., Mahon, B. Z., Nakayama, K., \& Caramazza, A. (2008). Unconscious processing dissociates along categorical lines. Proceedings of the National Academy of Sciences, 105(39), 15214-15218. http://doi.org/10.1073/pnas.0805867105

*Alpers, G., \& Pauli, P. (2006). Emotional pictures predominate in binocular rivalry. Cognition \& Emotion, 20(5), 596-607. http://doi.org/10.1080/02699930500282249 


\section{ARE VISUAL THREATS PRIORITISED WITHOUT AWARENESS?}

*Alpers, G. W., \& Gerdes, A. B. M. (2007). Here is looking at you: emotional faces predominate in binocular rivalry. Emotion (Washington, D.C.), 7(3), 495-506. http://doi.org/10.1037/1528-3542.7.3.495

*Alpers, G. W., Ruhleder, M., Walz, N., Mühlberger, A., \& Pauli, P. (2005). Binocular rivalry between emotional and neutral stimuli: a validation using fear conditioning and EEG. International Journal of Psychophysiology: Official Journal of the International Organization of Psychophysiology, 57(1), 25-32. http://doi.org/10.1016/j.ijpsycho.2005.01.008

*Amting, J. M., Greening, S. G., \& Mitchell, D. G. V. (2010). Multiple Mechanisms of Consciousness: The Neural Correlates of Emotional Awareness. The Journal of Neuroscience, 30(30), 10039-10047. http://doi.org/10.1523/JNEUROSCI.6434-09.2010

*Anderson, E. C., Dryman, M. T., Worthington, J., Hoge, E. A., Fischer, L. E., Pollack, M. H., ... Simon, N. M. (2013). Smiles may go unseen in generalized social anxiety disorder: evidence from binocular rivalry for reduced visual consciousness of positive facial expressions. Journal of Anxiety Disorders, 27(7), 619-626. http://doi.org/10.1016/j.janxdis.2013.07.004

*Anderson, E., Siegel, E. H., Bliss-Moreau, E., \& Barrett, L. F. (2011). The Visual Impact of Gossip. Science, 332(6036), 1446-1448. http://doi.org/10.1126/science.1201574

Baker, D. H. (2010). Visual Consciousness: The Binocular Rivalry Explosion. Current Biology, 20(15), R644-R646. http://doi.org/10.1016/j.cub.2010.06.010 


\section{ARE VISUAL THREATS PRIORITISED WITHOUT AWARENESS?}

Baker, D. H., \& Graf, E. W. (2009). Natural images dominate in binocular rivalry. Proceedings of the National Academy of Sciences, 106(13), 5436-5441.

http://doi.org/10.1073/pnas.0812860106

*Bannerman, R. L., Milders, M., De Gelder, B., \& Sahraie, A. (2008). Influence of emotional facial expressions on binocular rivalry. Ophthalmic \& Physiological Optics: The Journal of the British College of Ophthalmic Opticians (Optometrists), 28(4), 317-326.

http://doi.org/10.1111/j.1475-1313.2008.00568.x

*Bannerman, R. L., Regener, P., \& Sahraie, A. (2011). Binocular rivalry: a window into emotional processing in aging. Psychology and Aging, 26(2), 372-380. http://doi.org/10.1037/a0022029

Bargh, J. A., \& Morsella, E. (2008). The Unconscious Mind. Perspectives on Psychological Science: A Journal of the Association for Psychological Science, 3(1), 73-79.

Bar-Haim, Y., Lamy, D., Pergamin, L., Bakermans-Kranenburg, M. J., \& van IJzendoorn, M. H. (2007). Threat-related attentional bias in anxious and nonanxious individuals: a meta-analytic study. Psychological Bulletin, 133(1), 1-24. http://doi.org/10.1037/0033-2909.133.1.1

Baumgartner, C., Pataraia, E., Lindinger, G., \& Deecke, L. (2000). Neuromagnetic recordings in temporal lobe epilepsy. Journal of Clinical Neurophysiology: Official Publication of the American Electroencephalographic Society, 17(2), 177-189. 


\section{ARE VISUAL THREATS PRIORITISED WITHOUT AWARENESS?}

*Beaver, J. D., Mogg, K., \& Bradley, B. P. (2005). Emotional conditioning to masked stimuli and modulation of visuospatial attention. Emotion (Washington, D.C.), 5(1), 67-79. http://doi.org/10.1037/1528-3542.5.1.67

Beck, A.T., Ward, C., Mendelson, M., Mock, J., \& Erbaugh, J (1961). An inventory for measuring depression. Archives of General Psychiatry, 4, 561-571.

Becker, B. J. (2005). Failsafe N or File-Drawer Number. In H. R. R. Co-Chair, A. J. S. Co-Author, \& M. B. D. A. L. PI (Eds.), Publication Bias in Meta-Analysis (pp. 111-125). John Wiley \& Sons, Ltd. Retrieved from http://onlinelibrary.wiley.com/doi/10.1002/0470870168.ch7/summary

Begg, C. B., and J. A. Berlin. 1988. "Publication Bias: A Problem in Interpreting Medical Data. Journal of the Royal Statistical Society Series B, 151, 419-463.

Berry, J. W. (1969). Ecology and Socialization as Factors in Figural Assimilation and the Resolution of Binocular Rivalry. International Journal of Psychology, 4(4), 271-280. http://doi.org/10.1080/00207596908247277

Bishop, S. J. (2007). Neurocognitive mechanisms of anxiety: an integrative account. Trends in Cognitive Sciences, 11(7), 307-316. http://doi.org/10.1016/j.tics.2007.05.008

Bonneh, Y. S., Cooperman, A., \& Sagi, D. (2001). Motion-induced blindness in normal observers. Nature, 411(6839), 798-801. http://doi.org/10.1038/35081073 


\section{ARE VISUAL THREATS PRIORITISED WITHOUT AWARENESS?}

Blake, R., \& Logothetis, N. K. (2002). Visual competition. Nature Reviews. Neuroscience, 3(1), 13-21. http://doi.org/10.1038/nrn701

Blake, R., O’Shea, R. P., \& Mueller, T. J. (1992). Spatial zones of binocular rivalry in central and peripheral vision. Visual Neuroscience, 8(05), 469-478. http://doi.org/10.1017/S0952523800004971

Bradley, M. M., Codispoti, M., Cuthbert, B. N., \& Lang, P. J. (2001). Emotion and motivation I: defensive and appetitive reactions in picture processing. Emotion (Washington, D.C.), 1(3), 276-298.

Brascamp, J. W., \& Blake, R. (2012). Inattention abolishes binocular rivalry: perceptual evidence. Psychological Science, 23(10), 1159-1167. http://doi.org/10.1177/0956797612440100

Breitmeyer, B. G. (2015). Psychophysical "blinding" methods reveal a functional hierarchy of unconscious visual processing. Consciousness and Cognition, 35, 234-250. http://doi.org/10.1016/j.concog.2015.01.012

Breitmeyer, B. G., \& Ogmen, H. (2000). Recent models and findings in visual backward masking: a comparison, review, and update. Perception \& Psychophysics, 62(8), 1572-1595.

Buuren, S. van. (2012). Flexible Imputation of Missing Data. CRC Press. 


\section{ARE VISUAL THREATS PRIORITISED WITHOUT AWARENESS?}

Campbell BA, Wood G, McBride T. Origins of orienting and defensive responses: An evolutionary perspective. In: Lang PJ, Simons RF, Balaban MT, editors. Attention and orienting: Sensory and motivational processes. Hillsdale, NJ: Lawrence Erlbaum Associates, Inc.; 1997. pp. 41-67.

*Capitão, L. P., Underdown, S. J. V., Vile, S., Yang, E., Harmer, C. J., \& Murphy, S. E. (2014). Anxiety increases breakthrough of threat stimuli in continuous flash suppression. Emotion (Washington, D.C.), 14(6), 1027-1036. http://doi.org/10.1037/a0037801

*Carlson, J. M., Cha, J., Harmon-Jones, E., Mujica-Parodi, L. R., \& Hajcak, G. (2014). Influence of the BDNF genotype on amygdalo-prefrontal white matter microstructure is linked to nonconscious attention bias to threat. Cerebral Cortex (New York, N.Y.: 1991), 24(9), 22492257. http://doi.org/10.1093/cercor/bht089

*Carlson, J. M., Cha, J., \& Mujica-Parodi, L. R. (2013). Functional and structural amygdala Anterior cingulate connectivity correlates with attentional bias to masked fearful faces. Cortex, 49(9), 2595-2600. http://doi.org/10.1016/j.cortex.2013.07.008

*Carlson, J. M., Fee, A. L., \& Reinke, K. S. (2009, November 21). Backward masked snakes and guns modulate spatial attention. Retrieved February 2, 2015, from http://www.epjournal.net/articles/backward-masked-snakes-and-guns-modulate-spatialattention/ 


\section{ARE VISUAL THREATS PRIORITISED WITHOUT AWARENESS?}

*Carlson, J. M., \& Mujica-Parodi, L. R. (2014). Facilitated Attentional Orienting and Delayed Disengagement to Conscious and Nonconscious Fearful Faces. Journal of Nonverbal Behavior, 1-9. http://doi.org/10.1007/s10919-014-0185-1

*Carlson, J. M., Mujica-Parodi, L. R., Harmon-Jones, E., \& Hajcak, G. (2012). The orienting of spatial attention to backward masked fearful faces is associated with variation in the serotonin transporter gene. Emotion, 12(2), 203-207. http://doi.org/10.1037/a0025170

*Carlson, J. M., \& Reinke, K. S. (2008). Masked fearful faces modulate the orienting of covert spatial attention. Emotion (Washington, D.C.), 8(4), 522-529. http://doi.org/10.1037/a0012653

*Carlson, J. M., \& Reinke, K. S. (2010). Spatial attention-related modulation of the N170 by backward masked fearful faces. Brain and Cognition, 73(1), 20-27. http://doi.org/10.1016/j.bandc.2010.01.007

*Carlson, J. M., Reinke, K. S., \& Habib, R. (2009). A left amygdala mediated network for rapid orienting to masked fearful faces. Neuropsychologia, 47(5), 1386-1389. http://doi.org/10.1016/j.neuropsychologia.2009.01.026

Carter, O., \& Cavanagh, P. (2007). Onset Rivalry: Brief Presentation Isolates an Early Independent Phase of Perceptual Competition. PLoS ONE, 2(4), e343. http://doi.org/10.1371/journal.pone.0000343 


\section{ARE VISUAL THREATS PRIORITISED WITHOUT AWARENESS?}

Carter, O. L., Presti, D. E., Callistemon, C., Ungerer, Y., Liu, G. B., \& Pettigrew, J. D. (2005a). Meditation alters perceptual rivalry in Tibetan Buddhist monks. Current Biology, 15(11), R412-R413. http://doi.org/10.1016/j.cub.2005.05.043

Carter, O. L., Presti, D. E., Callistemon, C., Ungerer, Y., Liu, G. B., \& Pettigrew, J. D. (2005b). Meditation alters perceptual rivalry in Tibetan Buddhist monks. Current Biology: $C B, 15(11)$, R412-413. http://doi.org/10.1016/j.cub.2005.05.043

Calvo, M. G., \& Avero, P. (2005). Time course of attentional bias to emotional scenes in anxiety: Gaze direction and duration. Cognition \& Emotion, 19(3), 433-451. http://doi.org/10.1080/02699930441000157

Cheesman, J., \& Merikle, P. M. (1984). Priming with and without awareness. Perception \& Psychophysics, 36(4), 387-395. http://doi.org/10.3758/BF03202793

*Chen, Y.-C., \& Yeh, S.-L. (2012). Look into my eyes and I will see you: unconscious processing of human gaze. Consciousness and Cognition, 21(4), 1703-1710. http://doi.org/10.1016/j.concog.2012.10.001

Cheung, M. W.-L. (2014). Modeling dependent effect sizes with three-level meta-analyses: a structural equation modeling approach. Psychological Methods, 19(2), 211-229. http://doi.org/10.1037/a0032968 


\section{ARE VISUAL THREATS PRIORITISED WITHOUT AWARENESS?}

Chun, M. M., \& Marois, R. (2002). The dark side of visual attention. Current Opinion in Neurobiology, 12(2), 184-189. http://doi.org/10.1016/S0959-4388(02)00309-4

Codispoti, M., \& De Cesarei, A. (2007). Arousal and attention: picture size and emotional reactions. Psychophysiology, 44(5), 680-686. http://doi.org/10.1111/j.1469$\underline{8986.2007 .00545 . x}$

Cohen, J. (1977). Statistical power analysis for the behavioral sciences. Routledge.

Crick, F., \& Koch, C. (1998). Consciousness and neuroscience. Cerebral Cortex, 8(2), 97-107. http://doi.org/10.1093/cercor/8.2.97

Cumming, G. (2011). Understanding The New Statistics: Effect Sizes, Confidence Intervals, and Meta-Analysis. New York: Routledge.

Cumming, G. (2013). The New Statistics Why and How. Psychological Science, 0956797613504966. http://doi.org/10.1177/0956797613504966

Dehaene, S., \& Changeux, J.-P. (2011). Experimental and theoretical approaches to conscious processing. Neuron, 70(2), 200-227. http://doi.org/10.1016/j.neuron.2011.03.018

Dehaene, S., Changeux, J.-P., Naccache, L., Sackur, J., \& Sergent, C. (2006a). Conscious, preconscious, and subliminal processing: a testable taxonomy. Trends in Cognitive Sciences, 10(5), 204-211. http://doi.org/10.1016/j.tics.2006.03.007 


\section{ARE VISUAL THREATS PRIORITISED WITHOUT AWARENESS?}

Dehaene, S., Changeux, J.-P., Naccache, L., Sackur, J., \& Sergent, C. (2006b). Conscious, preconscious, and subliminal processing: a testable taxonomy. Trends in Cognitive Sciences, 10(5), 204-211. http://doi.org/10.1016/j.tics.2006.03.007

Desimone, R., \& Duncan, J. (1995). Neural Mechanisms of Selective Visual Attention. Annual Review of Neuroscience, 18(1), 193-222. http://doi.org/10.1146/annurev.ne.18.030195.001205

Dieter, K. C., \& Tadin, D. (2011). Understanding attentional modulation of binocular rivalry: a framework based on biased competition. Frontiers in Human Neuroscience, 5, 155. http://doi.org/10.3389/fnhum.2011.00155

Dubois, J., \& Faivre, N. (2014). Invisible, but how? The depth of unconscious processing as inferred from different suppression techniques. Frontiers in Psychology, 5. http://doi.org/10.3389/fpsyg.2014.01117

Duval, S. J. (2005). The trim and fill method. In H. R. Rothstein, A. J. Sutton, \& M. Borenstein (Eds.) Publication bias in meta-analysis: Prevention, assessment, and adjustments (pp. 127144). Chichester, England: Wiley

Enns, J. T., \& Di Lollo, V. (2000). What's new in visual masking? Trends in Cognitive Sciences, 4(9), 345-352. http://doi.org/10.1016/S1364-6613(00)01520-5 


\section{ARE VISUAL THREATS PRIORITISED WITHOUT AWARENESS?}

Eysenck, M. W., Derakshan, N., Santos, R., \& Calvo, M. G. (2007). Anxiety and cognitive performance: attentional control theory. Emotion (Washington, D.C.), 7(2), 336-353. http://doi.org/10.1037/1528-3542.7.2.336

Fogelson, S. V., Kohler, P. J., Miller, K. J., Granger, R., \& Tse, P. U. (2014). Unconscious neural processing differs with method used to render stimuli invisible. Frontiers in Psychology, 5. http://doi.org/10.3389/fpsyg.2014.00601

*Fox, E. (2002). Processing emotional facial expressions: the role of anxiety and awareness. Cognitive, Affective \& Behavioral Neuroscience, 2(1), 52-63.

*Fox, E., Cahill, S., \& Zougkou, K. (2010). Preconscious processing biases predict emotional reactivity to stress. Biological Psychiatry, 67(4), 371-377. http://doi.org/10.1016/j.biopsych.2009.11.018

Gainotti, G., Caltagirone, C., \& Zoccolotti, P. (1993). Left/right and cortical/subcortical dichotomies in the neuropsychological study of human emotions. Cognition and Emotion, 7(1), 71-93. http://doi.org/10.1080/02699939308409178

Gayet, S., Van der Stigchel, S., \& Paffen, C. L. E. (2014). Breaking continuous flash suppression: competing for consciousness on the pre-semantic battlefield. Frontiers in Psychology, 5, 460. http://doi.org/10.3389/fpsyg.2014.00460 


\section{ARE VISUAL THREATS PRIORITISED WITHOUT AWARENESS?}

*Gerdes, A., \& Alpers, G. W. (2014). You see what you fear: spiders gain preferential access to conscious perception in spider-phobic patients. Journal of Experimental Psychopathology, 5(1), 14-28.

*Getov, S., Kanai, R., Bahrami, B., \& Rees, G. (2015). Human brain structure predicts individual differences in preconscious evaluation of facial dominance and trustworthiness. Social Cognitive and Affective Neuroscience, 10(5), 690-699. http://doi.org/10.1093/scan/nsu103

Goodale, M., \& Milner, D. (2013). Sight Unseen: An Exploration of Conscious and Unconscious Vision. Oxford University Press.

Graf, E. W., \& Adams, W. J. (2008). Surface organization influences bistable vision. Journal of Experimental Psychology. Human Perception and Performance, 34(2), 502-508. http://doi.org/10.1037/0096-1523.34.2.502

*Gray, K. L. H., Adams, W. J., \& Garner, M. (2009). The influence of anxiety on the initial selection of emotional faces presented in binocular rivalry. Cognition, 113(1), 105-110. http://doi.org/10.1016/j.cognition.2009.06.009

*Gray, K. L. H., Adams, W. J., Hedger, N., Newton, K. E., \& Garner, M. (2013). Faces and awareness: low-level, not emotional factors determine perceptual dominance. Emotion (Washington, D.C.), 13(3), 537-544. http://doi.org/10.1037/a0031403 


\section{ARE VISUAL THREATS PRIORITISED WITHOUT AWARENESS?}

Green, M. F., Glahn, D., Engel, S. A., Nuechterlein, K. H., Sabb, F., Strojwas, M., \& Cohen, M. S. (2005b). Regional Brain Activity Associated with Visual Backward Masking. Journal of Cognitive Neuroscience, 17(1), 13-23. http://doi.org/10.1162/0898929052880011

Green, D. M. Swets, J. A. (1966). Signal detection theory and psychophysics. New York: Wiley.

Greenhouse, J.B., Iyengar, S., 1994. Sensitivity analysis and diagnostics. In: Cooper, H., Hedges, L.V. (Eds.), The Handbook of Research Synthesis. Russell Sage Publications, New York.

Grissom, R. J., \& Kim, J. J. (2005). Effect Sizes for Research: A Broad Practical Approach. Lawrence Erlbaum Associates.

Hannula, D. E., Simons, D. J., \& Cohen, N. J. (2005). Imaging implicit perception: promise and pitfalls. Nature Reviews Neuroscience, 6(3), 247-255. http://doi.org/10.1038/nrn1630

Hassin, R. R. (2013). Yes It Can On the Functional Abilities of the Human Unconscious. Perspectives on Psychological Science, 8(2), 195-207. http://doi.org/10.1177/1745691612460684

*Hedger, N., Adams, W. J., \& Garner, M. (2015). Autonomic arousal and attentional orienting to visual threat are predicted by awareness. Journal of Experimental Psychology. Human Perception and Performance, 41(3), 798-806. http://doi.org/10.1037/xhp0000051 


\section{ARE VISUAL THREATS PRIORITISED WITHOUT AWARENESS?}

Hedger, N., Adams, W. J., \& Garner, M. (2015b). Fearful Faces Have a Sensory Advantage in the Competition for Awareness. Journal of Experimental Psychology. Human Perception and Performance. http://doi.org/10.1037/xhp000012

*Helzer, E. G., Connor-Smith, J. K., \& Reed, M. A. (2009). Traits, States, and Attentional Gates: Temperament and Threat Relevance as Predictors of Attentional Bias to Social Threat. Anxiety, Stress, and Coping, 22(1), 57-76. http://doi.org/10.1080/10615800802272244

Hesselmann, G., \& Moors, P. (2015). Definitely maybe: can unconscious processes perform the same functions as conscious processes? Frontiers in Psychology, 6. http://doi.org/10.3389/fpsyg.2015.00584

Howard, I. P., \& Rogers, B. J. (1996). Binocular Vision and Stereopsis. Oxford University Press. Retrieved from http://www.oxfordscholarship.com/view/10.1093/acprof:oso/9780195084764.001.0001/acpro $\underline{\mathrm{f}-9780195084764}$

*Hunt, C., Keogh, E., \& French, C. C. (2007). Anxiety sensitivity, conscious awareness and selective attentional biases in children. Behaviour Research and Therapy, 45(3), 497-509. http://doi.org/10.1016/j.brat.2006.04.001

Itti, L., \& Koch, C. (2001). Computational modelling of visual attention. Nature Reviews. Neuroscience, 2(3), 194-203. http://doi.org/10.1038/35058500 


\section{ARE VISUAL THREATS PRIORITISED WITHOUT AWARENESS?}

Izatt, G., Dubois, J., Faivre, N., \& Koch, C. (2014). A direct comparison of unconscious face processing under masking and interocular suppression. Frontiers in Psychology, 5. http://doi.org/10.3389/fpsyg.2014.00659

James, W. (1890). Principles of psychology. New York: Holt.

Jiang, Y., \& He, S. (2006). Cortical responses to invisible faces: dissociating subsystems for facial-information processing. Current Biology: CB, 16(20), 2023-2029. http://doi.org/10.1016/j.cub.2006.08.084

*Jusyte, A., \& Schönenberg, M. (2014). Subliminal cues bias perception of facial affect in patients with social phobia: evidence for enhanced unconscious threat processing. Frontiers in Human Neuroscience, 8. http://doi.org/10.3389/fnhum.2014.00580

*Keogh, E., Thompson, T., \& Hannent, I. (2003). Selective attentional bias, conscious awareness and the fear of pain. Pain, 104(1-2), 85-91.

Kim, C.-Y., \& Blake, R. (2005). Psychophysical magic: rendering the visible "invisible." Trends in Cognitive Sciences, 9(8), 381-388. http://doi.org/10.1016/j.tics.2005.06.012

Knapen, T., Brascamp, J., Pearson, J., Ee, R. van, \& Blake, R. (2011). The Role of Frontal and Parietal Brain Areas in Bistable Perception. The Journal of Neuroscience, 31(28), 1029310301. http://doi.org/10.1523/JNEUROSCI.1727-11.2011 


\section{ARE VISUAL THREATS PRIORITISED WITHOUT AWARENESS?}

Koch, C. (2004). The Quest for Consciousness: A Neurobiological Approach (1 edition). Denver, Colo: Roberts \& Company Publishers.

Koch, C., \& Tsuchiya, N. (2007). Attention and consciousness: two distinct brain processes. Trends in Cognitive Sciences, 11(1), 16-22. http://doi.org/10.1016/j.tics.2006.10.012

Kouider, S., Berthet, V., \& Faivre, N. (2011). Preference is biased by crowded facial expressions. Psychological Science, 22(2), 184-189. http://doi.org/10.1177/0956797610396226

*Koster, E. H. W., Verschuere, B., Burssens, B., Custers, R., \& Crombez, G. (2007). Attention for emotional faces under restricted awareness revisited: do emotional faces automatically attract attention? Emotion (Washington, D.C.), 7(2), 285-295. http://doi.org/10.1037/15283542.7.2.285

Kovács, G., Vogels, R., \& Orban, G. A. (1995). Cortical correlate of pattern backward masking. Proceedings of the National Academy of Sciences of the United States of America, 92(12), $5587-5591$.

Kovács, I., Papathomas, T. V., Yang, M., \& Fehér, Á. (1996a). When the brain changes its mind: Interocular grouping during binocular rivalry. Proceedings of the National Academy of Sciences, 93(26), 15508-15511. 


\section{ARE VISUAL THREATS PRIORITISED WITHOUT AWARENESS?}

Kovács, I., Papathomas, T. V., Yang, M., \& Fehér, Á. (1996b). When the brain changes its mind: Interocular grouping during binocular rivalry. Proceedings of the National Academy of Sciences, 93(26), 15508-15511.

Lähteenmäki, M., Hyönä, J., Koivisto, M., \& Nummenmaa, L. (2015). Affective processing requires awareness. Journal of Experimental Psychology. General, 144(2), 339-365. http://doi.org/10.1037/xge0000040

Lakens, D. (2013). Calculating and reporting effect sizes to facilitate cumulative science: a practical primer for t-tests and ANOVAs. Frontiers in Psychology, 4. http://doi.org/10.3389/fpsyg.2013.00863

Lamme, V. A. F. (2003). Why visual attention and awareness are different. Trends in Cognitive Sciences, 7(1), 12-18.

LeDoux, J. E. (2013). The slippery slope of fear. Trends in Cognitive Sciences, 17(4), 155-156. http://doi.org/10.1016/j.tics.2013.02.004

Lee, D. H., Susskind, J. M., \& Anderson, A. K. (2013). Social transmission of the sensory benefits of eye widening in fear expressions. Psychological Science, 24(6), 957-965. http://doi.org/10.1177/0956797612464500

Lee, S.-H., \& Blake, R. (2004). A fresh look at interocular grouping during binocular rivalry. Vision Research, 44(10), 983-991. http://doi.org/10.1016/j.visres.2003.12.007 


\section{ARE VISUAL THREATS PRIORITISED WITHOUT AWARENESS?}

*Lerner, Y., Singer, N., Gonen, T., Weintraub, Y., Cohen, O., Rubin, N., ... Hendler, T. (2012). Feeling without seeing? Engagement of ventral, but not dorsal, amygdala during unaware exposure to emotional faces. Journal of Cognitive Neuroscience, 24(3), 531-542. http://doi.org/10.1162/jocn_a_00165

Levelt, W., 1965: On Binocular Rivalry, Soesterberg, the Netherlands, Institute for Perception RVO-TNO

Lin, Z., \& He, S. (2009). Seeing the invisible: The scope and limits of unconscious processing in binocular rivalry. Progress in Neurobiology, 87(4), 195-211. http://doi.org/10.1016/j.pneurobio.2008.09.002

López-López, J. A., Marín-Martínez, F., Sánchez-Meca, J., Van den Noortgate, W., \& Viechtbauer, W. (2014). Estimation of the predictive power of the model in mixed-effects meta-regression: A simulation study. British Journal of Mathematical and Statistical Psychology, 67(1), 30-48. http://doi.org/10.1111/bmsp.12002

Lovibond, S. H., \& Lovibond, P. F. (1996). Manual for the depression anxiety stress scales. Psychology Foundation of Australia.

Macmillan, N. A. Creelman, C. D. (2005). Detection theory: A user's guide. New York: Cambridge University Press. 


\section{ARE VISUAL THREATS PRIORITISED WITHOUT AWARENESS?}

Mamassian, P., \& Goutcher, R. (2005). Temporal dynamics in bistable perception. Journal of Vision, 5(4), 7. http://doi.org/10.1167/5.4.7

*Maoz, K., Abend, R., Fox, N. A., Pine, D. S., \& Bar-Haim, Y. (2013). Subliminal attention bias modification training in socially anxious individuals. Frontiers in Human Neuroscience, 7, 389. http://doi.org/10.3389/fnhum.2013.00389

Mathews, A., \& MacLeod, C. (2005a). Cognitive Vulnerability to Emotional Disorders. Annual Review of Clinical Psychology, 1(1), 167-195. http://doi.org/10.1146/annurev.clinpsy.1.102803.143916

Mathews, A., \& MacLeod, C. (2005b). Cognitive vulnerability to emotional disorders. Annual Review of Clinical Psychology, 1, 167-195. http://doi.org/10.1146/annurev.clinpsy.1.102803.143916

Matt GE, Cook TD (2009).“'Threats to the Validity of Generalized Inferences.’'In HM Cooper, LV Hedges, JC Valentine (eds.),The Handbook of Research Synthesis and Meta-Analysis, 2nd edition. Russell Sage Foundation.

McCrory, E. J., De Brito, S. A., Kelly, P. A., Bird, G., Sebastian, C. L., Mechelli, A., ... Viding, E. (2013). Amygdala activation in maltreated children during pre-attentive emotional processing. The British Journal of Psychiatry: The Journal of Mental Science, 202(4), 269276. http://doi.org/10.1192/bjp.bp.112.116624 


\section{ARE VISUAL THREATS PRIORITISED WITHOUT AWARENESS?}

Merikle, P. M., Smilek, D., \& Eastwood, J. D. (2001). Perception without awareness: perspectives from cognitive psychology. Cognition, 79(1-2), 115-134.

Mitchell, J. F., Stoner, G. R., \& Reynolds, J. H. (2004). Object-based attention determines dominance in binocular rivalry. Nature, 429(6990), 410-413. http://doi.org/10.1038/nature02584

Mm, B., M, C., Bn, C., \& Pj, L. (2001). Emotion and motivation I: defensive and appetitive reactions in picture processing. Emotion (Washington, D.C.), 1(3), 276-298.

Mogg, K., \& Bradley, B. P. (1998). A cognitive-motivational analysis of anxiety. Behaviour Research and Therapy, 36(9), 809-848.

*Mogg, K., \& Bradley, B. P. (1999). Orienting of Attention to Threatening Facial Expressions Presented under Conditions of Restricted Awareness. Cognition \& Emotion, 13(6), 713-740. http://doi.org/10.1080/026999399379050

Mogg, K., \& Bradley, B. P. (1999). Some methodological issues in assessing attentional biases for threatening faces in anxiety: a replication study using a modified version of the probe detection task. Behaviour Research and Therapy, 37(6), 595-604.

*Mogg, K., \& Bradley, B. P. (2002). Selective orienting of attention to masked threat faces in social anxiety. Behaviour Research and Therapy, 40(12), 1403-1414. 


\section{ARE VISUAL THREATS PRIORITISED WITHOUT AWARENESS?}

Mogg, K., \& Bradley, B. P. (2005). Attentional Bias in Generalized Anxiety Disorder Versus Depressive Disorder. Cognitive Therapy and Research, 29(1), 29-45. http://doi.org/10.1007/s10608-005-1646-y

Mogg, K., \& Bradley, B. P. (2006). Time course of attentional bias for fear-relevant pictures in spider-fearful individuals. Behaviour Research and Therapy, 44(9), 1241-1250. http://doi.org/10.1016/j.brat.2006.05.003

*Mogg, K., Bradley, B. P., \& Hallowell, N. (1994). Attentional bias to threat: roles of trait anxiety, stressful events, and awareness. The Quarterly Journal of Experimental Psychology. A, Human Experimental Psychology, 47(4), 841-864.

*Mogg, K., Bradley, B. P., \& Williams, R. (1995). Attentional bias in anxiety and depression: the role of awareness. The British Journal of Clinical Psychology / the British Psychological Society, 34 ( Pt 1), 17-36.

Mogg, K., Garner, M., \& Bradley, B. P. (2007). Anxiety and orienting of gaze to angry and fearful faces. Biological Psychology, 76(3), 163-169. http://doi.org/10.1016/j.biopsycho.2007.07.005

*Monk, C. S., Telzer, E. H., Mogg, K., Bradley, B. P., Mai, X., Louro, H. M. C., ... Pine, D. S. (2008a). Amygdala and ventrolateral prefrontal cortex activation to masked angry faces in children and adolescents with generalized anxiety disorder. Archives of General Psychiatry, 65(5), 568-576. http://doi.org/10.1001/archpsyc.65.5.568 


\section{ARE VISUAL THREATS PRIORITISED WITHOUT AWARENESS?}

Montgomery, S. A., \& Asberg, M. (1979). A new depression scale designed to be sensitive to change. British Journal of Psychiatry, 134, 382-389.

Mormann, F., Dubois, J., Kornblith, S., Milosavljevic, M., Cerf, M., Ison, M., ... Koch, C. (2011). A category-specific response to animals in the right human amygdala. Nature Neuroscience, 14(10), 1247-1249. http://doi.org/10.1038/nn.2899

Morris, S. B., \& DeShon, R. P. (2002). Combining effect size estimates in meta-analysis with repeated measures and independent-groups designs. Psychological Methods, 7(1), 105-125. http://doi.org/10.1037/1082-989X.7.1.105

*Murphy, S. E., Downham, C., Cowen, P. J., \& Harmer, C. J. (2008). Direct effects of diazepam on emotional processing in healthy volunteers. Psychopharmacology, 199(4), 503-513. http://doi.org/10.1007/s00213-008-1082-2

Nesse, R. M. (1999). Proximate and evolutionary studies of anxiety, stress and depression: synergy at the interface. Neuroscience and Biobehavioral Reviews, 23(7), 895-903.

Nguyen, V. A., Freeman, A. W., \& Alais, D. (2003). Increasing depth of binocular rivalry suppression along two visual pathways. Vision Research, 43(19), 2003-2008.

Ohman, A. (2005). The role of the amygdala in human fear: automatic detection of threat. Psychoneuroendocrinology, 30(10), 953-958. http://doi.org/10.1016/j.psyneuen.2005.03.019 


\section{ARE VISUAL THREATS PRIORITISED WITHOUT AWARENESS?}

Ohman, A., Carlsson, K., Lundqvist, D., \& Ingvar, M. (2007). On the unconscious subcortical origin of human fear. Physiology \& Behavior, 92(1-2), 180-185.

http://doi.org/10.1016/j.physbeh.2007.05.057

Ohman, A., \& Mineka, S. (2001). Fears, phobias, and preparedness: toward an evolved module of fear and fear learning. Psychological Review, 108(3), 483-522.

*Oliver, L. D., Mao, A., \& Mitchell, D. G. V. (2014). "Blindsight” and subjective awareness of fearful faces: Inversion reverses the deficits in fear perception associated with core psychopathic traits. Cognition \& Emotion, 1-22.

http://doi.org/10.1080/02699931.2014.976182

Ooi, T. L., \& He, Z. J. (1999a). Binocular rivalry and visual awareness: the role of attention. Perception, 28(5), 551-574.

Ooi, T. L., \& He, Z. J. (1999b). Binocular rivalry and visual awareness: the role of attention. Perception, 28(5), 551-574.

Paffen, C., \& Alais, D. (2011). Attentional modulation of binocular rivalry. Frontiers in Human Neuroscience, 5, 105. http://doi.org/10.3389/fnhum.2011.00105

Pasley, B. N., Mayes, L. C., \& Schultz, R. T. (2004a). Subcortical discrimination of unperceived objects during binocular rivalry. Neuron, 42(1), 163-172. 


\section{ARE VISUAL THREATS PRIORITISED WITHOUT AWARENESS?}

Pasley, B. N., Mayes, L. C., \& Schultz, R. T. (2004b). Subcortical discrimination of unperceived objects during binocular rivalry. Neuron, 42(1), 163-172.

Pessoa, L. (2005). To what extent are emotional visual stimuli processed without attention and awareness? Current Opinion in Neurobiology, 15(2), 188-196.

http://doi.org/10.1016/j.conb.2005.03.002

Pessoa, L. (2008). On the relationship between emotion and cognition. Nature Reviews Neuroscience, 9(2), 148-158. http://doi.org/10.1038/nrn2317

Pessoa, L. (2010). Emotion and attention effects: is it all a matter of timing? Not yet. Frontiers in Human Neuroscience, 4, 172. http://doi.org/10.3389/fnhum.2010.00172

Pessoa, L., \& Adolphs, R. (2010). Emotion processing and the amygdala: from a "low road" to "many roads" of evaluating biological significance. Nature Reviews. Neuroscience, 11(11), 773-783. http://doi.org/10.1038/nrn2920

Pessoa, L., Japee, S., Sturman, D., \& Ungerleider, L. G. (2006). Target visibility and visual awareness modulate amygdala responses to fearful faces. Cerebral Cortex (New York, N.Y.: 1991), 16(3), 366-375. http://doi.org/10.1093/cercor/bhi115 


\section{ARE VISUAL THREATS PRIORITISED WITHOUT AWARENESS?}

Posner, M. I., Snyder, C. R., \& Davidson, B. J. (1980). Attention and the detection of signals. Journal of Experimental Psychology, 109(2), 160-174.

Piech, R. M., McHugo, M., Smith, S. D., Dukic, M. S., Van Der Meer, J., Abou-Khalil, B., \& Zald, D. H. (2010). Fear-enhanced visual search persists after amygdala lesions. Neuropsychologia, 48(12), 3430-3435. http://doi.org/10.1016/j.neuropsychologia.2010.07.009

Piech, R. M., McHugo, M., Smith, S. D., Dukic, M. S., Van Der Meer, J., Abou-Khalil, B., ... Zald, D. H. (2011). Attentional capture by emotional stimuli is preserved in patients with amygdala lesions. Neuropsychologia, 49(12), 3314-3319. http://doi.org/10.1016/j.neuropsychologia.2011.08.004

Raes, A. K., Koster, E. H. W., Van Damme, S., Fias, W., \& De Raedt, R. (2010). Aversive conditioning under conditions of restricted awareness: effects on spatial cueing. Quarterly Journal of Experimental Psychology (2006), 63(12), 2336-2358. http://doi.org/10.1080/17470218.2010.492995

Raudenbush, S. W. (1994). Random effects models. In H. Cooper, \& L. V. Hedges (Eds.), The handbook of research synthesis (pp. 301-321). New York: Russell Sage Foundation

Reingold, E. M. (2004). Unconscious perception: assumptions and interpretive difficulties. Consciousness and Cognition, 13(1), 117-122. http://doi.org/10.1016/j.concog.2003.11.002 


\section{ARE VISUAL THREATS PRIORITISED WITHOUT AWARENESS?}

*Ritchie, K., Bannerman, R. L., \& Sahraie, A. (2011). The effect of fear in the periphery in binocular rivalry. Perception, 40(12), 1395-1401.

Rolls, E. T., Tovée, M. J., \& Panzeri, S. (1999). The Neurophysiology of Backward Visual Masking: Information Analysis. Journal of Cognitive Neuroscience, 11(3), 300-311. http://doi.org/10.1162/089892999563409

Rosenthal, R. (1991). Meta-Analytic Procedures for Social Research (Revised edition). Newbury Park: SAGE Publications, Inc.

Schmidt, F. L., Oh, I.-S., \& Hayes, T. L. (2009). Fixed- versus random-effects models in metaanalysis: Model properties and an empirical comparison of differences in results. British Journal of Mathematical and Statistical Psychology, 62(1), 97-128. http://doi.org/10.1348/000711007X255327

*Schultheiss, O. C., \& Hale, J. A. (2007). Implicit Motives Modulate Attentional Orienting to Facial Expressions of Emotion. Motivation and Emotion, 31(1), 13-24. http://doi.org/10.1007/s11031-006-9042-9

Shimaoka, D., \& Kaneko, K. (2011). Dynamical systems modeling of Continuous Flash Suppression. Vision Research, 51(6), 521-528. http://doi.org/10.1016/j.visres.2011.01.009 


\section{ARE VISUAL THREATS PRIORITISED WITHOUT AWARENESS?}

*Singer, N., Eapen, M., Grillon, C., Ungerleider, L. G., \& Hendler, T. (2012). Through the eyes of anxiety: Dissecting threat bias via emotional-binocular rivalry. Emotion (Washington, D.C.), 12(5), 960-969. http://doi.org/10.1037/a0027070

Spielberger, C. D., Gorsuch, R. L., Lushene, R., Vagg, P. R., \& Jacobs, G. A. (1983). Manual for the State-Trait Anxiety Inventory. Palo Alto, CA: Consulting Psychologists Press.

*Stein, T., Seymour, K., Hebart, M. N., \& Sterzer, P. (2013). Rapid Fear Detection Relies on High Spatial Frequencies. Psychological Science, 0956797613512509. http://doi.org/10.1177/0956797613512509

*Stein, T., \& Sterzer, P. (2012). Not just another face in the crowd: detecting emotional schematic faces during continuous flash suppression. Emotion (Washington, D.C.), 12(5), 988-996. http://doi.org/10.1037/a0026944

*Sterzer, P., Hilgenfeldt, T., Freudenberg, P., Bermpohl, F., \& Adli, M. (2011). Access of emotional information to visual awareness in patients with major depressive disorder. Psychological Medicine, 41(8), 1615-1624. http://doi.org/10.1017/S0033291710002540

*Stewart, L. H., Ajina, S., Getov, S., Bahrami, B., Todorov, A., \& Rees, G. (2012). Unconscious evaluation of faces on social dimensions. Journal of Experimental Psychology. General, 141(4), 715-727. http://doi.org/10.1037/a0027950 


\section{ARE VISUAL THREATS PRIORITISED WITHOUT AWARENESS?}

*Stone, A., \& Valentine, T. (2007). Angry and Happy Faces Perceived Without Awareness: A Comparison with the Affective Impact of Masked Famous Faces. European Journal of Cognitive Psychology, 19(2), 161-186.

*Sutton, T. M., \& Altarriba, J. (2011). The automatic activation and perception of emotion in word processing: Evidence from a modified dot probe paradigm. Journal of Cognitive Psychology, 23(6), 736-747. http://doi.org/10.1080/20445911.2011.554392

*Sylvers, P. D., Brennan, P. A., \& Lilienfeld, S. O. (2011). Psychopathic traits and preattentive threat processing in children: a novel test of the fearlessness hypothesis. Psychological Science, 22(10), 1280-1287. http://doi.org/10.1177/0956797611420730

Szczepanowski, R., \& Pessoa, L. (2007). Fear perception: can objective and subjective awareness measures be dissociated? Journal of Vision, 7(4), 10. http://doi.org/10.1167/7.4.10

Tamietto, M., \& de Gelder, B. (2010). Neural bases of the non-conscious perception of emotional signals. Nature Reviews Neuroscience, 11(10), 697-709. http://doi.org/10.1038/nrn2889

Tamietto, M., Pullens, P., de Gelder, B., Weiskrantz, L., \& Goebel, R. (2012). Subcortical connections to human amygdala and changes following destruction of the visual cortex. Current Biology: CB, 22(15), 1449-1455. http://doi.org/10.1016/j.cub.2012.06.006 


\section{ARE VISUAL THREATS PRIORITISED WITHOUT AWARENESS?}

*Thomason, M. E., Henry, M. L., Hamilton, J. P., Joormann, J., Pine, D. S., Ernst, M., ... Gotlib, I. H. (2010). Neural and behavioral responses to threatening emotion faces in children as a function of the short allele of the serotonin transporter gene. Biological Psychology, 85(1), 38-44. http://doi.org/10.1016/j.biopsycho.2010.04.009

Tong, F., \& Engel, S. A. (2001). Interocular rivalry revealed in the human cortical blind-spot representation. Nature, 411(6834), 195-199. http://doi.org/10.1038/35075583

Tong, F., Meng, M., \& Blake, R. (2006). Neural bases of binocular rivalry. Trends in Cognitive Sciences, 10(11), 502-511. http://doi.org/10.1016/j.tics.2006.09.003

Treisman, A. M. (1969). Strategies and models of selective attention. Psychological Review, 76(3), 282-299. http://doi.org/10.1037/h0027242

Tsuchiya, N., \& Koch, C. (2005). Continuous flash suppression reduces negative afterimages. Nature Neuroscience, 8(8), 1096-1101. http://doi.org/10.1038/nn1500

Tsuchiya, N., Koch, C., Gilroy, L. A., \& Blake, R. (2006). Depth of interocular suppression associated with continuous flash suppression, flash suppression, and binocular rivalry. Journal of Vision, 6(10), 1068-1078. http://doi.org/10.1167/6.10.6

Tsuchiya, N., Moradi, F., Felsen, C., Yamazaki, M., \& Adolphs, R. (2009). Intact rapid detection of fearful faces in the absence of the amygdala. Nature Neuroscience, 12(10), 1224-1225. http://doi.org/10.1038/nn.2380 


\section{ARE VISUAL THREATS PRIORITISED WITHOUT AWARENESS?}

Ungerleider, S. K., \& G, L. (2000). Mechanisms of Visual Attention in the Human Cortex. Annual Review of Neuroscience, 23(1), 315-341. http://doi.org/10.1146/annurev.neuro.23.1.315

Van den Bussche, E., Van den Noortgate, W., \& Reynvoet, B. (2009). Mechanisms of masked priming: A meta-analysis. Psychological Bulletin, 135(3), 452-477.

http://doi.org/10.1037/a0015329

Vanrullen, R. (2011). Four common conceptual fallacies in mapping the time course of recognition. Frontiers in Psychology, 2, 365. http://doi.org/10.3389/fpsyg.2011.00365

Van Loon, A. M., Knapen, T., Scholte, H. S., St John-Saaltink, E., Donner, T. H., \& Lamme, V. A. F. (2013a). GABA shapes the dynamics of bistable perception. Current Biology: CB, 23(9), 823-827. http://doi.org/10.1016/j.cub.2013.03.067

Van Loon, A. M., Knapen, T., Scholte, H. S., St John-Saaltink, E., Donner, T. H., \& Lamme, V. A. F. (2013b). GABA shapes the dynamics of bistable perception. Current Biology: $C B$, 23(9), 823-827. http://doi.org/10.1016/j.cub.2013.03.067

Viechtbauer, W. (2010). Conducting meta-analyses in R with the metafor package. Journal of Statistical Software, 36, 1-48. 


\section{ARE VISUAL THREATS PRIORITISED WITHOUT AWARENESS?}

Vuilleumier, P. (2005). How brains beware: neural mechanisms of emotional attention. Trends in Cognitive Sciences, 9(12), 585-594. http://doi.org/10.1016/j.tics.2005.10.011

Whalen, P. J., Kagan, J., Cook, R. G., Davis, F. C., Kim, H., Polis, S., ... Johnstone, T. (2004). Human Amygdala Responsivity to Masked Fearful Eye Whites. Science, 306(5704), 20612061. http://doi.org/10.1126/science. 1103617

Wheatstone, C., 1838: On some remarkable, and hitherto unobserved, phenomena of binocular vision. Phil. Trans. R. Soc. Lond. 128, 371-394.

Wiens, S. (2006). Remain aware of awareness. Nature Reviews Neuroscience, 6(3). http://doi.org/10.1038/nrn1630-c1

Wiens, S. (2008). Concepts of visual consciousness and their measurement. Advances in Cognitive Psychology, 3(1-2), 349-359. http://doi.org/10.2478/v10053-008-0035-y

Wiens, S., \& Öhman, A. (2007). Probing unconscious emotional processes: On becoming a successful masketeer. In J. A. Coan \& J. J. B. Allen (Eds.) Handbook of emotion elicitation and assessment. New York: Oxford University Press, pp. 65-90

Williams, M. A., Morris, A. P., McGlone, F., Abbott, D. F., \& Mattingley, J. B. (2004). Amygdala responses to fearful and happy facial expressions under conditions of binocular suppression. The Journal of Neuroscience: The Official Journal of the Society for Neuroscience, 24(12), 2898-2904. http://doi.org/10.1523/JNEUROSCI.4977-03.2004 


\section{ARE VISUAL THREATS PRIORITISED WITHOUT AWARENESS?}

Williams, J. M., Watts, F. N., MacLeod, C., \& Mathews, A. (1988). Cognitive psychology and emotional disorders. Chichester, UK: Wiley

Wilson, E. J., MacLeod, C., Mathews, A., \& Rutherford, E. M. (2006). The causal role of interpretive bias in anxiety reactivity. Journal of Abnormal Psychology, 115(1), 103-111. http://doi.org/10.1037/0021-843X.115.1.103

*Wirth, M. M., \& Schultheiss, O. C. (2007). Basal testosterone moderates responses to anger faces in humans. Physiology \& Behavior, 90(2-3), 496-505. http://doi.org/10.1016/j.physbeh.2006.10.016

Yang, E., \& Blake, R. (2012). Deconstructing continuous flash suppression. Journal of Vision, 12(3), 8. http://doi.org/10.1167/12.3.8

*Yang, E., Zald, D. H., \& Blake, R. (2007). Fearful expressions gain preferential access to awareness during continuous flash suppression. Emotion (Washington, D.C.), 7(4), 882-886. http://doi.org/10.1037/1528-3542.7.4.882

*Yang, Y.-H., \& Yeh, S.-L. (2011). Accessing the meaning of invisible words. Consciousness and Cognition, 20(2), 223-233. http://doi.org/10.1016/j.concog.2010.07.005

*Yoon, K. L., Hong, S. W., Joormann, J., \& Kang, P. (2009). Perception of facial expressions of emotion during binocular rivalry. Emotion (Washington, D.C.), 9(2), 172-182. http://doi.org/10.1037/a0014714 
ARE VISUAL THREATS PRIORITISED WITHOUT AWARENESS?

Yu, K., \& Blake, R. (1992). Do recognizable figures enjoy an advantage in binocular rivalry? Journal of Experimental Psychology. Human Perception and Performance, 18(4), 11581173. 
ARE VISUAL THREATS PRIORITISED WITHOUT AWARENESS?

\section{Footnotes}

1. As others have noted, this method is likely to be biased, since the choice of adding a zero effect size to the observed effects neglects the possibility of unpublished studies finding negative effects (Begg \& Berlin, 1988) which would substantially reduce the fail-safe $N$. Moreover, this method also does not directly model the effect of i) the heterogeneity of the observed effects and ii) the sample sizes of the added studies, meaning the effect of adding $N$ studies with an averaged null effect would be the same regardless of whether they had sample sizes of 10 or 10,000 (Becker, 2005). These technical issues should be considered when interpreting fail-safe $N$ values that appear to be of a considerable size. 
ARE VISUAL THREATS PRIORITISED WITHOUT AWARENESS? 
ARE VISUAL THREATS PRIORITISED WITHOUT AWARENESS? 
ARE VISUAL THREATS PRIORITISED WITHOUT AWARENESS? 
ARE VISUAL THREATS PRIORITISED WITHOUT AWARENESS? 
ARE VISUAL THREATS PRIORITISED WITHOUT AWARENESS? 
ARE VISUAL THREATS PRIORITISED WITHOUT AWARENESS? 
ARE VISUAL THREATS PRIORITISED WITHOUT AWARENESS? 